Electronic Supporting Information for

\title{
Modifying $\mathrm{Li}^{+}$and Anion Diffusivity in Polyacetal Electrolytes: A Pulsed-Field-Gradient NMR Study of Ion Self-Diffusion
}

David M. Halat, ${ }^{1,2,3, \dagger}$ Rachel L. Snyder, ${ }^{2,4, \dagger}$ Siddharth Sundararaman, ${ }^{2,5}$ Youngwoo Choo, ${ }^{2,3}$ Kevin W. Gao, ${ }^{1,2,3}$ Zach J. Hoffman, ${ }^{1,2,3}$ Brooks A. Abel, ${ }^{2,4}$ Lorena S. Grundy, ${ }^{1,2,3}$ Michael D. Galluzzo, ${ }^{1,2,3}$ Madeleine P. Gordon, ${ }^{5,6}$ Hasan Celik, ${ }^{1}$ Jeffrey J. Urban, ${ }^{5}$ David Prendergast, ${ }^{2,5}$ Geoffrey W. Coates, ${ }^{*, 2,4}$ Nitash P. Balsara, ${ }^{*, 1,2,3}$ and Jeffrey A. Reimer*,1,2,3

${ }^{1}$ Department of Chemical and Biomolecular Engineering and College of Chemistry, University of California, Berkeley, California 94720, United States

${ }^{2}$ Joint Center for Energy Storage Research, Argonne National Laboratory, Lemont, Illinois 60439, United States

${ }^{3}$ Materials Sciences Division, Lawrence Berkeley National Laboratory, Berkeley, California 94720, United States

${ }^{4}$ Department of Chemistry and Chemical Biology, Baker Laboratory, Cornell University, Ithaca, New York 14853, United States

${ }^{5}$ The Molecular Foundry, Lawrence Berkeley National Laboratory, Berkeley, California 94720, United States

${ }^{6}$ Applied Science and Technology Graduate Group, University of California, Berkeley, California, 94720, United States

\section{Table of Contents}

1. General Synthetic Considerations and Instrumentation $\quad$ S2

2. General Materials $\quad$ S3

3. Small Molecule Synthesis $\quad$ S4

$\begin{array}{ll}\text { 4. Polymer Synthesis } & \text { S7 }\end{array}$

5. Gel Permeation Chromatography (GPC) of Neat Polyacetals $\quad$ S12

6. Differential Scanning Calorimetry (DSC) of Neat Polyacetals $\quad$ S13

7. Thermogravimetric Analysis (TGA) of Neat Polyacetals $\quad$ S15

8. NMR Spectra of Monomers and Neat Polyacetals $\quad$ S16

9. Preparation and Characterization of Polymer Electrolytes $\quad$ S28

10. Pulsed-field-gradient (PFG) NMR Instrumentation and Calibration $\quad$ S31

11. Further PFG-NMR Details: Parameter Definitions and Additional Experiments $\quad$ S34

$\begin{array}{ll}\text { 12. Additional PFG Figures and Tables } & \text { S39 }\end{array}$

$\begin{array}{ll}\text { 13. Molecular Dynamics (MD) Simulations } & \text { S47 }\end{array}$

14. Raman Spectroscopy of Polymer Electrolytes $\quad$ S49 


\section{General Synthetic Considerations and Instrumentation}

Synthetic considerations - All manipulations of air- and water-sensitive compounds were carried out under nitrogen in an MBraun Labmaster glovebox or by using standard Schlenk line techniques.

$\underline{{ }^{1} H \text { and }{ }^{13} C N M R}$ - Spectra were recorded on a Bruker AVANCE III HD $\left({ }^{1} \mathrm{H}, 500 \mathrm{MHz}\right)$ spectrometer with a broadband Prodigy cryoprobe, Varian INOVA $300\left({ }^{1} \mathrm{H}, 300 \mathrm{MHz}\right)$, or Varian INOVA $400\left({ }^{1} \mathrm{H}, 400 \mathrm{MHz}\right)$ spectrometer. Chemical shifts $(\delta)$ for ${ }^{1} \mathrm{H}$ and ${ }^{13} \mathrm{C}$ NMR spectra were referenced to protons on the residual solvent (for ${ }^{1} \mathrm{H}$ ) and deuterated solvent itself (for ${ }^{13} \mathrm{C}$ ). Two-dimensional band-selective HSQC NMR spectroscopy was recorded using a standard pulse sequence (bsHSQCAD).

High-resolution mass spectrometry (HRMS) - Analyses were performed on a Thermo Scientific Exactive Orbitrap MS system equipped with an Ion Sense DART ion source.

Thermogravimetric analysis (TGA) - Analyses were performed on a TA Instruments Q500 Thermogravimetric Analyzer. The samples were heated in a nitrogen atmosphere from $25^{\circ} \mathrm{C}$ to $500{ }^{\circ} \mathrm{C}$ at a rate of $10^{\circ} \mathrm{C} / \mathrm{min}$.

Gel permeation chromatography (GPC) - Analyses were carried out using an Agilent 1260 Infinity GPC System equipped with an Agilent 1260 Infinity autosampler and a refractive index detector. The Agilent GPC system was equipped with two Agilent PolyPore columns (5 micron, $4.6 \mathrm{~mm}$ ID) which were eluted with THF at $30^{\circ} \mathrm{C}$ at $0.3 \mathrm{~mL} / \mathrm{min}$ and calibrated using monodisperse polystyrene standards. 


\section{General Materials}

Dichloromethane for air-sensitive reactions was purchased from Fisher, sparged with ultrahigh purity (UHP) grade nitrogen, passed through two columns of alumina, and dispensed under nitrogen into an oven-dried Straus flask followed by degassing via three freeze-pump-thaw cycles. Otherwise, solvents (acetonitrile, diethyl ether, heptane, hexanes, and isopropanol) were used as received. 1,3-Dioxolane (EO-MO) was purchased from Oakwood Chemical, dried over $\mathrm{CaH}_{2}$ for 3 days, isolated via vacuum transfer, and degassed via three freeze-pump-thaw cycles. LiTFSI was purchased from Millipore Sigma. All other reagents were purchased from commercial sources (Millipore Sigma, Oakwood Chemical, TCI, and Fisher) and used without further purification. 


\section{Small Molecule Synthesis}

\section{1,3,6,9,12-Pentaoxacyclotetradecane (4EO-MO)}

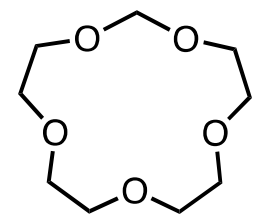

Tetraethylene glycol (30 g, $0.19 \mathrm{~mol}, 1.0$ equiv), paraformaldehyde ( $6.0 \mathrm{~g}$, $0.20 \mathrm{~mol}, 1.3$ equiv), poly(phosphoric acid) ( $0.66 \mathrm{~g}, 5.7 \mathrm{mmol}, 0.030$ equiv), and heptane $(100 \mathrm{~mL})$ were combined in a $250 \mathrm{~mL}$ flask with a Dean-Stark trap, reflux condenser, and magnetic stir bar. The reaction mixture was stirred at $110^{\circ} \mathrm{C}$ for $4 \mathrm{~h}$, during which a significant amount of paraformaldehyde was trapped in the condenser. Water was collected as the bottom layer in the Dean-Stark trap. The reaction was cooled to room temperature and residual heptane was removed via rotary evaporation. The viscous, crude oligomeric product was distilled at $200{ }^{\circ} \mathrm{C}$ under high vacuum into a receiving flask cooled with a dry ice/acetone bath over several hours. The obtained mixture of tetraethylene glycol and 4EO-MO was then purified via fractional distillation under high vacuum at $130{ }^{\circ} \mathrm{C}$ to give the product in $31 \%$ yield. $4 \mathrm{EO}-\mathrm{MO}$ was dried over $\mathrm{CaH}_{2}$ for three days, distilled, and degassed via three freeze-pump-thaw cycles. This procedure is identical to that used in our prior report. ${ }^{1}{ }^{1} \mathbf{H} \mathbf{~ N M R}\left(500 \mathrm{MHz}, \mathrm{CDCl}_{3}\right) \delta 4.74(\mathrm{~s}$, 2H), $3.78(\mathrm{~m}, 8 \mathrm{H}), 3.68(\mathrm{~m}, 8 \mathrm{H})$ ppm. ${ }^{13} \mathbf{C}$ NMR $\left(125 \mathrm{MHz}, \mathrm{CDCl}_{3}\right) \delta 96.57,71.07,70.61,68.06$ ppm. HRMS (DART-MS): $m / z$ calculated for $\mathrm{C}_{9} \mathrm{H}_{18} \mathrm{O}_{5}[\mathrm{H}]^{+}$207.1232, found 207.1218.

\section{1,3,6,9-Tetraoxacycloundecane (3EO-MO)}

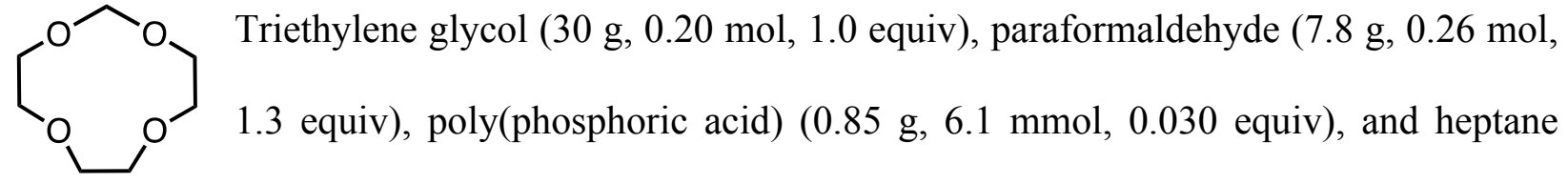
$(100 \mathrm{~mL})$ were combined in a $250 \mathrm{~mL}$ flask with a magnetic stir bar, Dean-Stark trap, and reflux condenser. The reaction was stirred at $115^{\circ} \mathrm{C}$ for $8 \mathrm{~h}$, and water was collected as the bottom layer in the Dean-Stark trap. Residual heptane was removed from the reaction via rotary evaporation to 
give a viscous mixture of oligomers. The crude oligomerized product was distilled over several hours under high vacuum at $170-190{ }^{\circ} \mathrm{C}$ into a receiving flask that had been cooled with a dry ice/acetone bath. An external trap was used to collect paraformaldehyde that accumulated during heating. This mixture of triethylene glycol and 3EO-MO was purified by a second fractional distillation at $100-120^{\circ} \mathrm{C}$ under high vacuum. The clear, colorless product was dried over $\mathrm{CaH}_{2}$ for three days, distilled, and degassed via three freeze-pump-thaw cycles. The product was obtained in 54\% yield. This procedure is identical to that used in our prior report. ${ }^{1}{ }^{1} \mathbf{H}$ NMR (500 $\left.\mathrm{MHz}, \mathrm{CDCl}_{3}\right) \delta 4.62(\mathrm{~s}, 2 \mathrm{H}), 3.67(\mathrm{~m}, 8 \mathrm{H}), 3.53(\mathrm{~m}, 8 \mathrm{H}) \mathrm{ppm} .{ }^{13} \mathbf{C}$ NMR $\left(125 \mathrm{MHz}, \mathrm{CDCl}_{3}\right)$ $\delta 96.08,70.52,70.24,67.70$ ppm. HRMS (DART-MS): $\mathrm{m} / z$ calculated for $\mathrm{C}_{7} \mathrm{H}_{14} \mathrm{O}_{4}[\mathrm{H}]^{+}$ 163.0965, found 163.0962.

\section{1,3,6-Trioxocane (2EO-MO)}

O Diethylene glycol (100 g, 0.94 mol, 1.0 equiv), paraformaldehyde (37 g, $1.2 \mathrm{~mol}$, 1.3 equiv), polyphosphoric acid ( $4.0 \mathrm{~g}, 28 \mathrm{mmol}, 0.030$ equiv), and heptane (160 mL) were combined in a $250 \mathrm{~mL}$ flask with a magnetic stir bar and fitted with a Dean-Stark adapter and condenser. The reaction was stirred at $115^{\circ} \mathrm{C}$ for $12 \mathrm{~h}$ and water was collected as the bottom layer in the trap. After cooling the reaction mixture to room temperature, heptane was removed via rotary evaporation to give a cloudy, viscous solution. This oligomerized product was distilled at $150-180{ }^{\circ} \mathrm{C}$ under high vacuum into a receiving flask cooled with a dry ice/acetone bath. The crude mixture of diethylene glycol and 2EO-MO was then fractionally distilled under high vacuum at $80{ }^{\circ} \mathrm{C}$ to give clear, colorless, $2 \mathrm{EO}-\mathrm{MO}$ in $70 \%$ yield. The monomer was dried over $\mathrm{CaH}_{2}$ for 3 days, distilled, and degassed via three freeze-pump-thaw cycles. This procedure is identical to that used in our prior report. ${ }^{1}{ }^{1} \mathbf{H}$ NMR $\left(500 \mathrm{MHz}, \mathrm{CDCl}_{3}\right) \delta 4.57(\mathrm{~s}, 2 \mathrm{H}), 3.50(\mathrm{~s}, 8 \mathrm{H}) \mathrm{ppm} .{ }^{13} \mathbf{C}$ 
NMR $\left(125 \mathrm{MHz}, \mathrm{CDCl}_{3}\right) \delta 97.91,72.58,70.61 \mathrm{ppm}$. HRMS (DART-MS): $\mathrm{m} / z$ calculated for $\mathrm{C}_{5} \mathrm{H}_{10} \mathrm{O}_{3}[\mathrm{H}]^{+}$119.0703, found 119.0703 .

\section{1,3,5-Trioxepane (EO-2MO)}

O A $250 \mathrm{~mL}$ round bottom flask with a magnetic stir bar was charged with polyphosphoric acid (4.60 g, $32 \mathrm{mmol}, 0.06$ equiv), dioxolane ( $75 \mathrm{ml}, 1.08 \mathrm{~mol}, 2.0$ equiv), and paraformaldehyde $\left(16.11 \mathrm{~g}, 0.54 \mathrm{~mol}, 1.0\right.$ equiv). The mixture was heated at $70^{\circ} \mathrm{C}$ for $3 \mathrm{~h}$ followed by cooling to room temperature and allowing to stand for $3 \mathrm{~h}$. The reaction mixture was then filtered and distilled by heating to $150^{\circ} \mathrm{C}$ under static vacuum and cooling the receiving flask with a dry ice/acetone bath. The distillate comprising dioxolane and 1,3,5-trioxepane was collected and fractionally distilled under static vacuum, collecting the fraction with b.p. $=40{ }^{\circ} \mathrm{C}$, which contained pure 1,3,5-trioxepane. The product was dried over $\mathrm{CaH}_{2}$ for 24 hours, distilled, and degassed via three freeze-pump-thaw cycles prior to use. Typical yields were $20-30 \%$. This procedure is identical to that used in our prior report. ${ }^{1} \mathbf{H} \mathbf{~ N M R}\left(300 \mathrm{MHz}, \mathrm{CDCl}_{3}\right): \delta 4.84(\mathrm{~d}, \mathrm{~J}=$ $4.1 \mathrm{~Hz}, 4 \mathrm{H}), 3.74(\mathrm{~d}, \mathrm{~J}=4.0 \mathrm{~Hz}, 4 \mathrm{H}) \mathrm{ppm} .{ }^{13} \mathbf{C} \mathbf{~ N M R}\left(125 \mathrm{MHz}, \mathrm{CDCl}_{3}\right):$ 92.86, $69.87 \mathrm{ppm}$.

\section{Sodium 2-trimethylsilylethoxide (NaOEtTMS)}

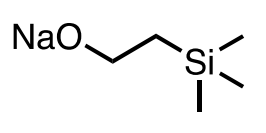

In a glovebox under nitrogen atmosphere, sodium hydride $(\mathrm{NaH}, 90 \%$;

$1.2 \mathrm{~g}, 48 \mathrm{mmol}, 0.95$ equiv) was added to a $100 \mathrm{~mL}$ round bottom flask equipped with a magnetic stir bar, which was then sealed with a rubber septum and removed from the glovebox. Under a positive flow of nitrogen vented to a mineral oil bubbler, diethyl ether $(40 \mathrm{~mL})$ was added to the reaction vessel. The solution was cooled to $0{ }^{\circ} \mathrm{C}$ in an ice bath for 10 minutes and the $\mathrm{N}_{2}$ flow was stopped. Immediately, 2-trimethylsilylethanol $(6.0 \mathrm{~g}, 51 \mathrm{mmol}$, 
1.0 equiv) was added dropwise via syringe to the stirring solution, which was vented into the mineral oil bubbler. After addition, the reaction was removed from the ice bath and stirred for $12 \mathrm{~h}$ overnight. Then, using Schlenk techniques, the slurry solution was transferred via cannula to an air-free fritted filter under vacuum to remove unreacted $\mathrm{NaH}$. A clear brown liquid was collected in a $250 \mathrm{~mL}$ three-neck round bottom receiving flask. Acetonitrile $(\mathrm{MeCN} ; 100 \mathrm{~mL})$ was then added to the receiving flask to precipitate a white solid. The solution was placed in an ice bath and allowed to precipitate for $1 \mathrm{~h}$ to improve the yield. Then, this slurry solution was passed through another air-free fritted filter, which was subsequently sealed off. The white crystalline product was dried under high vacuum overnight to remove any residual solvent and obtained in $42 \%$ isolated yield. Pure product was stored in a glovebox under nitrogen atmosphere. ${ }^{1} \mathbf{H}$ NMR (500 MHz, $\left.\mathrm{C}_{6} \mathrm{D}_{6}\right): \delta 3.52(\mathrm{~m}, 2 \mathrm{H}), 0.77(\mathrm{~m}, 2 \mathrm{H}),-0.03(\mathrm{~s}, 9 \mathrm{H}) \mathrm{ppm} .{ }^{13} \mathbf{C}$ NMR $\left(125 \mathrm{MHz}, \mathrm{C}_{6} \mathrm{D}_{6}\right): 24.35,5.08$, $1.26 \mathrm{ppm}$.

\section{Polymer Synthesis}

\section{Poly(1,3,6,9,12-pentaoxacyclotetradecane) [P(4EO-MO)]}

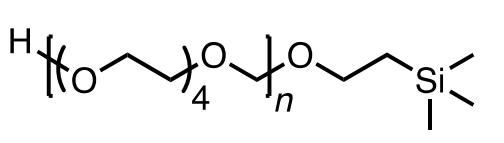

In a glovebox under nitrogen atmosphere, 4EO-MO $(10 \mathrm{~g}$, $48 \mathrm{mmol}, 400$ equiv), and $\mathrm{CH}_{2} \mathrm{Cl}_{2}(6.0 \mathrm{~mL})$ were combined

in a $100 \mathrm{~mL}$ round bottom flask with a magnetic stir bar. The flask was sealed with a rubber septum, brought out of the glovebox, and cooled in an ice bath. Then, while stirring, trimethylsilyl triflate ( $22 \mu \mathrm{L}, 0.12 \mathrm{mmol}, 1.0$ equiv) was added instantaneously through the septum using a gas tight syringe. The reaction was stirred at $0{ }^{\circ} \mathrm{C}$ for $7.5 \mathrm{~h}$, during which the viscosity increased significantly. The reaction was quenched by instantaneously adding a solution of sodium 2-trimethylsilylethoxide ( $0.34 \mathrm{~g}, 2.4 \mathrm{mmol}, 20$ equiv) in toluene $(2 \mathrm{~mL})$ that had been previously prepared in the glovebox to the reaction mixture and mixing vigorously. The reaction mixture was 
immediately precipitated into cold ether $(1 \mathrm{~L})$ to give a white powder. The product was dried under high vacuum overnight to remove residual solvent, then dried at $80{ }^{\circ} \mathrm{C}$ for $4 \mathrm{~h}$ to remove macrocyclic byproducts. The polymer was cooled to room temperature to give a viscous solid that crystallized over several days in $56 \%$ yield. This polymer sample is identical to that used in our prior report. $.^{1} M_{\mathrm{n}}=5.2 \mathrm{~kg} / \mathrm{mol} ; \mathrm{Ð}=2.09 ; T_{\mathrm{g}}=-67{ }^{\circ} \mathrm{C} ; T_{\mathrm{m}}=27,31{ }^{\circ} \mathrm{C} ; T_{\mathrm{d}(5 \%)}=338{ }^{\circ} \mathrm{C} .{ }^{1} \mathbf{H} \mathbf{~ N M R}$ $\left(500 \mathrm{MHz}, \mathrm{CDCl}_{3}\right): \delta 4.72(\mathrm{~d}, 2 \mathrm{H}), 3.68(\mathrm{~m}, 4 \mathrm{H}), 3.63(\mathrm{~m}, 12 \mathrm{H}) \mathrm{ppm} .{ }^{13} \mathrm{C}$ NMR $(125 \mathrm{MHz}$ $\left.\mathrm{CDCl}_{3}\right): 95.66,70.67,70.66,70.56,66.96 \mathrm{ppm}$.

\section{Poly(1,3,6,9-tetraoxacycloundecane) [P(3EO-MO)]}

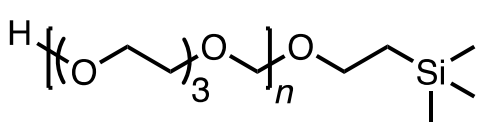

In a glovebox under nitrogen atmosphere, 3EO-MO $(8.0 \mathrm{~g}$, $49 \mathrm{mmol}, 200$ equiv) and $\mathrm{CH}_{2} \mathrm{Cl}_{2}$ were combined in a $100 \mathrm{~mL}$ round bottom flask with a magnetic stir bar. The flask was sealed with a rubber septum, brought out of the glovebox, and cooled to $0{ }^{\circ} \mathrm{C}$ in an ice bath. Polymerization was initiated by the instantaneous addition of methyl triflate ( $28 \mu \mathrm{L}, 0.25 \mathrm{mmol}, 1.0$ equiv) through the septum. After 30 minutes, the reaction began to turn slightly yellow and viscosity increased. After $2 \mathrm{~h}$, the reaction was quenched by the instantaneous addition of a solution of sodium 2trimethylsilylethoxide $(0.18 \mathrm{~g}, 1.3 \mathrm{mmol}, 5.0$ equiv) in toluene $(3.0 \mathrm{~mL})$ that had been prepared previously in the glovebox and shaken vigorously to mix. The reaction was immediately precipitated into cold hexanes $(1 \mathrm{~L})$ to give a viscous, slightly opaque product. The polymer was triturated in hexanes, decanted, and dried on high vacuum overnight to remove residual solvent. Product was then dried at $80{ }^{\circ} \mathrm{C}$ for $4 \mathrm{~h}$ to remove macrocyclic byproducts. The polymer was cooled to room temperature to give a clear, colorless gel in $65 \%$ yield. This polymer sample is identical to that used in our prior report. ${ }^{1} M_{\mathrm{n}}=13.6 \mathrm{~kg} / \mathrm{mol} ; \mathrm{Ð}=1.67 ; T_{\mathrm{g}}=-63{ }^{\circ} \mathrm{C} ; T_{\mathrm{d}(5 \%)}=266$ 
${ }^{\circ} \mathrm{C} .{ }^{1} \mathbf{H}$ NMR $\left(500 \mathrm{MHz}, \mathrm{CDCl}_{3}\right): \delta 4.73(\mathrm{~s}, 2 \mathrm{H}), 3.69(\mathrm{~m}, 4 \mathrm{H}), 3.65(\mathrm{~m}, 8 \mathrm{H}) \mathrm{ppm} .{ }^{13} \mathbf{C}$ NMR $(125$

$\left.\mathrm{MHz}, \mathrm{CDCl}_{3}\right): 95.69,70.68,70.61,66.99 \mathrm{ppm}$.

\section{Poly(1,3,6-trioxocane) [P(2EO-MO)]}

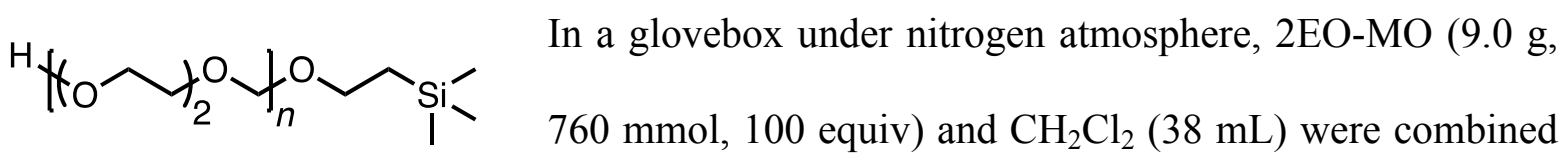
in a $50 \mathrm{~mL}$ round bottom flask with a magnetic stir bar. The flask was sealed with a rubber septum, brought out of the glovebox, and cooled to $0{ }^{\circ} \mathrm{C}$ in an ice bath. To initiate the polymerization, trimethylsilyl triflate (140 $\mu \mathrm{L}, 0.76 \mathrm{mmol}, 1.0$ equiv) was added instantaneously to the reaction mixture through the septum. After three minutes, the reaction gelled and turned slightly pink. After 5 minutes, a previously prepared sodium 2-trimethylsilylethoxide $(0.21 \mathrm{~g}, 1.5 \mathrm{mmol}, 2$ equiv) solution was added to the reaction mixture instantaneously, and the flask was shaken vigorously. The reaction mixture was immediately precipitated into cold isopropanol $(1 \mathrm{~L})$ to yield a white powder. The product was isolated via filtration, rinsed with cold hexanes, dried on high vacuum overnight to remove residual solvent, then dried at $80^{\circ} \mathrm{C}$ for $4 \mathrm{~h}$ to remove macrocyclic byproducts. After cooling to room temperature, white semi-crystalline product was obtained in $75 \%$ yield. This polymer sample is identical to that used in our prior report. ${ }^{1} M_{\mathrm{n}}=20.6 \mathrm{~kg} / \mathrm{mol} ; Đ=2.88 ; T_{\mathrm{g}}=-62$ ${ }^{\circ} \mathrm{C} ; T_{\mathrm{m}}=38{ }^{\circ} \mathrm{C} ; T_{\mathrm{d}(5 \%)}=341{ }^{\circ} \mathrm{C} .{ }^{1} \mathbf{H}$ NMR $\left(500 \mathrm{MHz}, \mathrm{CDCl}_{3}\right) \delta 4.74(\mathrm{~s}, 2 \mathrm{H}), 3.69(\mathrm{~m}, 8 \mathrm{H}) \mathrm{ppm}$. ${ }^{13}$ C NMR $\left(125 \mathrm{MHz}, \mathrm{CDCl}_{3}\right) \delta$ 95.73, 70.60, $67.02 \mathrm{ppm}$.

\section{Poly(1,3-dioxolane) [P(EO-MO)]}

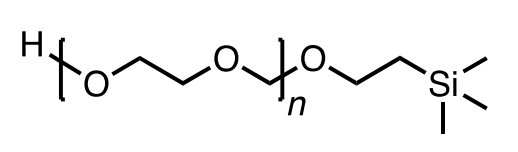

In a glovebox under nitrogen atmosphere, 1,3-dioxolane (EO-MO) (10.0 g, $135 \mathrm{mmol}, 300$ equiv) was added to a 
$20 \mathrm{~mL}$ vial with a magnetic stir bar and was sealed with a cap with septum. The cap was secured with electrical tape and the vial was brought out of the glovebox and cooled to $0{ }^{\circ} \mathrm{C}$ in an ice bath. Then, methyl triflate ( $50 \mu \mathrm{L}, 0.45 \mathrm{mmol}, 1.0$ equiv) was added instantaneously through the septum. After 15 minutes, the reaction mixture gelled and turned slightly pink. The reaction was quenched by instantaneously adding a previously prepared solution of sodium 2-trimethylsilylethoxide $(0.32 \mathrm{~g}, 23 \mathrm{mmol}, 5.0$ equiv) in toluene $(2.0 \mathrm{~mL})$ and shaking the reaction mixture vigorously. $\mathrm{CH}_{2} \mathrm{Cl}_{2}(10 \mathrm{~mL})$ was added to dilute the reaction mixture, which was then precipitated into cold diethyl ether (2 L) to give a white powdery solid. The solid was filtered and dried on high vacuum overnight to remove residual solvent, then dried at $80^{\circ} \mathrm{C}$ for $4 \mathrm{~h}$ to remove cyclic byproducts. The pure white solid product was obtained in $70 \%$ yield. This polymer sample is identical to that used in our prior report. ${ }^{1} M_{\mathrm{n}}=23.4 \mathrm{~kg} / \mathrm{mol} ; \mathrm{Ð}=2.12 ; T_{\mathrm{g}}=-64{ }^{\circ} \mathrm{C} ; T_{\mathrm{m}}=57{ }^{\circ} \mathrm{C} ; T_{\mathrm{d}(5 \%)}=341^{\circ} \mathrm{C} .{ }^{1} \mathbf{H}$ NMR (500 MHz, $\left.\mathrm{CDCl}_{3}\right): \delta 4.74(\mathrm{~s}, 2 \mathrm{H}), 3.71(\mathrm{~s}, 4 \mathrm{H}) \mathrm{ppm} .{ }^{13} \mathbf{C}$ NMR $\left(125 \mathrm{MHz}, \mathrm{CDCl}_{3}\right): 95.68$, $66.96 \mathrm{ppm}$.

\section{Poly(1,3,5-trioxepane) [P(EO-2MO)]}

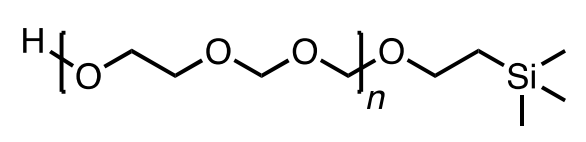

In a glovebox under nitrogen atmosphere, EO-2MO $(7.7 \mathrm{~g}$, $74 \mathrm{mmol}, 400$ equiv) and $\mathrm{CH}_{2} \mathrm{Cl}_{2}(18 \mathrm{~mL})$ were combined in a $50 \mathrm{~mL}$ round bottom flask with a magnetic stir bar. The flask was sealed with a rubber septum, brought out of the glovebox, and cooled in an ice bath. Then, trimethylsilyl triflate $(34 \mu \mathrm{L}$, $0.18 \mathrm{mmol}, 1.0$ equiv) was added using a gas tight syringe through the rubber septum. The reaction mixture gelled within seconds and was quenched after 3 minutes by the instantaneous addition of a solution of sodium 2-trimethylsilylethoxide $(0.10 \mathrm{~g}, 0.74 \mathrm{mmol}, 4$ equiv) in toluene $(3 \mathrm{~mL})$, which had been previously prepared in the glovebox. The reaction mixture was diluted with 
$\mathrm{CH}_{2} \mathrm{Cl}_{2}(20 \mathrm{~mL})$ and immediately precipitated into $1 \mathrm{~L}$ of cold isopropanol to give a fibrous white solid. The solution was filtered, and the solid was dried under high vacuum overnight to remove residual solvent, then dried at $80{ }^{\circ} \mathrm{C}$ under high vacuum to remove macrocyclic byproducts and cooled to room temperature to give a white solid in $60 \%$ yield. This polymer sample is identical to that used in our prior report. ${ }^{1} M_{\mathrm{n}}=24.9 \mathrm{~kg} / \mathrm{mol} ; \mathrm{Ð}=2.04 ; T_{\mathrm{g}}=-66{ }^{\circ} \mathrm{C} ; T_{\mathrm{m}}=28{ }^{\circ} \mathrm{C} ; T_{\mathrm{d}(5 \%)}=$ $366{ }^{\circ} \mathrm{C}^{1}{ }^{1} \mathrm{H}$ NMR $\left(500 \mathrm{MHz}, \mathrm{CDCl}_{3}\right): \delta 4.87(\mathrm{~s}, 1 \mathrm{H}), 4.80(\mathrm{~m}, 2 \mathrm{H}), 4.74(\mathrm{~m}, 1 \mathrm{H}), 3.71(\mathrm{~m}, 4 \mathrm{H})$ ppm. ${ }^{13} \mathrm{C}$ NMR (125 MHz, $\mathrm{CD}_{2} \mathrm{Cl}_{2}$ ): 96.05, 92.9, 92.46, 89.61, 89.15, 88.71, 68.04, 67.44 ppm.

Table S1. Summary of physical properties of neat polyacetal polymers and PEO.

\begin{tabular}{ccccccc}
\hline Polymer & $\begin{array}{c}\boldsymbol{P} \\
([\mathrm{O}] /[\mathrm{C}])\end{array}$ & $\begin{array}{c}\boldsymbol{M}_{\mathrm{n}} \\
(\mathrm{kg} / \mathrm{mol})\end{array}$ & $\mathbf{D}$ & $\boldsymbol{T}_{\mathrm{g}}\left({ }^{\circ} \mathrm{C}\right)$ & $\boldsymbol{T}_{\mathrm{m}}\left({ }^{\circ} \mathrm{C}\right)$ & $T_{\mathrm{d}(5 \%)}\left({ }^{\circ} \mathrm{C}\right)$ \\
\hline $\mathrm{P}(\mathrm{EO}-2 \mathrm{MO})$ & 0.75 & 24.9 & 2.04 & -66 & 28 & 366 \\
$\mathrm{P}(\mathrm{EO}-\mathrm{MO})$ & 0.67 & 23.4 & 2.12 & -64 & 57 & 341 \\
$\mathrm{P}(2 \mathrm{EO}-\mathrm{MO})$ & 0.60 & 20.6 & 2.88 & -62 & 38 & 341 \\
$\mathrm{P}(3 \mathrm{EO}-\mathrm{MO})$ & 0.57 & 13.6 & 1.67 & -63 & $-{ }^{c}$ & 266 \\
$\mathrm{P}($ 4EO-MO) & 0.56 & 5.2 & 2.09 & -67 & 27,31 & 338 \\
PEO & 0.50 & $5^{a}, 20^{a}$ & $1.01^{a}, 1.01^{a}$ & $-60^{b}$ & $67^{b}$ & $-{ }^{a}$ \\
\hline
\end{tabular}

${ }^{a}$ Not synthesized in the present study. ${ }^{b}$ Data from ref. ${ }^{4,5} \cdot{ }^{c}$ No melting transition observed. 


\section{Gel Permeation Chromatography (GPC) of Neat Polyacetals}
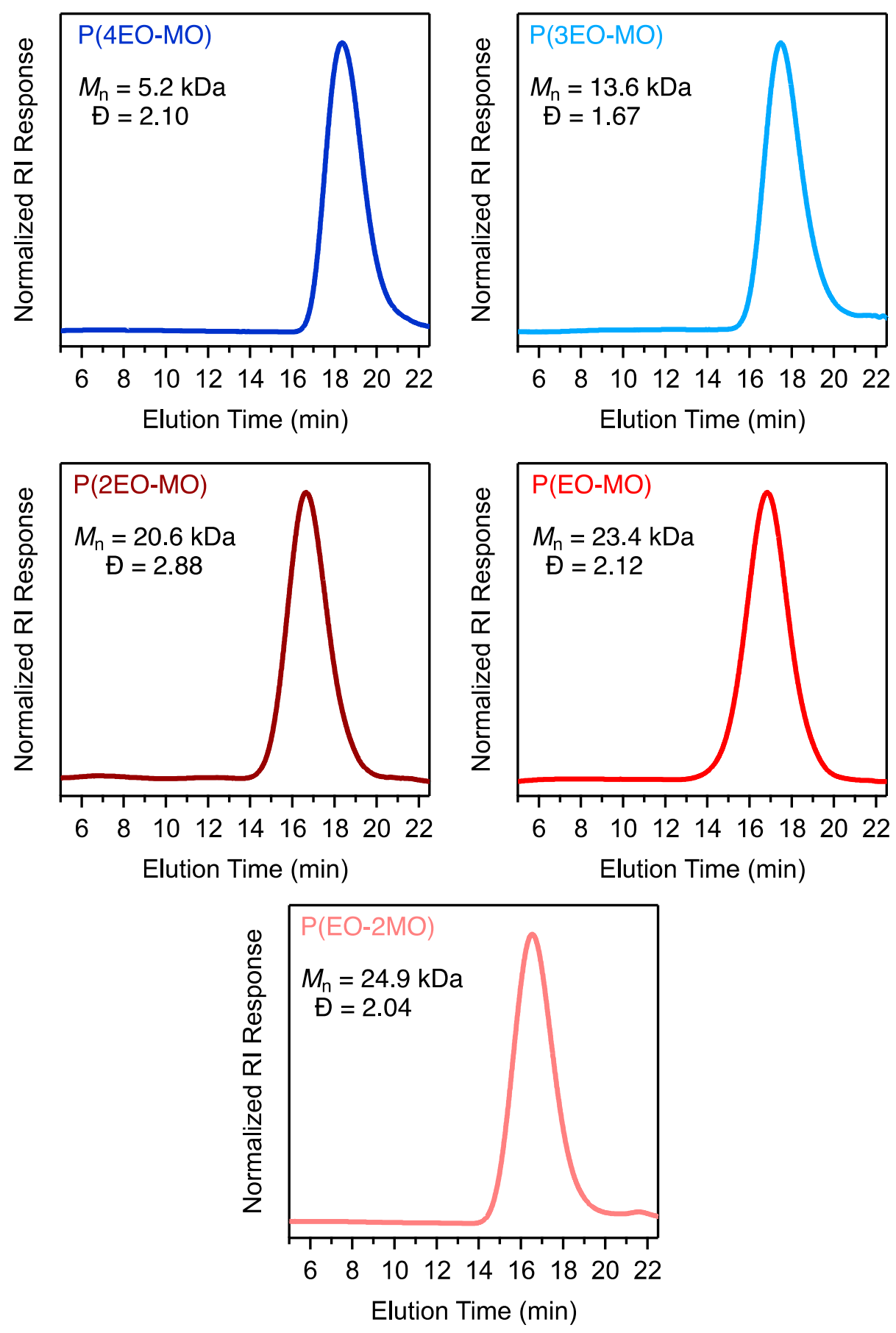

Figure S1. GPC traces of neat polyacetals showing monomodal distributions for all materials. 


\section{Differential Scanning Calorimetry (DSC) of Neat Polyacetals}

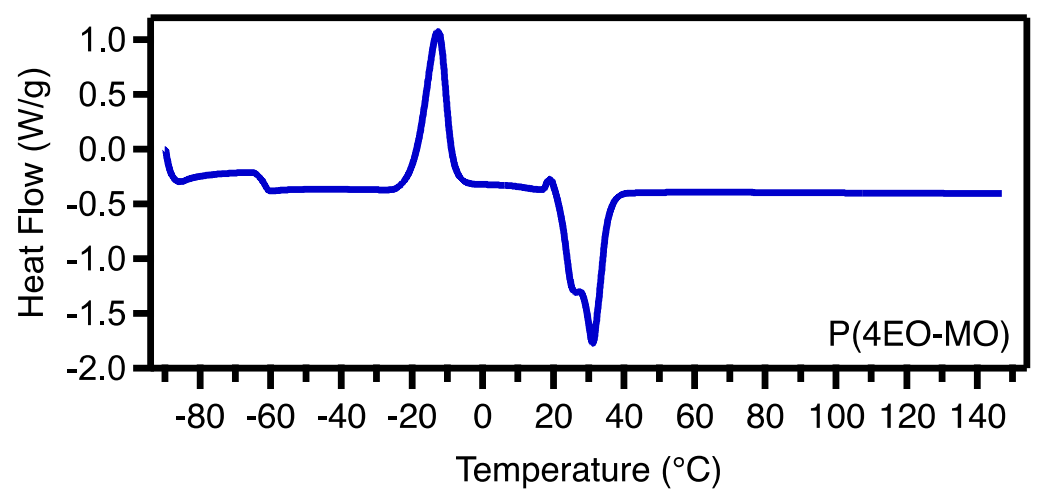

Figure S2. DSC trace from the second heating curve for $\mathrm{P}(4 \mathrm{EO}-\mathrm{MO})$. Data was taken at a heating rate of $10{ }^{\circ} \mathrm{C} / \mathrm{min}$. There is a strong endothermic crystallization peak during the second heating ramp, though no crystallization is observed during cooling. These samples were studied at temperatures well above the $T_{\mathrm{m}}$, so this crystallization behavior was not investigated further. $T_{\mathrm{g}}=-67{ }^{\circ} \mathrm{C} ; T_{\mathrm{m}}=27,31^{\circ} \mathrm{C}$.

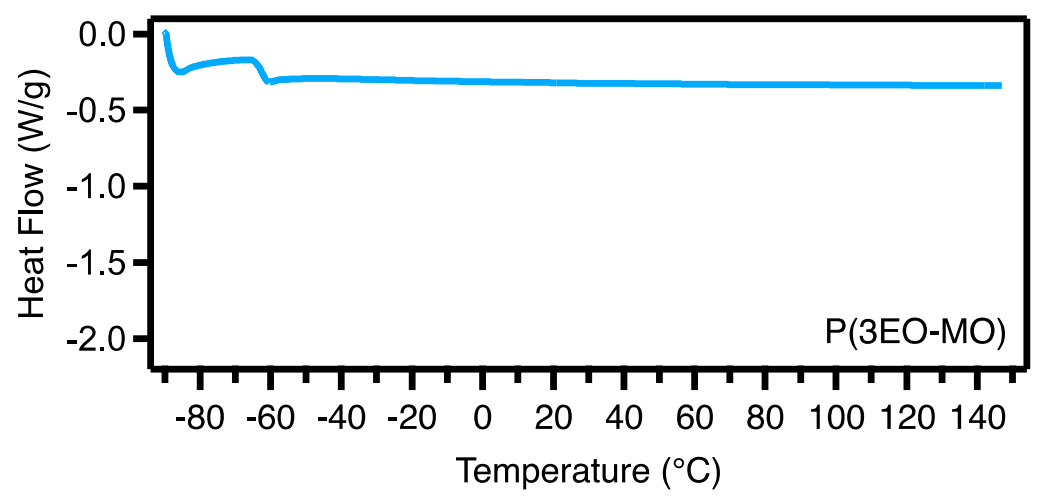

Figure S3. DSC trace from the second heating curve for $\mathrm{P}(3 \mathrm{EO}-\mathrm{MO})$. Data was taken at a heating rate of $10{ }^{\circ} \mathrm{C} / \mathrm{min} . T_{\mathrm{g}}=-63{ }^{\circ} \mathrm{C}$; no observed $T_{\mathrm{m}}$. 


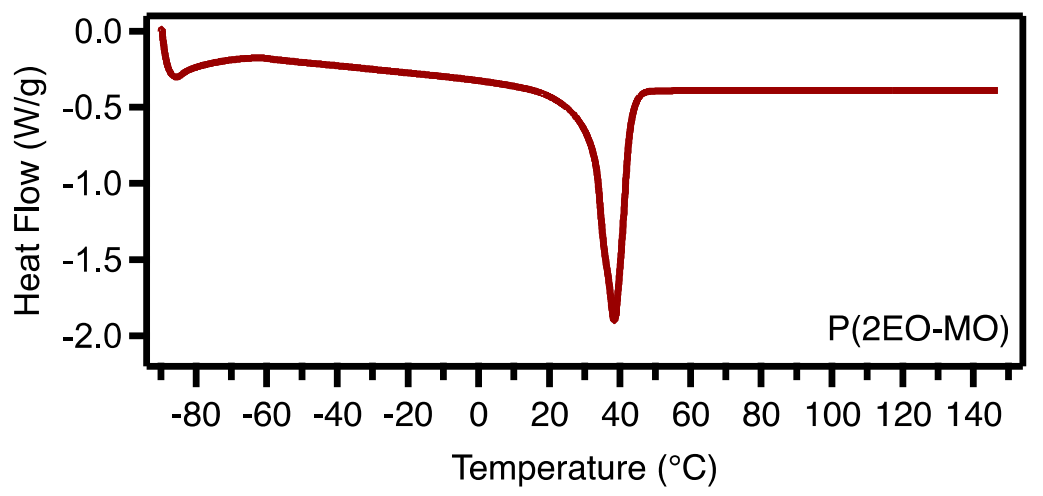

Figure S4. DSC trace from the second heating curve for $\mathrm{P}(2 \mathrm{EO}-\mathrm{MO})$. Data was taken at a heating rate of $10{ }^{\circ} \mathrm{C} / \mathrm{min} . T_{\mathrm{g}}=-62{ }^{\circ} \mathrm{C} ; T_{\mathrm{m}}=38{ }^{\circ} \mathrm{C}$.

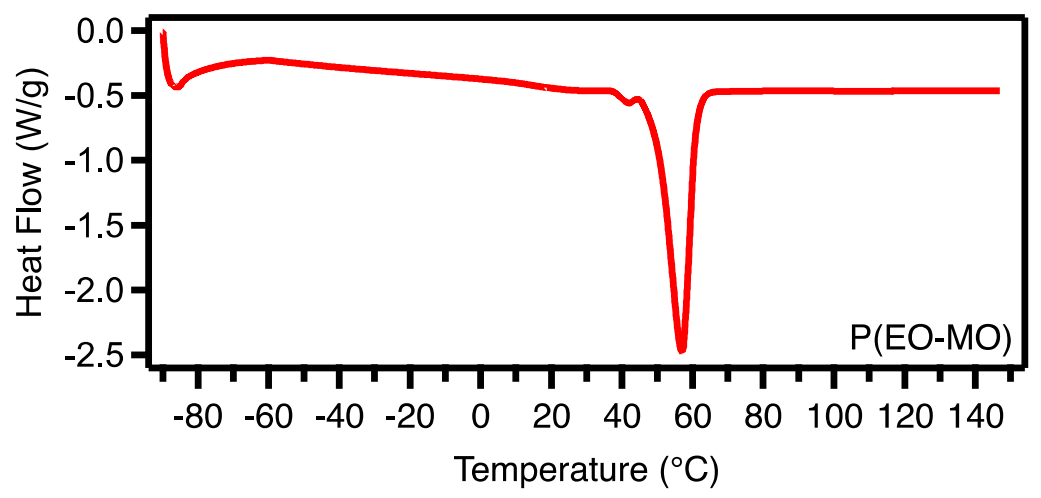

Figure S5. DSC trace from the second heating curve for $\mathrm{P}(\mathrm{EO}-\mathrm{MO})$. Data was taken at a heating rate of $10{ }^{\circ} \mathrm{C} / \mathrm{min} . T_{\mathrm{g}}=-64{ }^{\circ} \mathrm{C} ; T_{\mathrm{m}}=57^{\circ} \mathrm{C}$.

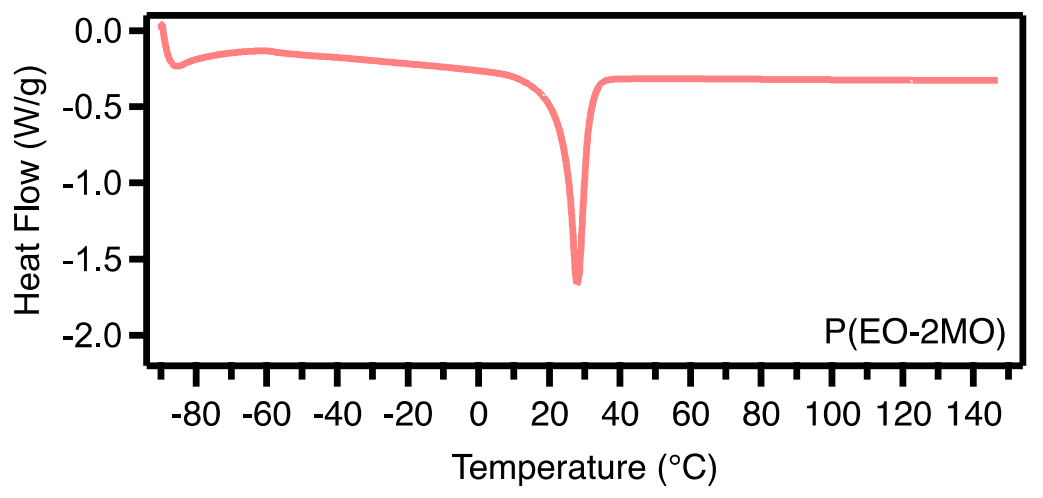


Figure S6. DSC trace from the second heating curve for $\mathrm{P}(\mathrm{EO}-2 \mathrm{MO})$. Data was taken at a heating rate of $10{ }^{\circ} \mathrm{C} / \mathrm{min} . T_{\mathrm{g}}=-66{ }^{\circ} \mathrm{C} ; T_{\mathrm{m}}=28{ }^{\circ} \mathrm{C}$. 


\section{Thermogravimetric Analysis (TGA) of Neat Polyacetals}
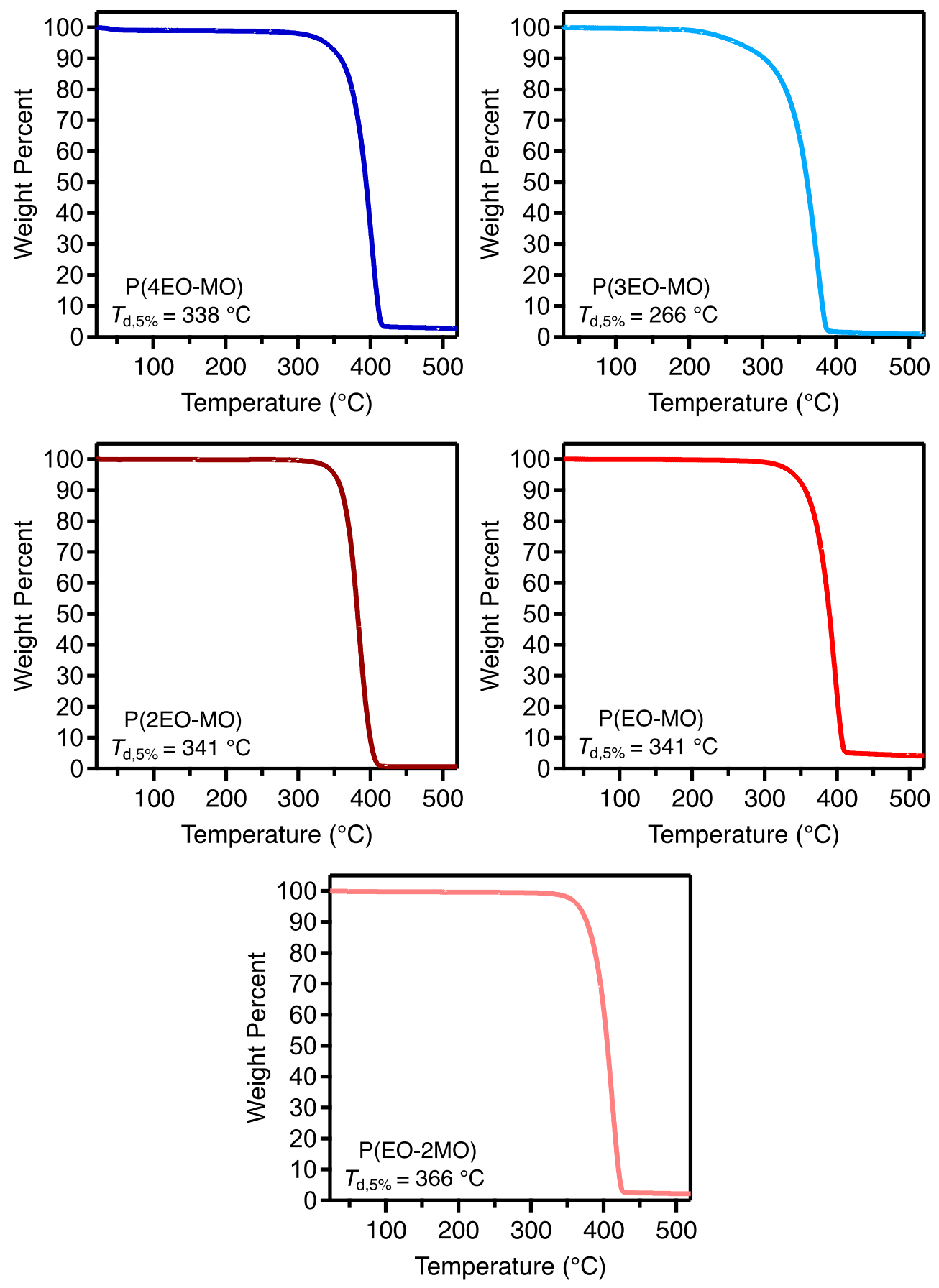

Figure S7. Thermogravimetric analyses of synthesized polyacetals. Most polymers were thermally stable to at least $338{ }^{\circ} \mathrm{C}$. $\mathrm{P}(3 \mathrm{EO}-\mathrm{MO})$ reached $5 \%$ weight loss at $266^{\circ} \mathrm{C}$, likely due to the presence of some residual acid catalyst. As the observed degradation temperatures were well above the temperature of all subsequent experiments done in this study $\left(90^{\circ} \mathrm{C}\right)$ we did not repurify the samples as it would cause loss of yield. 


\section{NMR Spectra of Monomers and Neat Polyacetals}
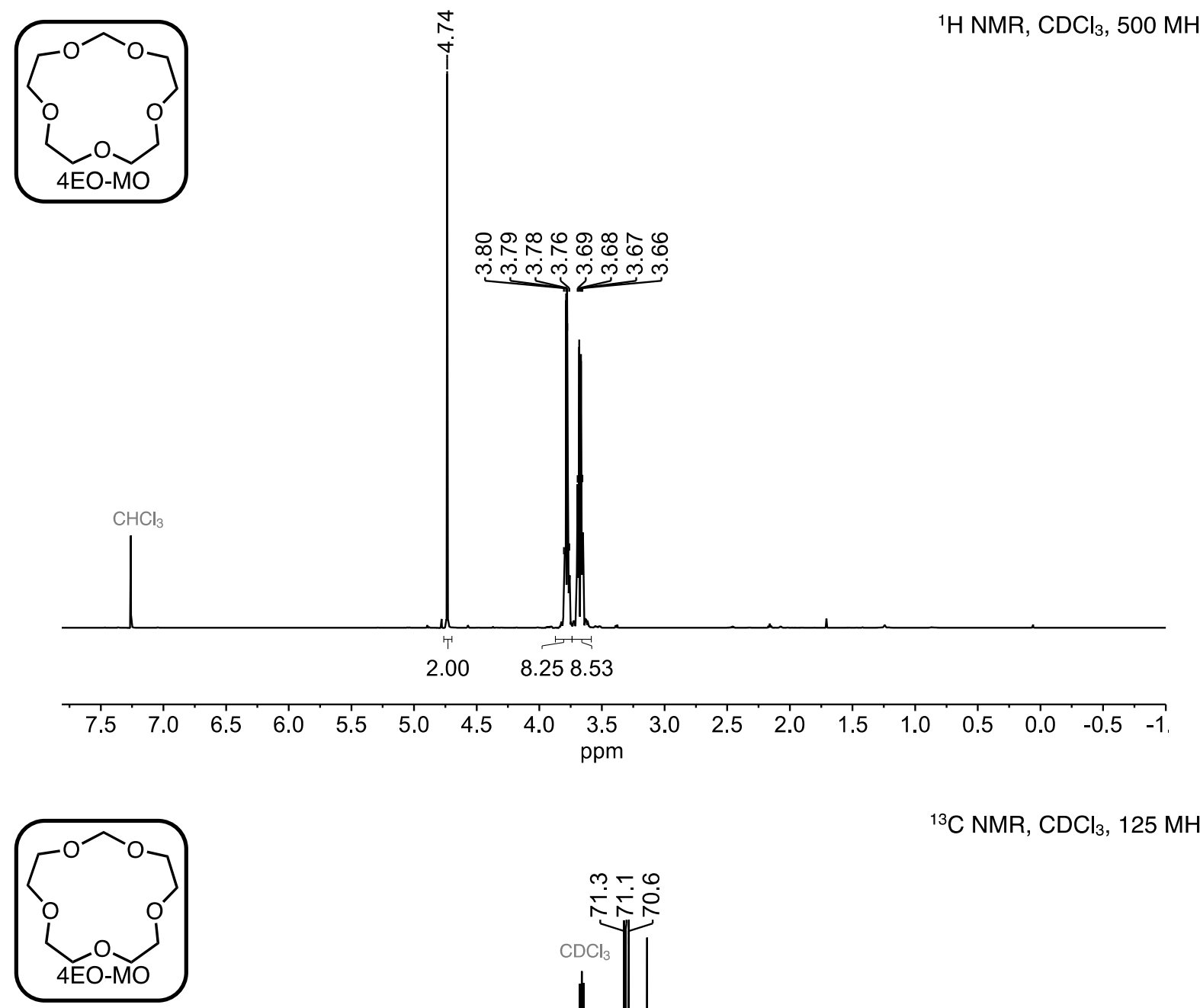

${ }^{13} \mathrm{C} \mathrm{NMR}, \mathrm{CDCl}_{3}, 125 \mathrm{MHz}$
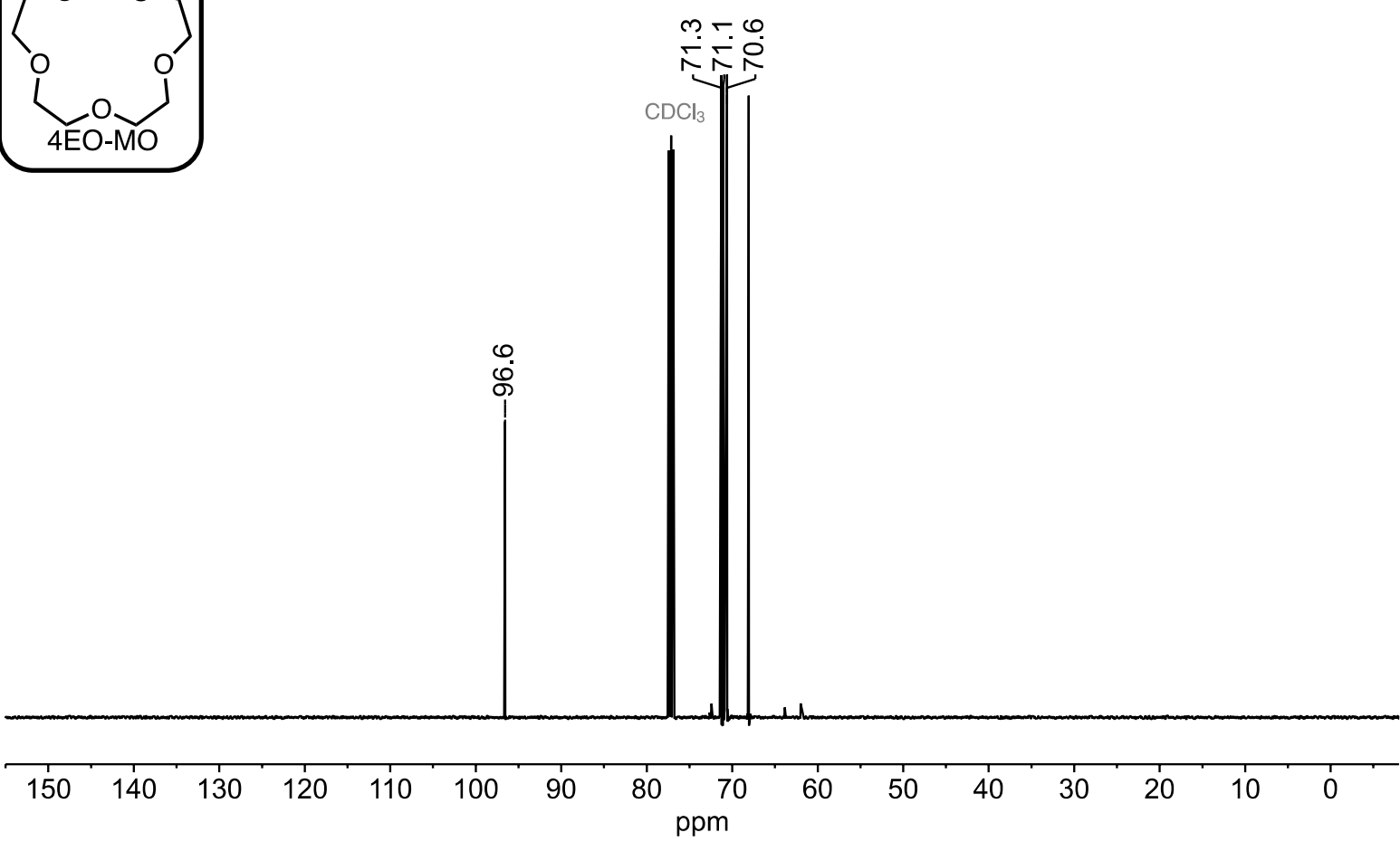


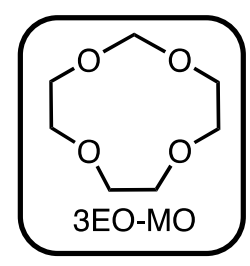

ติ

${ }^{1} \mathrm{H} \mathrm{NMR}, \mathrm{CDCl}_{3}, 500 \mathrm{MHz}$

$\mathrm{CHCl}_{3}$
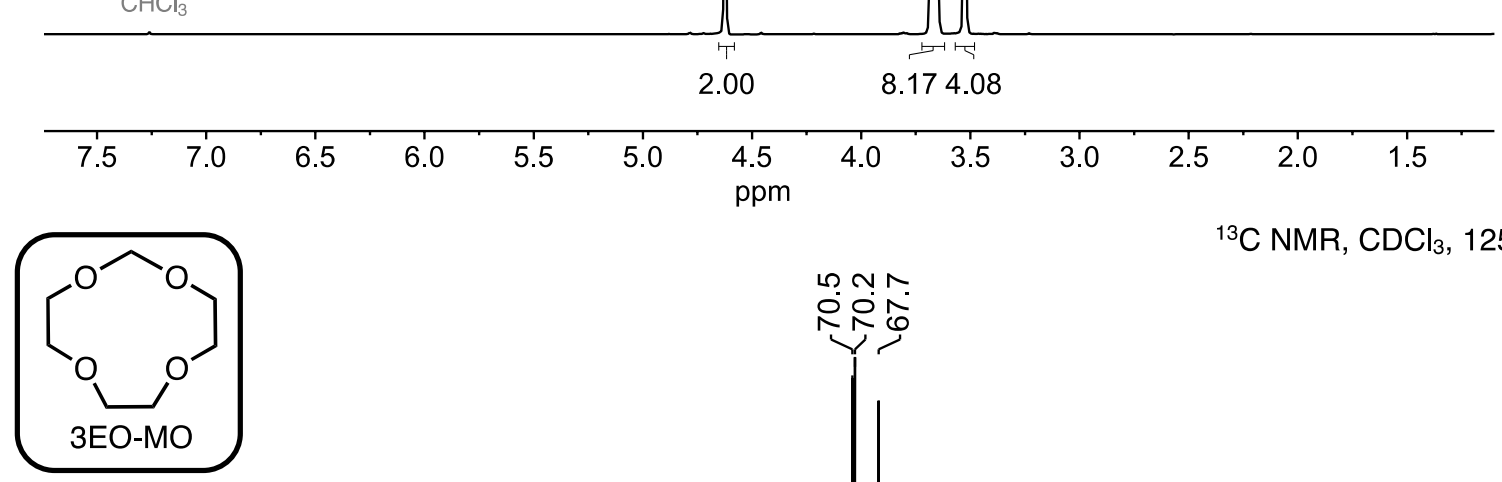

${ }^{13} \mathrm{C} \mathrm{NMR}, \mathrm{CDCl}_{3}, 125 \mathrm{MHz}$

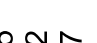

每
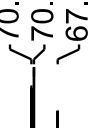


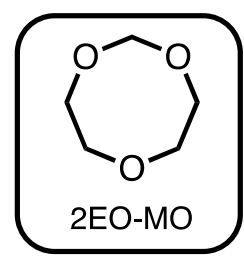

${ }^{1} \mathrm{H} \mathrm{NMR}, \mathrm{CDCl}_{3}, 500 \mathrm{MHz}$
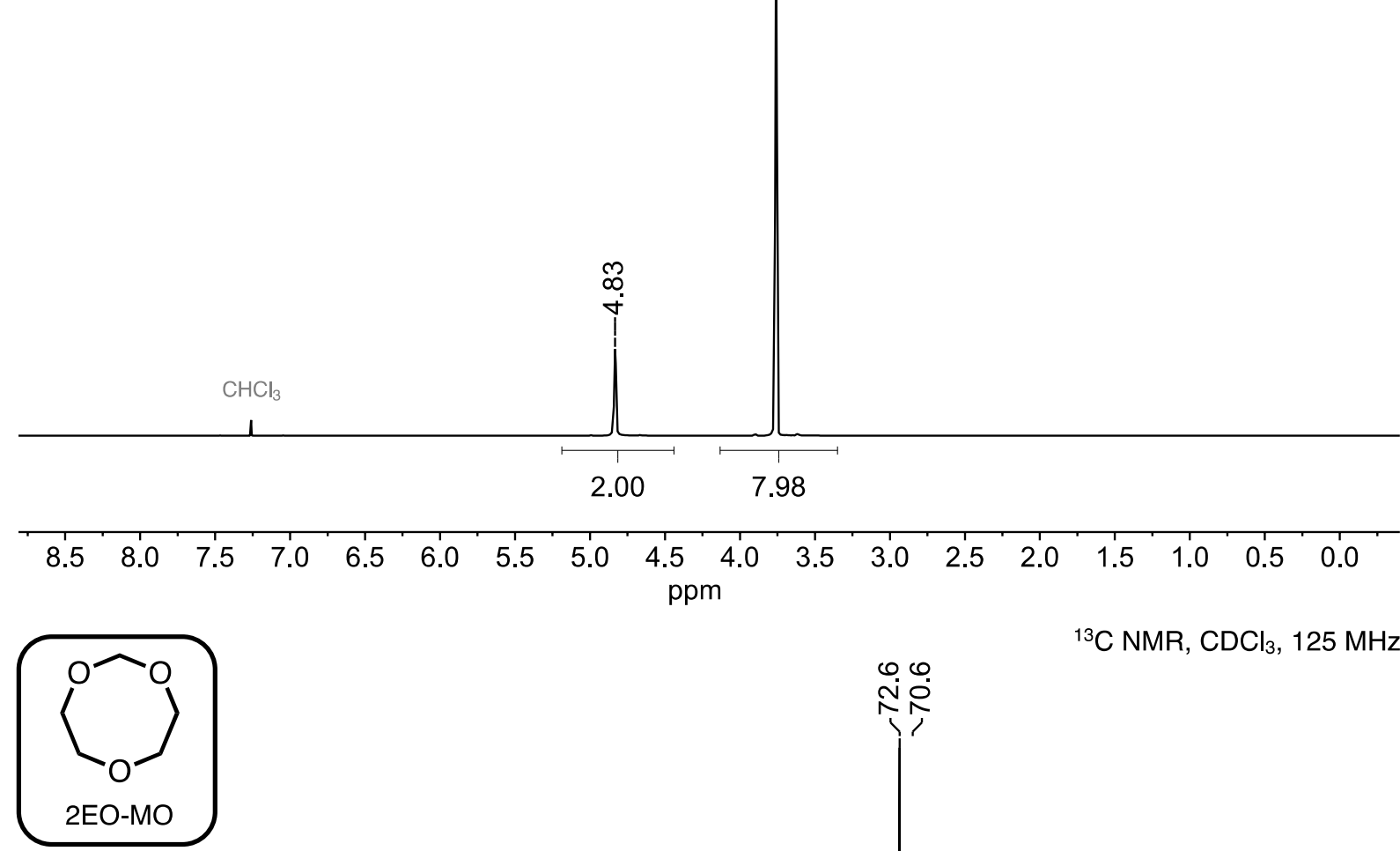

${ }^{13} \mathrm{C} \mathrm{NMR}, \mathrm{CDCl}_{3}, 125 \mathrm{MHz}$

ำ
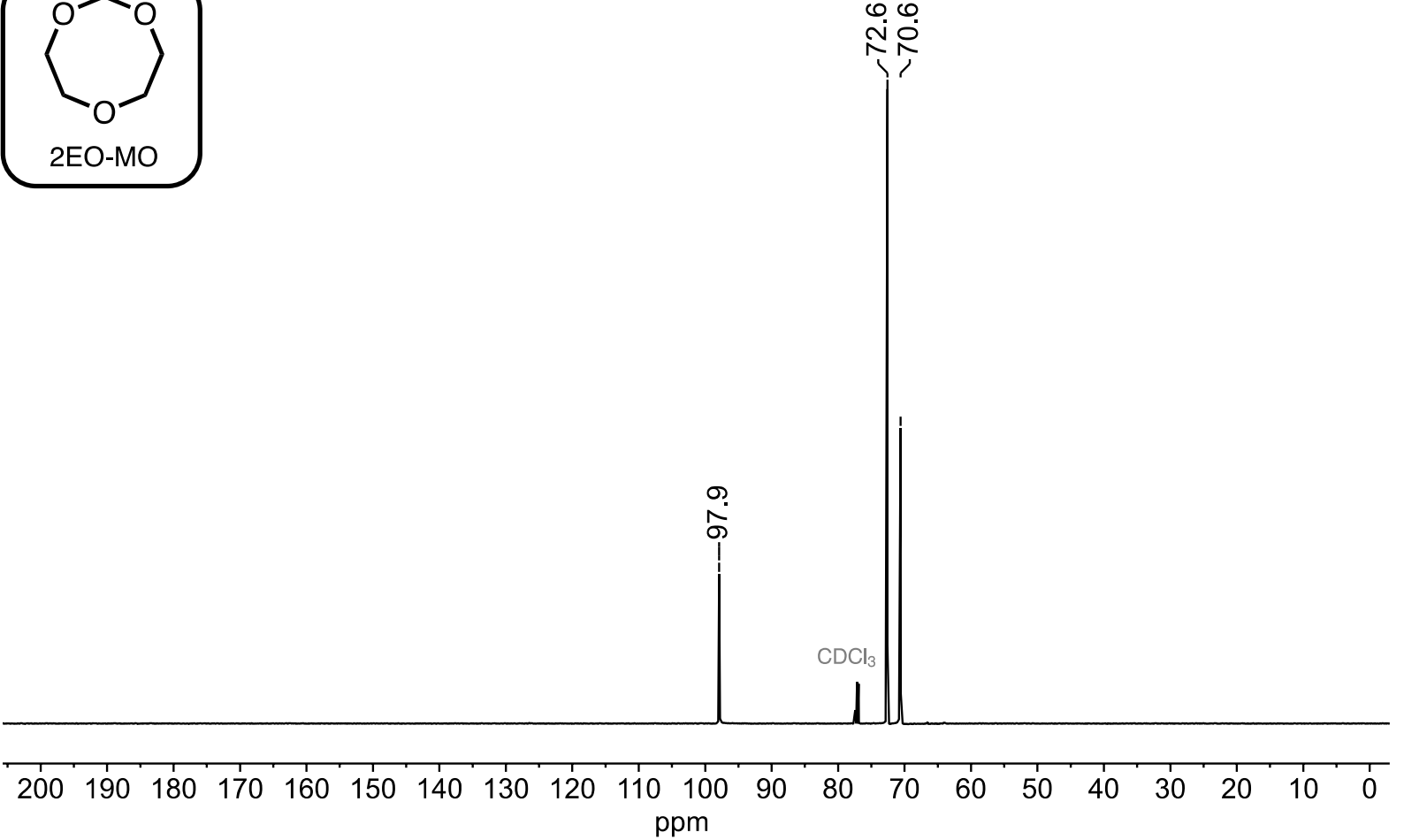


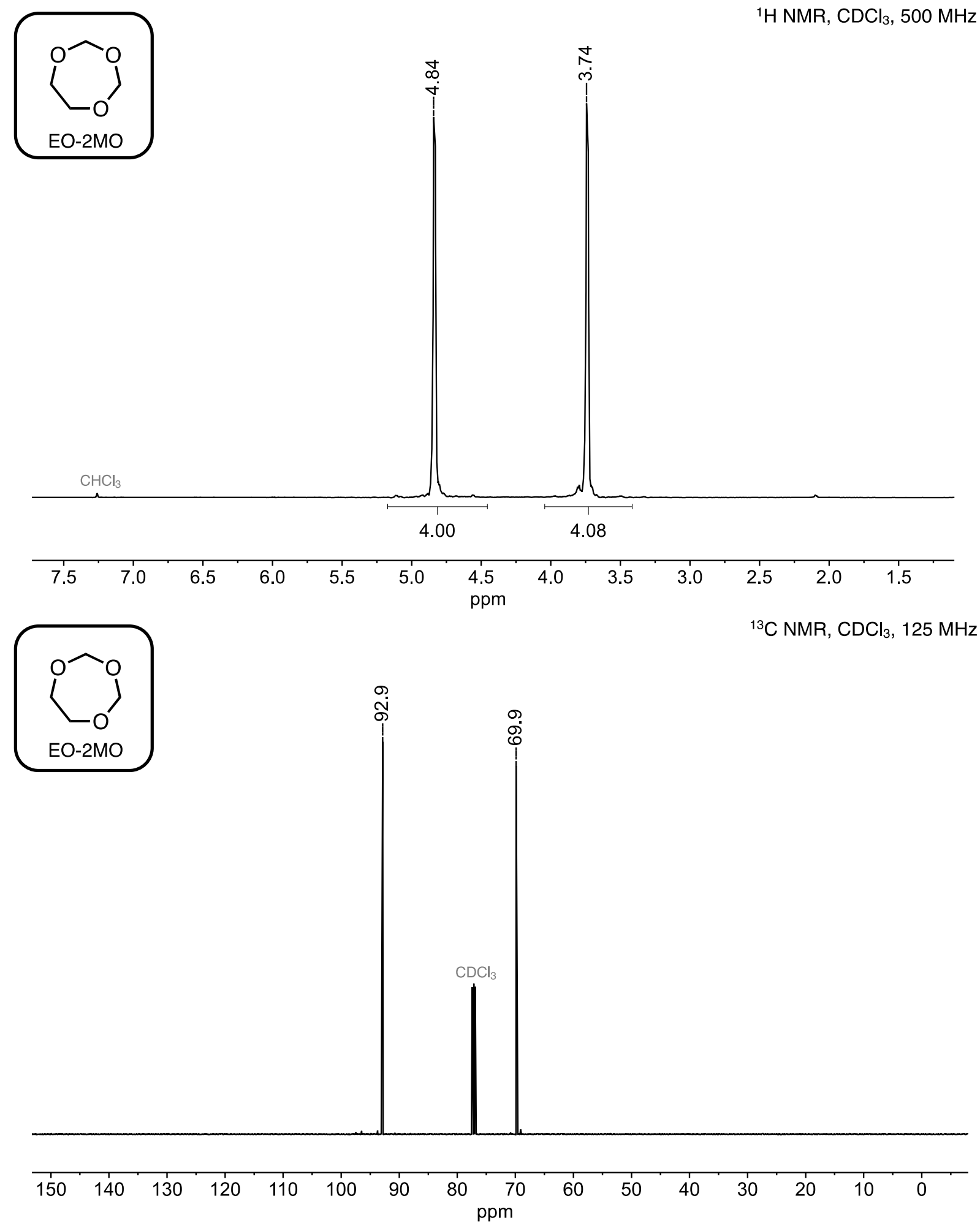




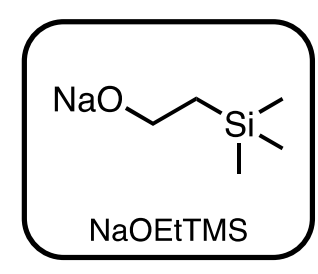

$+{ }^{1} \mathrm{H} \mathrm{NMR}, \mathrm{C}_{6} \mathrm{D}_{6}, 500 \mathrm{MHz}$

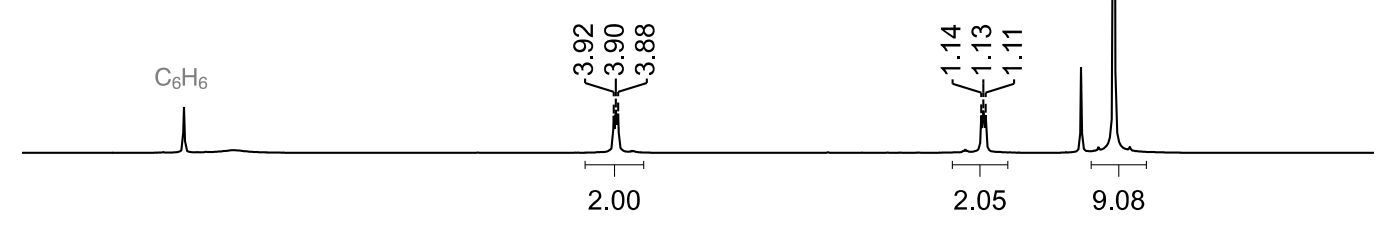

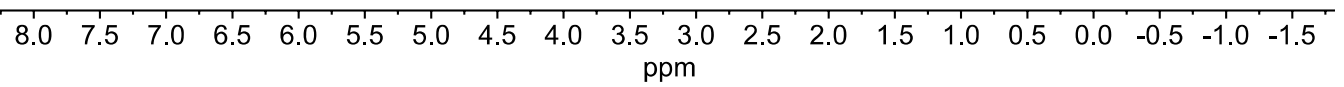

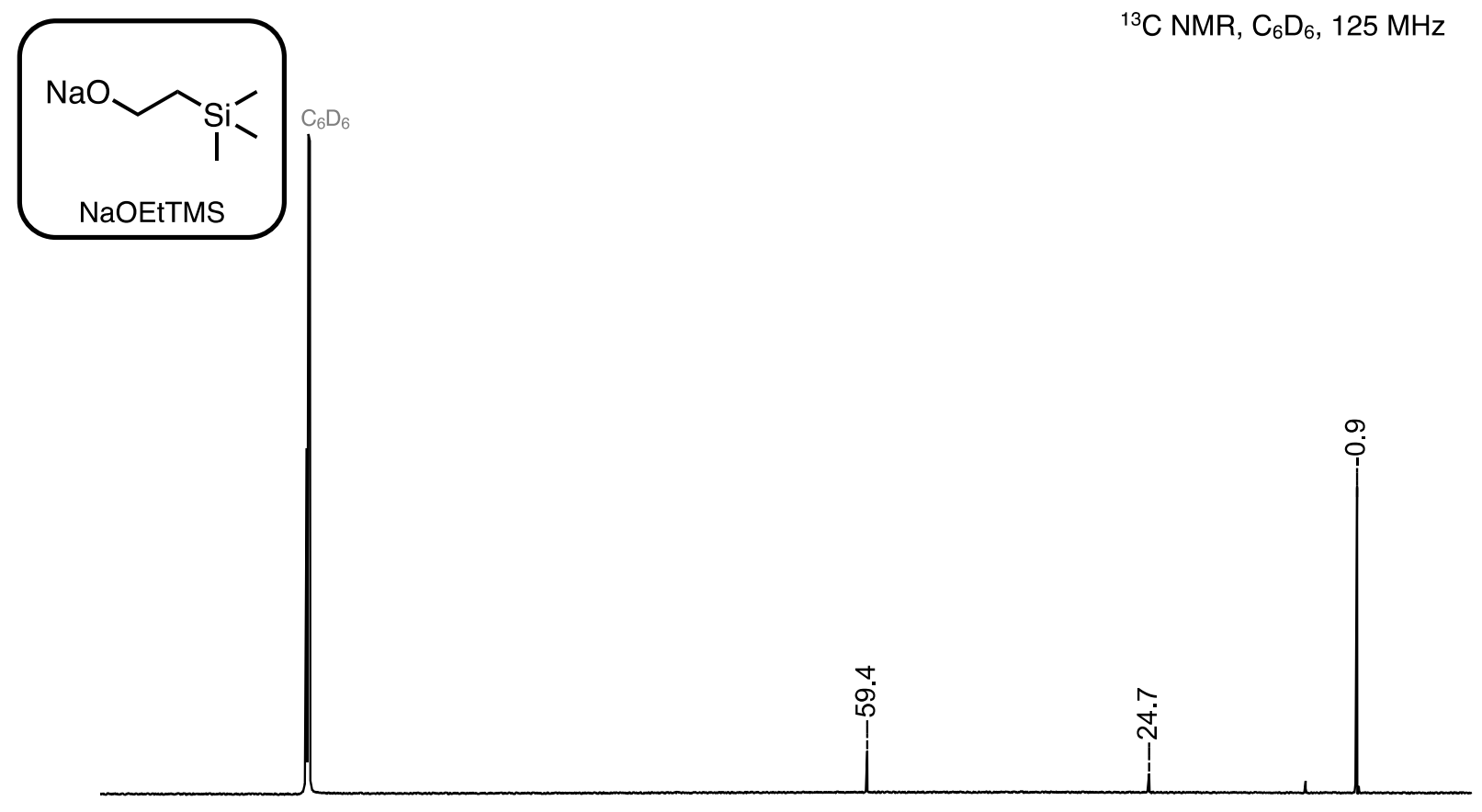

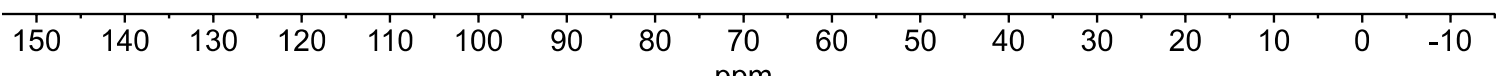




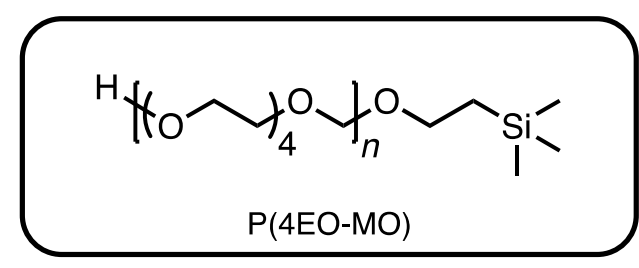

${ }^{1} \mathrm{H} \mathrm{NMR}, \mathrm{CDCl}_{3}, 500 \mathrm{MHz}$
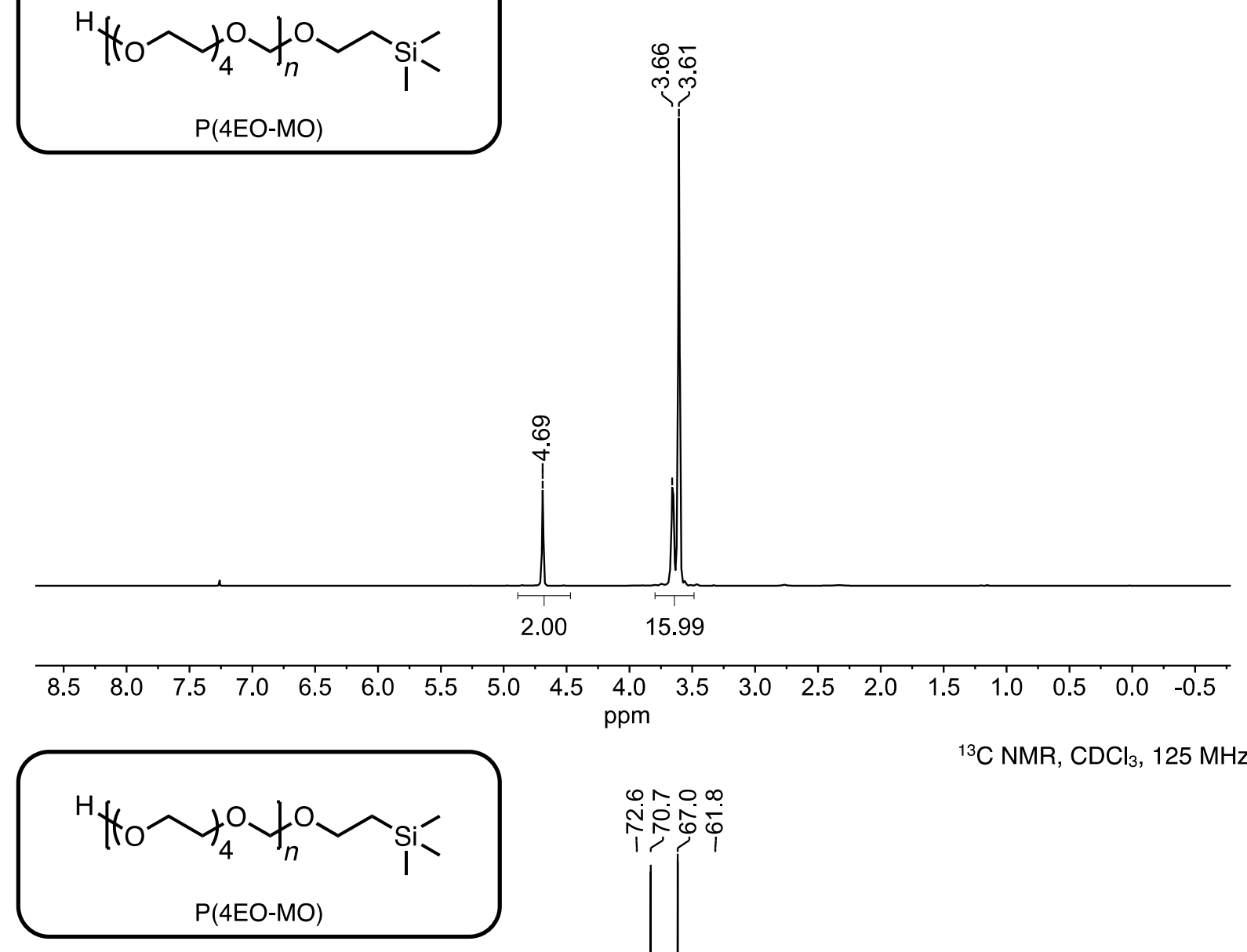

${ }^{13} \mathrm{C} \mathrm{NMR}, \mathrm{CDCl}_{3}, 125 \mathrm{MHz}$

\begin{tabular}{|c|c|c|c|c|c|c|c|c|c|c|c|c|c|c|c|c|c|c|}
\hline 8.5 & 8.0 & 7.5 & 7.0 & 6.5 & 6.0 & 5.5 & 5.0 & 4.5 & $\begin{array}{r}4.0 \\
\text { ppm }\end{array}$ & 3.5 & 3.0 & 2.5 & 2.0 & 1.5 & 1.0 & 0.5 & 0.0 & -0.5 \\
\hline
\end{tabular}



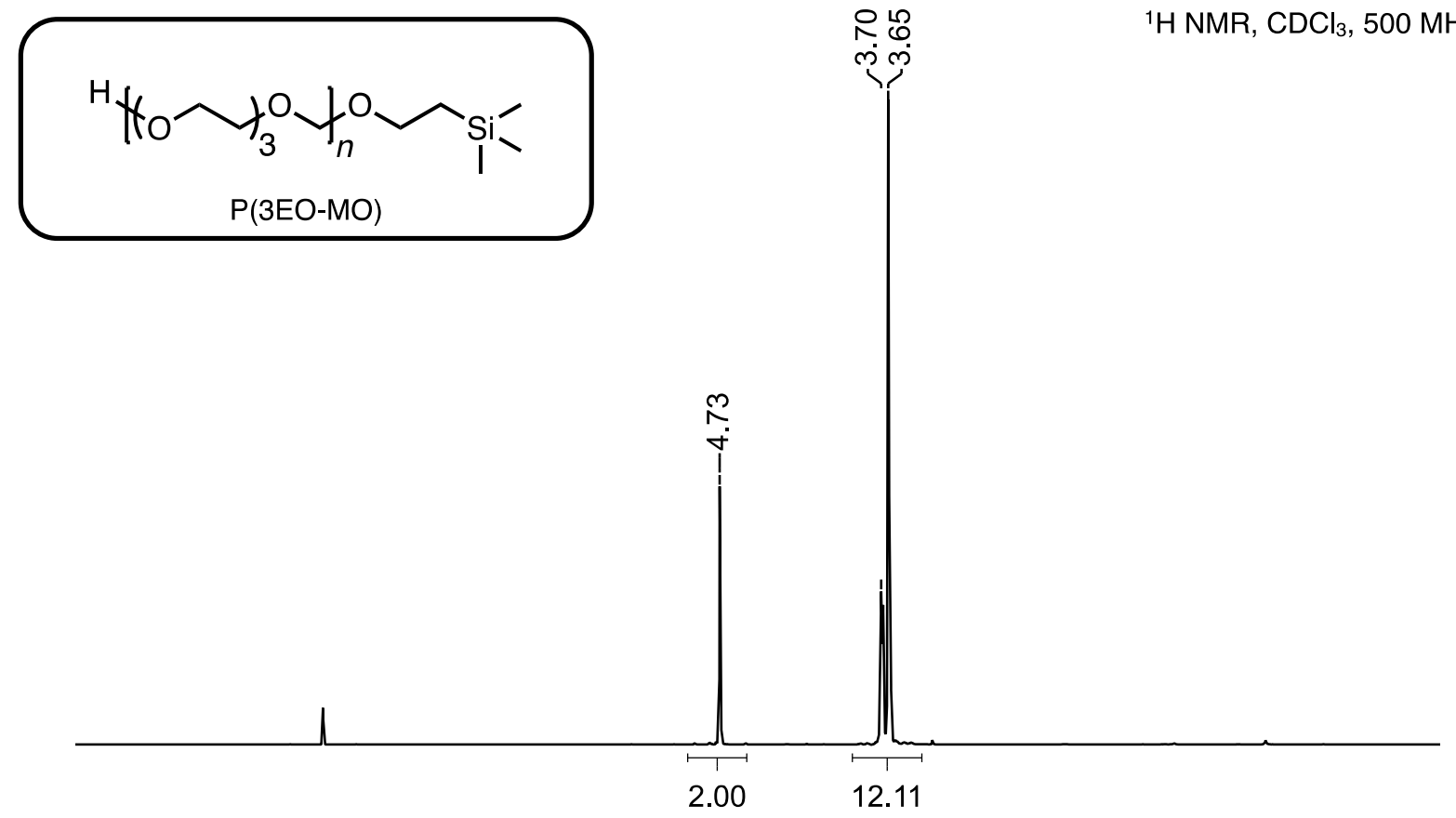

$\begin{array}{llllllllllllllllll}8.5 & 8.0 & 7.5 & 7.0 & 6.5 & 6.0 & 5.5 & \begin{array}{c}5.0 \\ \mathrm{ppm}\end{array} & 4.5 & 4.0 & 3.5 & 3.0 & 2.5 & 2.0 & 1.5 & 1.0 & 0.5\end{array}$

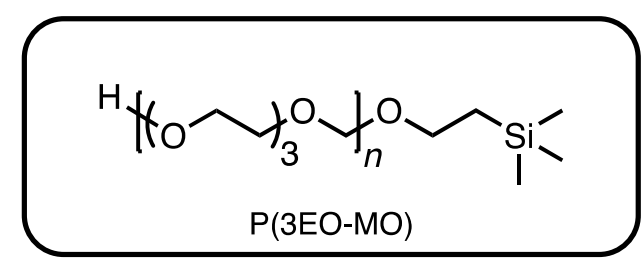

${ }^{13} \mathrm{C} \mathrm{NMR}, \mathrm{CDCl}_{3}, 125 \mathrm{MHz}$

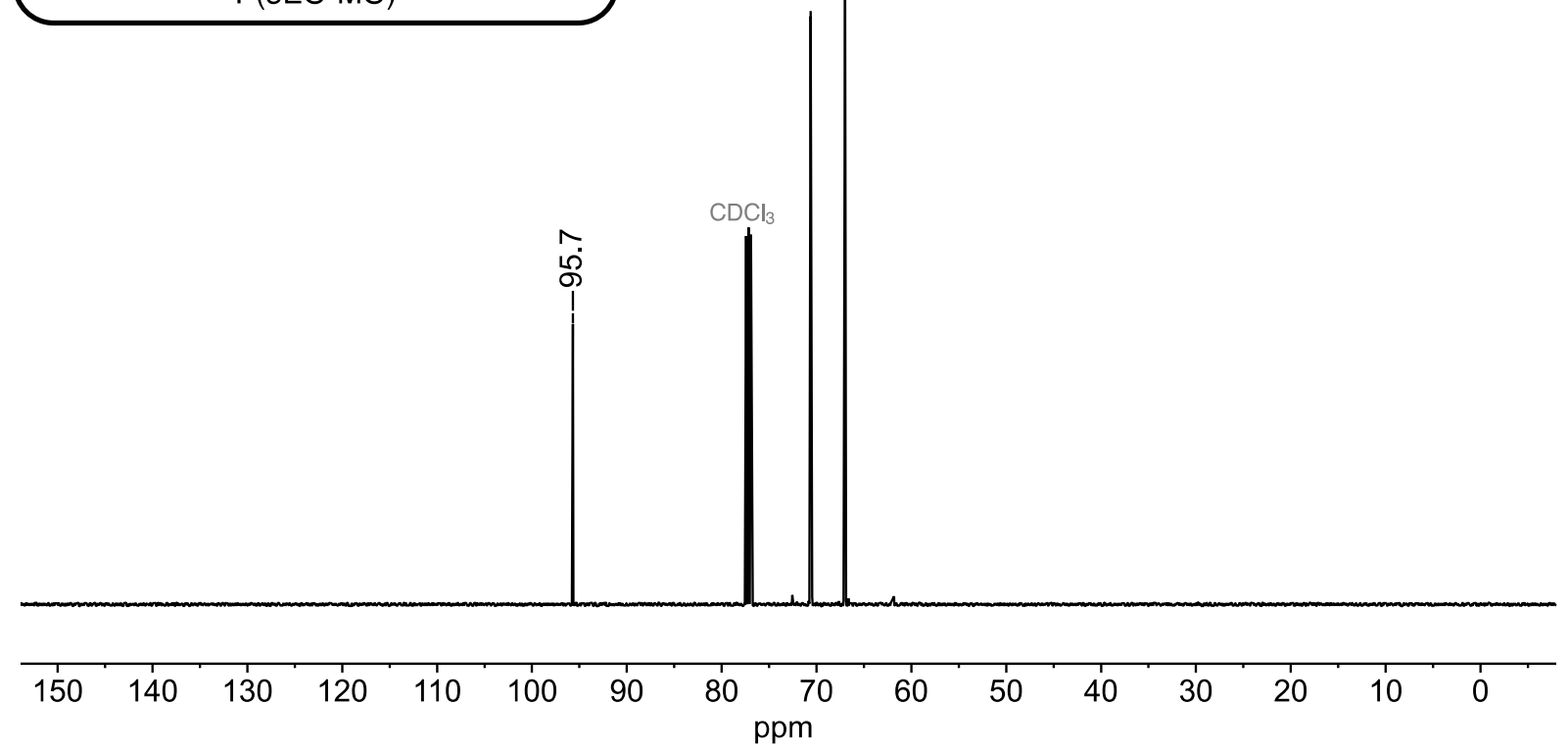




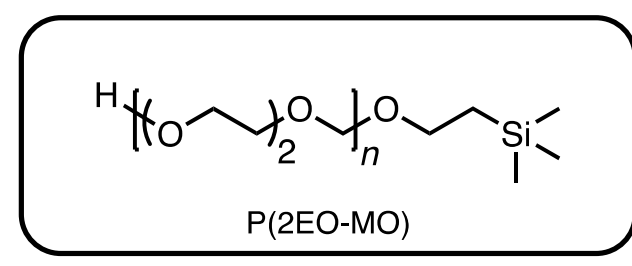

${ }^{1} \mathrm{H} \mathrm{NMR}, \mathrm{CDCl}_{3}, 500 \mathrm{MHz}$

유용

n்

กं?
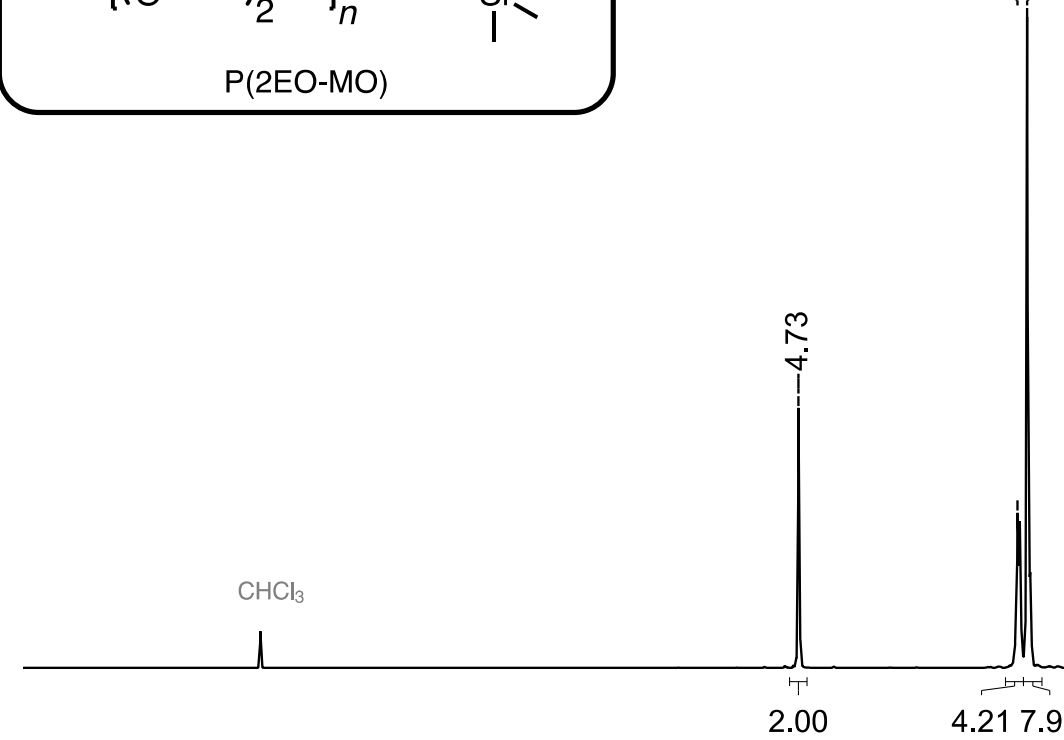

$\begin{array}{ll}2.00 & 4.217 .97\end{array}$

\begin{tabular}{llllllllllllll}
\hline 8.0 & 7.5 & 7.0 & 6.5 & 6.0 & 5.5 & $\begin{array}{c}5.0 \\
\mathrm{ppm}\end{array}$ & 4.5 & 4.0 & 3.5 & 3.0 & 2.5 & 2.0 & 1.5
\end{tabular}

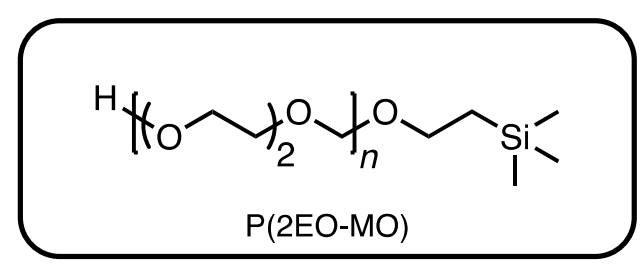

${ }^{13} \mathrm{C} \mathrm{NMR}, \mathrm{CDCl}_{3}, 125 \mathrm{MHz}$

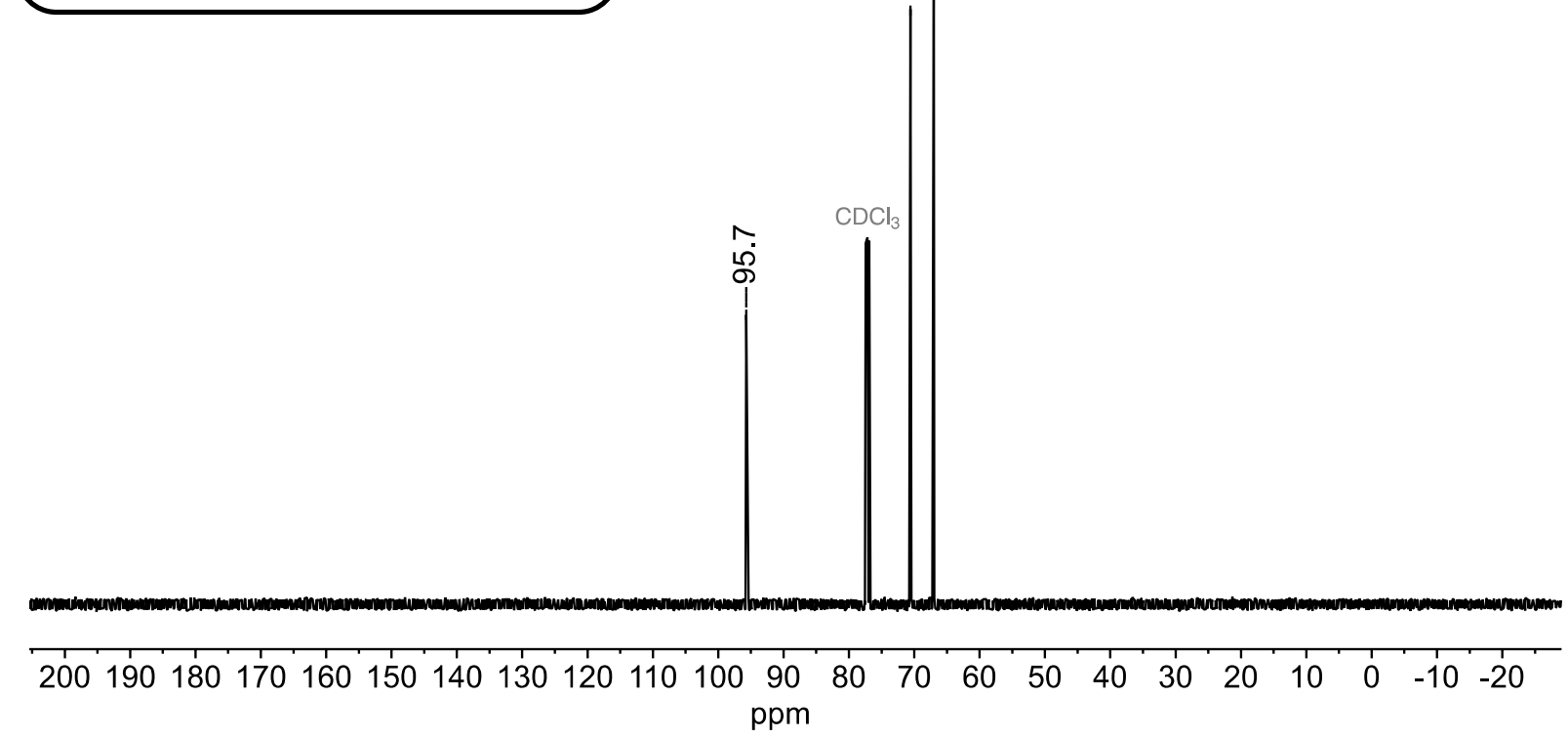




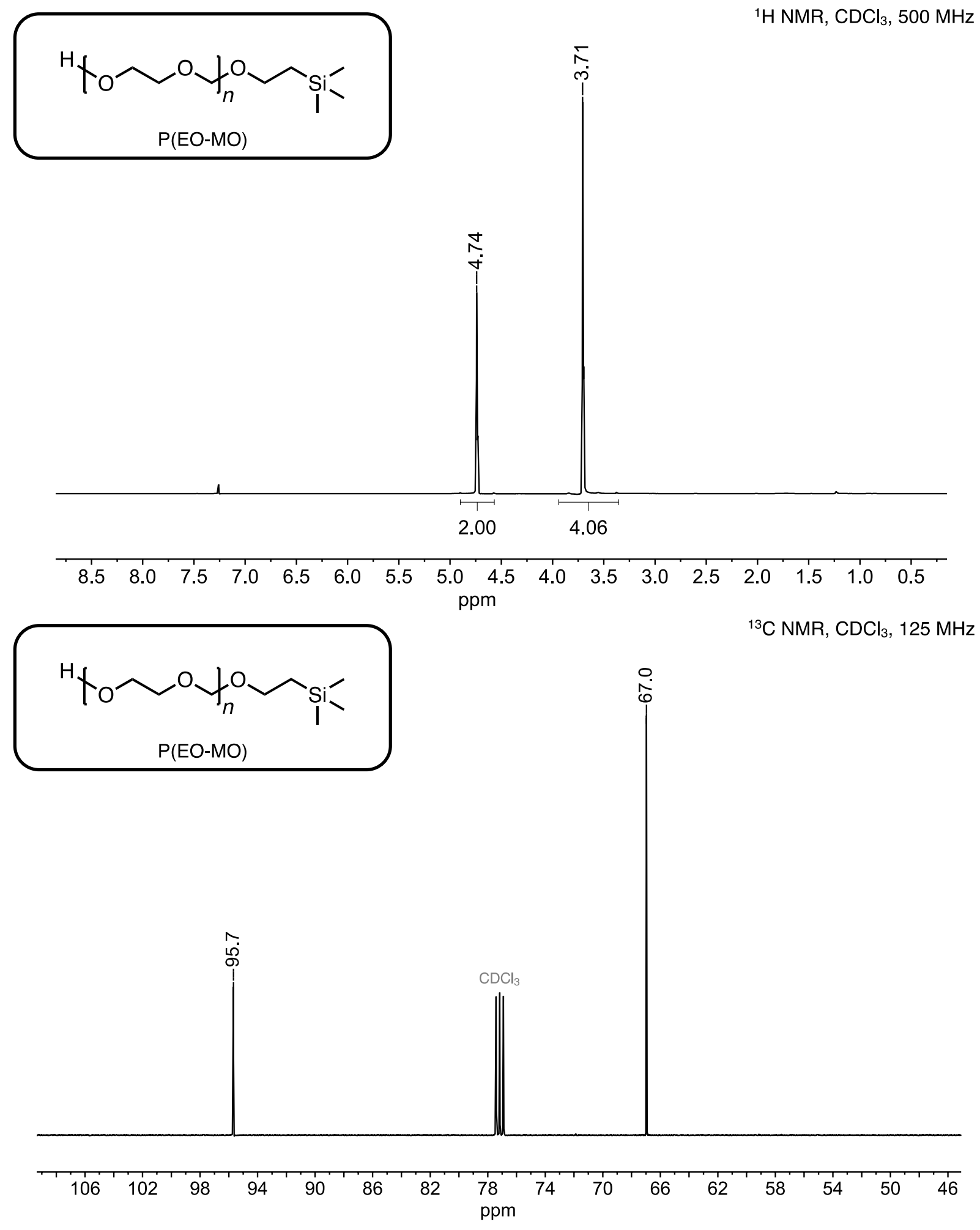




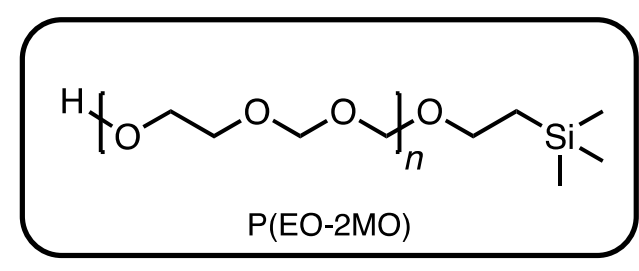

${ }^{1} \mathrm{H} \mathrm{NMR}, \mathrm{CDCl}_{3}, 500 \mathrm{MHz}$
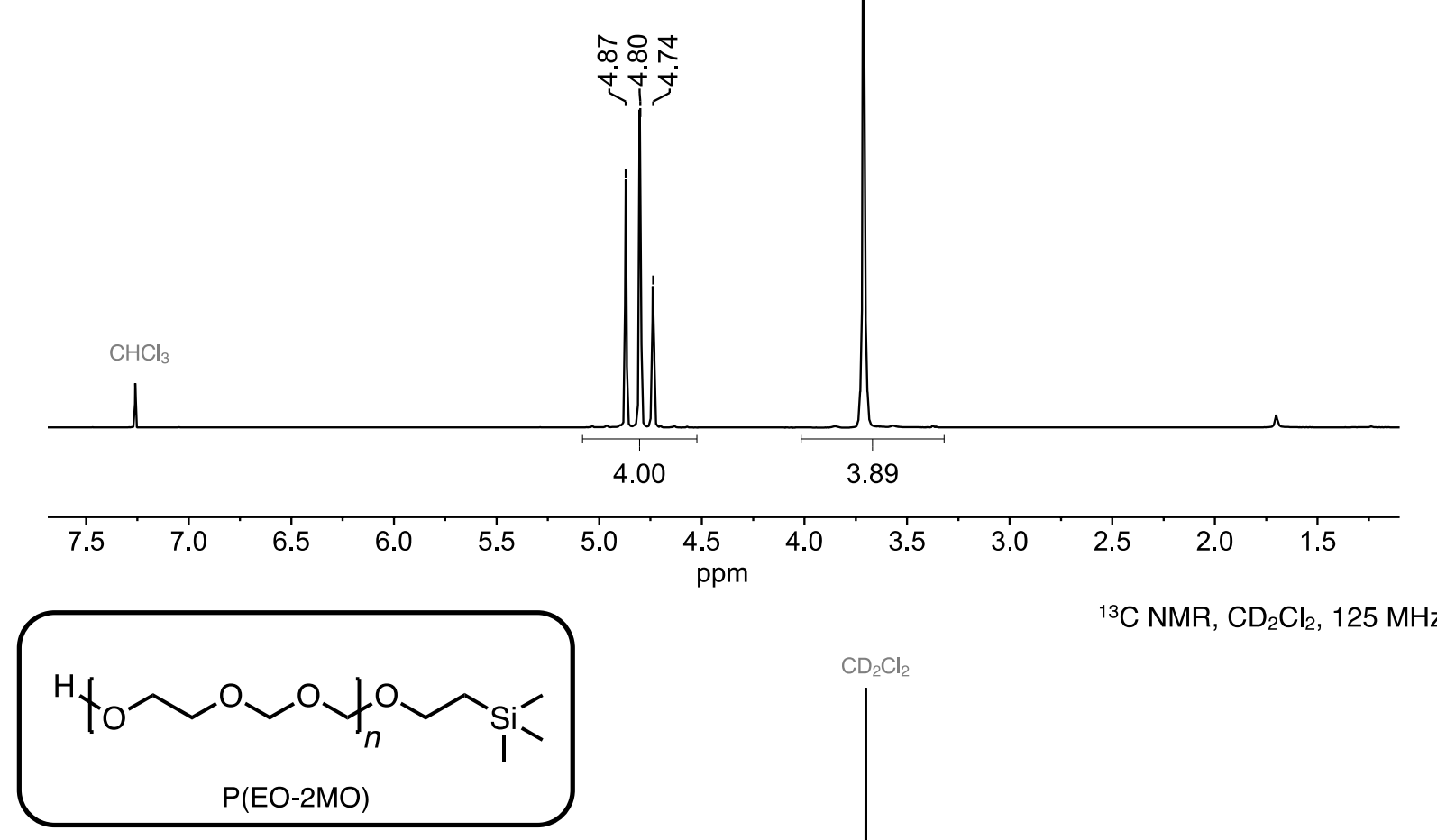

${ }^{13} \mathrm{C} \mathrm{NMR}, \mathrm{CD}_{2} \mathrm{Cl}_{2}, 125 \mathrm{MHz}$

ז

m 
P(EO-2MO): ${ }^{1} \mathrm{H}$ NMR (500 MHz, $\left.\mathrm{CDCl}_{3}\right)$

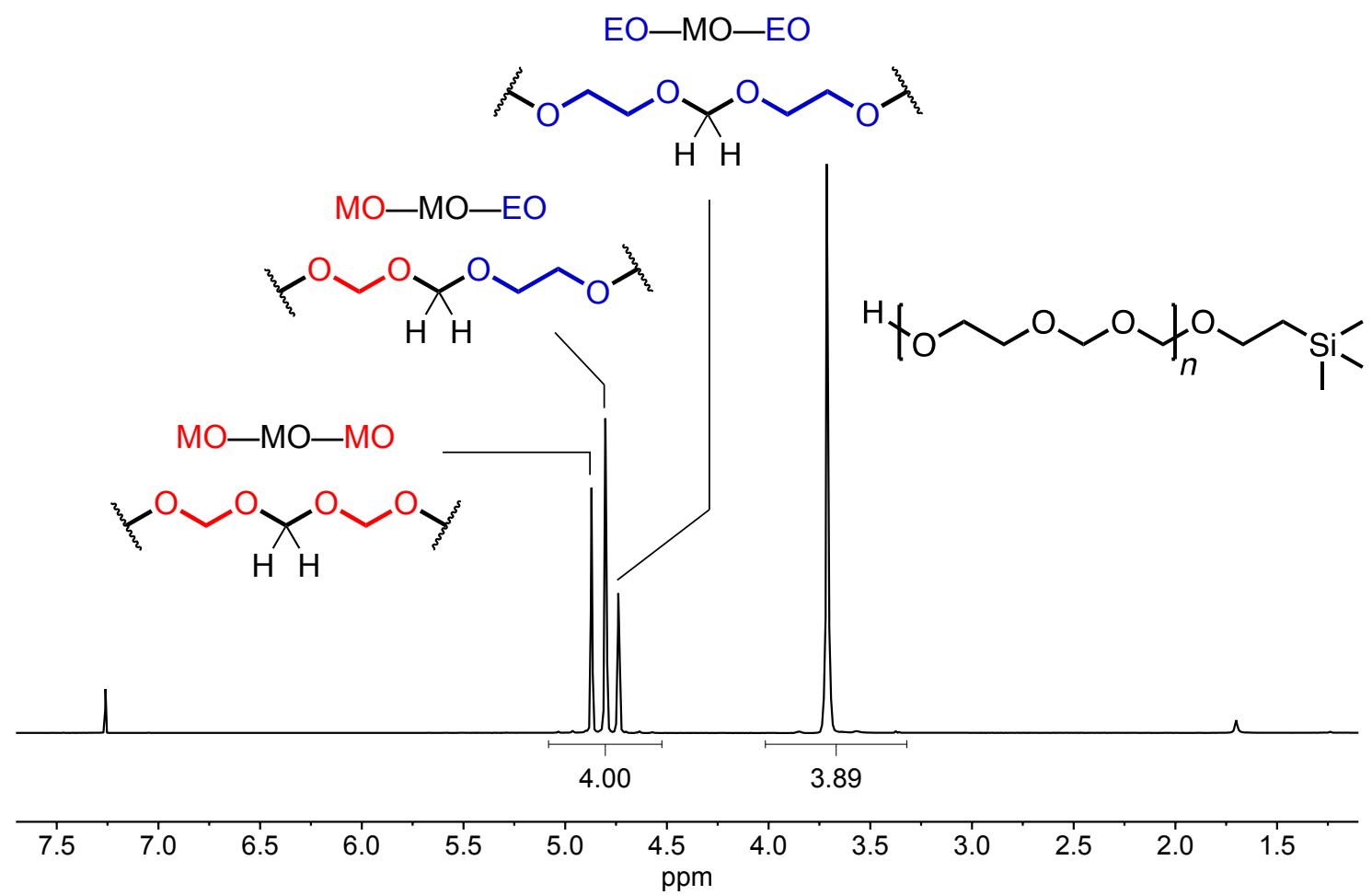

P(EO-2MO): ${ }^{13} \mathrm{C}$ NMR (125 MHz, $\left.\mathrm{CD}_{2} \mathrm{Cl}_{2}\right)$

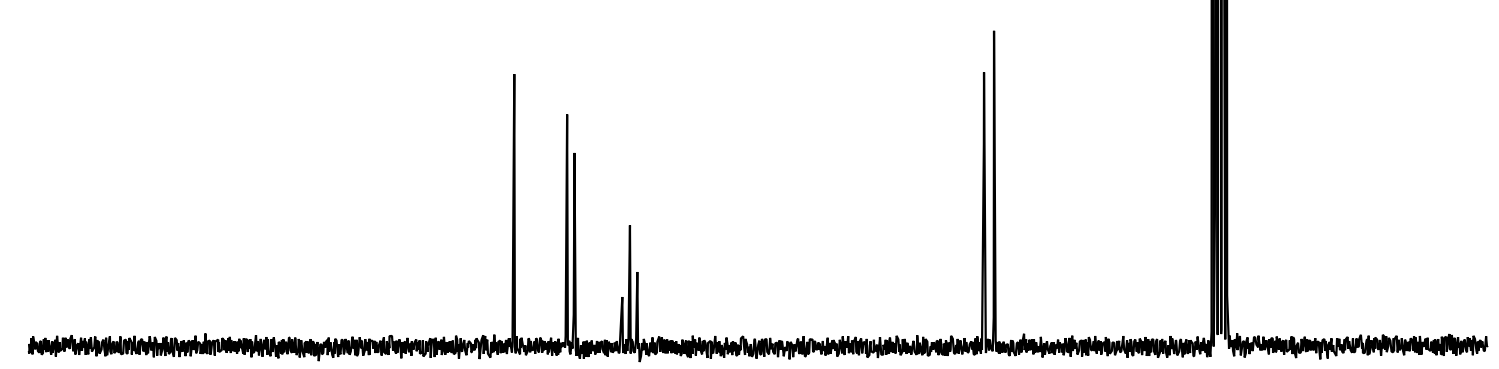

$\begin{array}{llllllllllllllllll}125 & 120 & 115 & 110 & 105 & 100 & 95 & 90 & 85 & \begin{array}{c}1 \\ \mathrm{ppm}\end{array} & 75 & 70 & 65 & 60 & 55 & 50 & 45 & 40\end{array}$ 
P(EO-2MO): bsHSQCAD 2D NMR (500 MHz for $\left.{ }^{1} \mathrm{H}, \mathrm{CD}_{2} \mathrm{Cl}_{2}\right)$

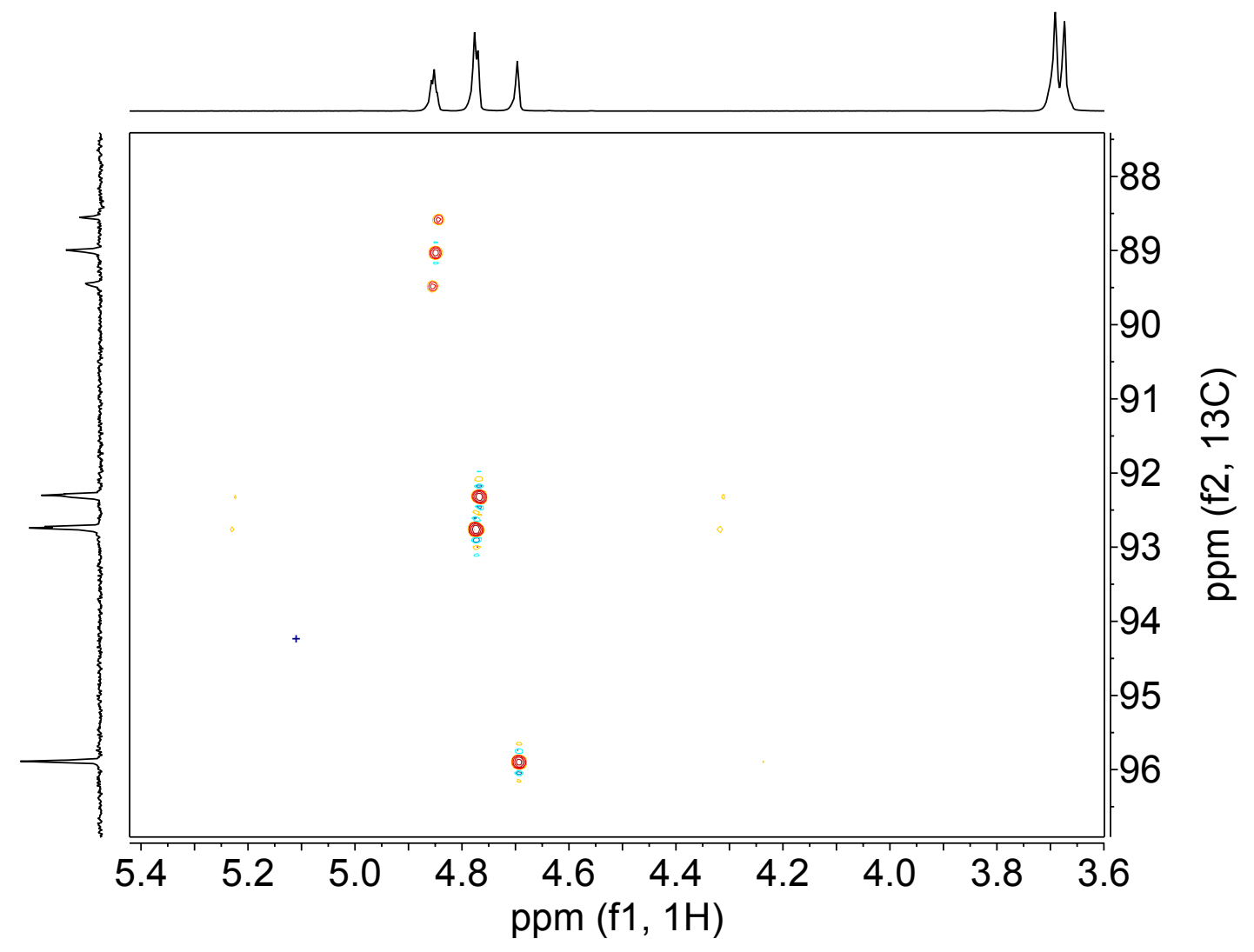




\section{Preparation and Characterization of Polymer Electrolytes}

Electrolytes were prepared by mixing the neat polymers with lithium bis(trifluoromethanesulfonyl)imide (LiTFSI) salt. Sample handling and preparation was performed in an argon-filled glovebox with $\mathrm{H}_{2} \mathrm{O}$ and $\mathrm{O}_{2}$ levels maintained below 1 ppm. Following our group's standard laboratory protocol, ${ }^{6}$ neat polymer samples were initially dried under vacuum at $90{ }^{\circ} \mathrm{C}$ for $24 \mathrm{~h}$, and LiTFSI was dried at $120{ }^{\circ} \mathrm{C}$ for $48 \mathrm{~h}$; both polymer and salt were then transferred into the glovebox under air-free conditions. The dry polymer and LiTFSI were mixed by dissolution into acetonitrile at $55^{\circ} \mathrm{C}$, followed by evaporation of the acetonitrile to give a homogeneous mixture of polymer and salt. Residual acetonitrile was removed by drying at $90{ }^{\circ} \mathrm{C}$ under active vacuum in the glovebox antechamber. DSC traces are flat and featureless during the first heat, suggesting complete solvent removal (Figure S9). Electrolytes were prepared at a range of salt concentrations. In this work, the concentration of LiTFSI salt dissolved in the polymer electrolyte is characterized by $r$, the ratio of $\mathrm{Li}^{+}$cations to oxygen atoms (i.e., from both $\mathrm{EO}$ and MO units) on the polymer, according to $r=[\mathrm{Li}] /[\mathrm{O}]$; this definition is consistent with previous work on $\mathrm{P}(2 \mathrm{EO}-\mathrm{MO})$-based polymer electrolytes. ${ }^{4}$ For each neat polymer, salt concentrations corresponding to $r=0.03,0.05,0.08$, and 0.10 were prepared. Glass transition temperatures, $T_{\mathrm{g}}$, of the polymer electrolytes (at $r=0.08$ ) were determined using DSC, and the resulting DSC curves are shown in Figure S8 and Figure S9. 


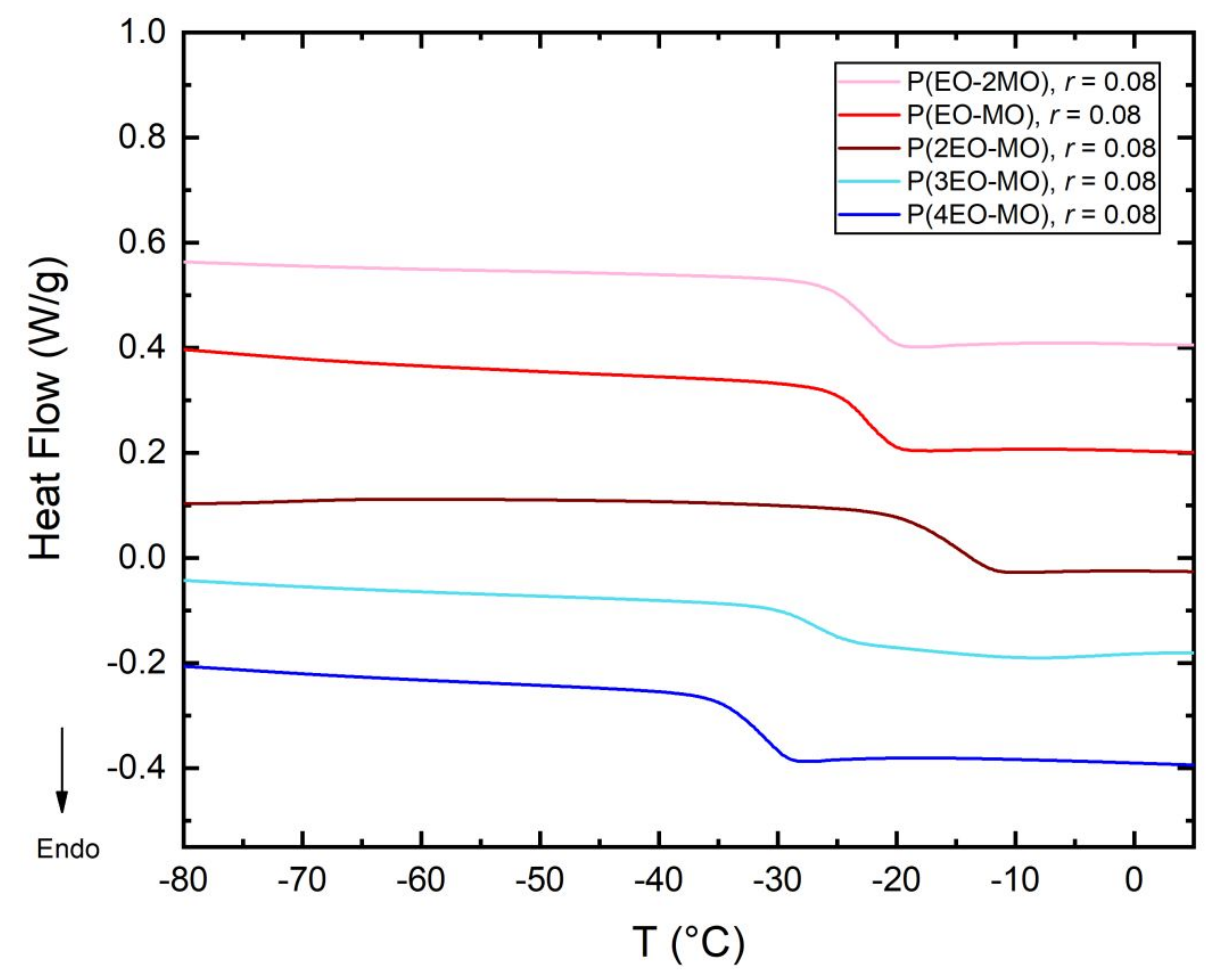

Figure S8. Differential scanning calorimetry (DSC) traces of the polyacetal electrolytes studied in this work at a salt concentration of $r=[\mathrm{Li}] /[\mathrm{O}]=0.08$. Curves are vertically offset for clarity; DSC traces were recorded from the second heating cycle with a scan rate of $10^{\circ} \mathrm{C} / \mathrm{min}$. Note the absence of melting transitions in any of the samples due to the disruption of crystallinity in the presence of salt. 


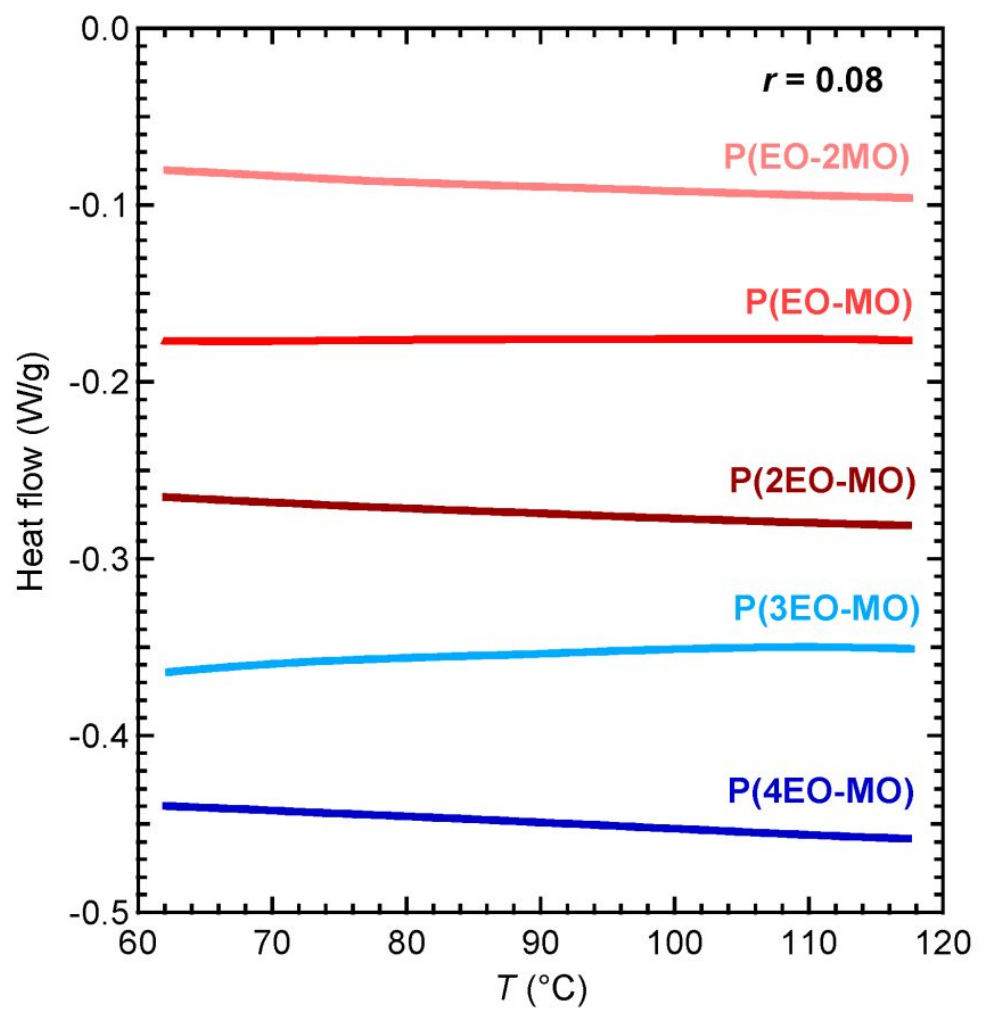

Figure S9. Differential scanning calorimetry (DSC) traces of the polyacetal electrolytes $(r=[\mathrm{Li}]$ $/[\mathrm{O}]=0.08)$ during first heat cycle at higher temperature $\left(60-120^{\circ} \mathrm{C}\right)$ to demonstrate absence of residual solvent; curves are vertically offset for clarity. 


\section{Pulsed-field-gradient (PFG) NMR Instrumentation and Calibration}

Prior to the PFG-NMR measurements, samples were loaded into $5 \mathrm{~mm}$ NMR tubes and sealed with air-tight caps within an argon-filled glovebox. All NMR experiments were performed at a

field strength of $11.7 \mathrm{~T}$ using a $500 \mathrm{MHz}$ Bruker Avance I spectrometer and a Bruker $5 \mathrm{~mm}$ double-resonance broadband observe $(\mathrm{BBO})$ probe equipped with a z-axis gradient with a maximum gradient strength of $\sim 0.5 \mathrm{~T} / \mathrm{m}$ and variable-temperature control. For the polymer electrolyte samples, ${ }^{7} \mathrm{Li}$ and ${ }^{19} \mathrm{~F}$ PFG-NMR measurements were performed at a sample temperature of $90{ }^{\circ} \mathrm{C}$ with Larmor frequencies of $194.4 \mathrm{MHz}\left({ }^{7} \mathrm{Li}\right)$ and $470.7 \mathrm{MHz}\left({ }^{19} \mathrm{~F}\right)$; the resonances observed for both nuclei corresponded to $\mathrm{Li}^{+}$cations and $\mathrm{TFSI}^{-}$anions dissolved in the polymer, respectively. Calibrated $\pi / 2 \mathrm{rf}$ pulse lengths of $7 \mu \mathrm{s}\left({ }^{7} \mathrm{Li}\right)$ and $8 \mu \mathrm{s}\left({ }^{19} \mathrm{~F}\right)$ were used; typical recycle delays were $3 \mathrm{~s}\left({ }^{7} \mathrm{Li}\right)$ and $2 \mathrm{~s}\left({ }^{19} \mathrm{~F}\right)$. Samples were subject to an initial equilibration and relaxation period of $20-30 \mathrm{~min}$ after heating to the sample temperature $\left(90{ }^{\circ} \mathrm{C}\right)$.

For determination of self-diffusion coefficients by PFG, the 13-interval stimulated-echo sequence using bipolar, sine-bell magnetic field gradient pulses was employed. ${ }^{7}$ The 13 -interval pulse sequence with relevant timings (and definitions of $\delta$ and $\Delta$ ) is depicted in Figure S10. Typical values of the gradient pulse length $(\delta)$, diffusion time $(\Delta)$, and maximum gradient strength $(g)$ 
were $10-20 \mathrm{~ms}, 0.8-1.8 \mathrm{~s}$, and $0.23 \mathrm{~T} / \mathrm{m}$, respectively, for ${ }^{7} \mathrm{Li}$; and $4-8 \mathrm{~ms}, 0.3-0.8 \mathrm{~s}$, and $0.33 \mathrm{~T} / \mathrm{m}$, respectively, for ${ }^{19} \mathrm{~F}$. In the PFG experiments, the gradient strength was varied, and all other parameters were held constant to ensure intensity changes were solely due to diffusion and not relaxation effects. To obtain self-diffusion coefficients, the integrated signal intensity $(I)$ as a function of gradient strength was fit to the modified Stejskal-Tanner equation applicable for the 13-interval sequence using sine-bell gradient pulses: $:^{7,8}$

$$
I=I_{0} \exp \left[-D(2 \delta g \gamma)^{2}\left(\Delta-\frac{\delta}{8}+\frac{3 \tau}{2}\right)\right]
$$

where $V$ is the nuclear gyromagnetic ratio, $I_{0}$ is the signal intensity at zero gradient strength, $\tau$ is the interpulse delay (see Figure $\mathrm{S} 10$ ), and $D$ is the self-diffusion coefficient. Further information about the modified Stejskal-Tanner equation used in this work, including the derivation of the corrected diffusion time $\Delta^{\prime}=\Delta-\frac{\delta}{8}+\frac{3 \tau}{2}$ (Eq. (S5)), is given below. Typical fits to the modified Stejskal-Tanner equation are shown in Figure S11. The diffusion times $(\Delta)$ used in this work were long (typically at least $500 \mathrm{~ms}$ for ${ }^{7} \mathrm{Li}$ and at least $200 \mathrm{~ms}$ for ${ }^{19} \mathrm{~F}$ ) due to hardware limitations on the maximum applied values of gradient strength and length. Where possible, measurements were repeated at shorter $\Delta$ values (with less attenuation consequently observed, and therefore a less 
satisfactory fit to the modified Stejskal-Tanner equation); the self-diffusion coefficients thus determined did not vary significantly within error (Figure S12).

The sample temperature was externally calibrated by measuring the previously reported temperature-dependent difference of the ${ }^{1} \mathrm{H}$ chemical shifts of the $-\mathrm{CH}_{2}$ - and $-\mathrm{OH}$ resonances of dry ethylene glycol, ${ }^{9}$ and gradient strengths were similarly calibrated with the aforementioned PFG-NMR sequence, using the known self-diffusion coefficient of ethylene glycol at the calibrated temperature. ${ }^{10}$ Data were acquired, processed and analyzed using Bruker TopSpin 2.1 and/or 3.6.

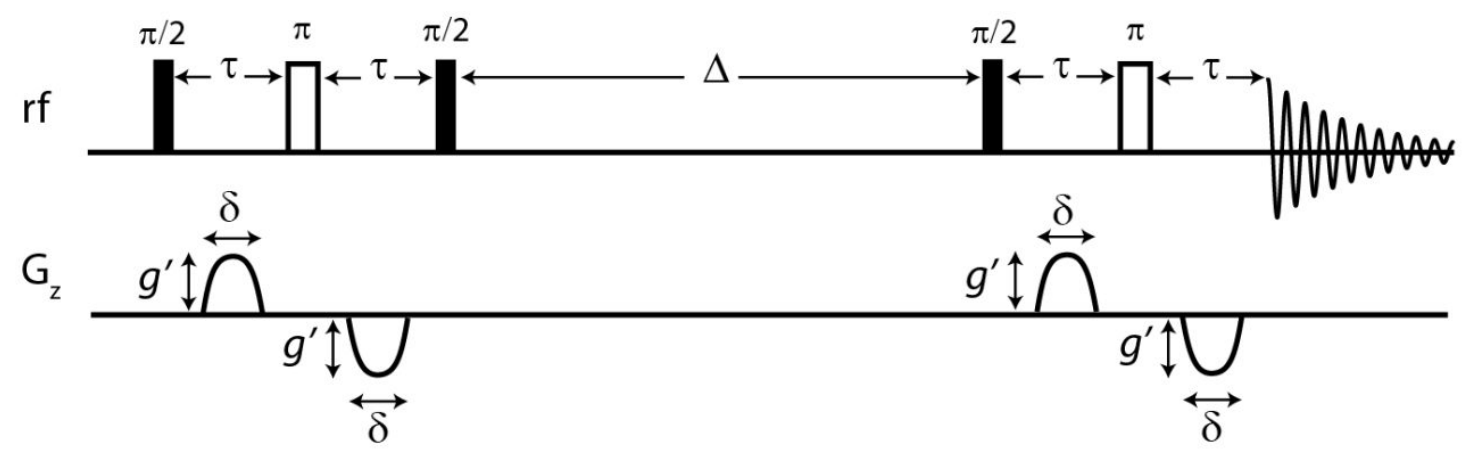

Figure S10. Depiction of the 13-interval stimulated-echo PFG sequence with bipolar magnetic field gradients ${ }^{7}$ used for measurement of self-diffusion coefficients. 

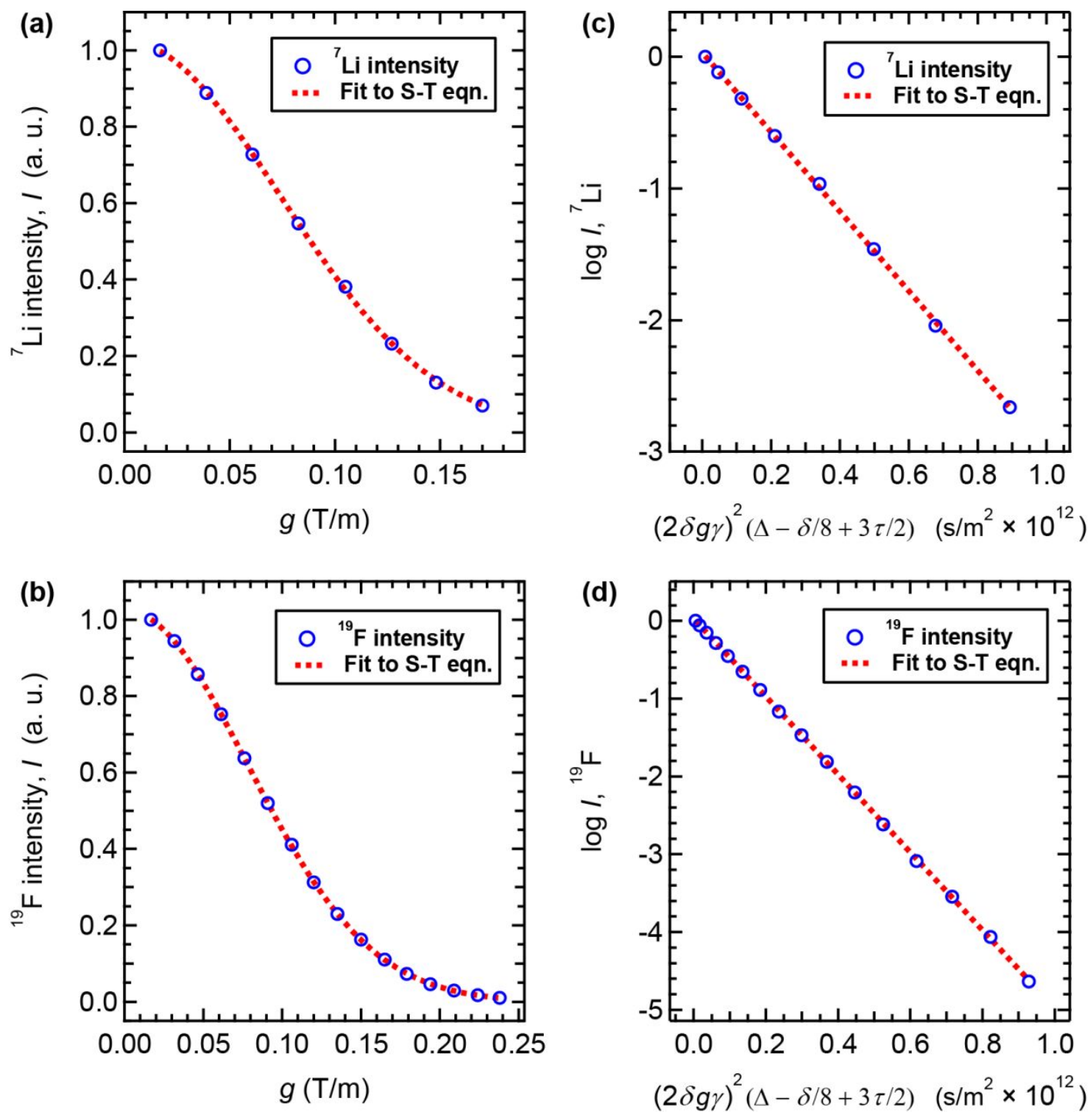

Figure S11. Representative ${ }^{7} \mathrm{Li}$ and ${ }^{19} \mathrm{~F}$ PFG-NMR attenuation data with fits to the modified Stejskal-Tanner equation as measured for $\mathrm{P}(\mathrm{EO}-2 \mathrm{MO})$ with $r=0.10$. (a) ${ }^{7} \mathrm{Li}$ and (b) ${ }^{19} \mathrm{~F}$ integrated signal intensity (of the resonances corresponding to $\mathrm{Li}^{+}$cations and $\mathrm{TFSI}^{-}$anions, respectively) plotted against gradient strength, $g$; the same (c) ${ }^{7} \mathrm{Li}$ and (d) ${ }^{19} \mathrm{~F}$ signal intensity data, plotted as the natural logarithm of the intensity $v s$. the quantity $(2 \delta g \gamma)^{2}\left(\Delta-\frac{\delta}{8}+\frac{3 \tau}{2}\right)$, giving a linear relationship with slope $-D$. (Here log denotes the natural logarithm.) 

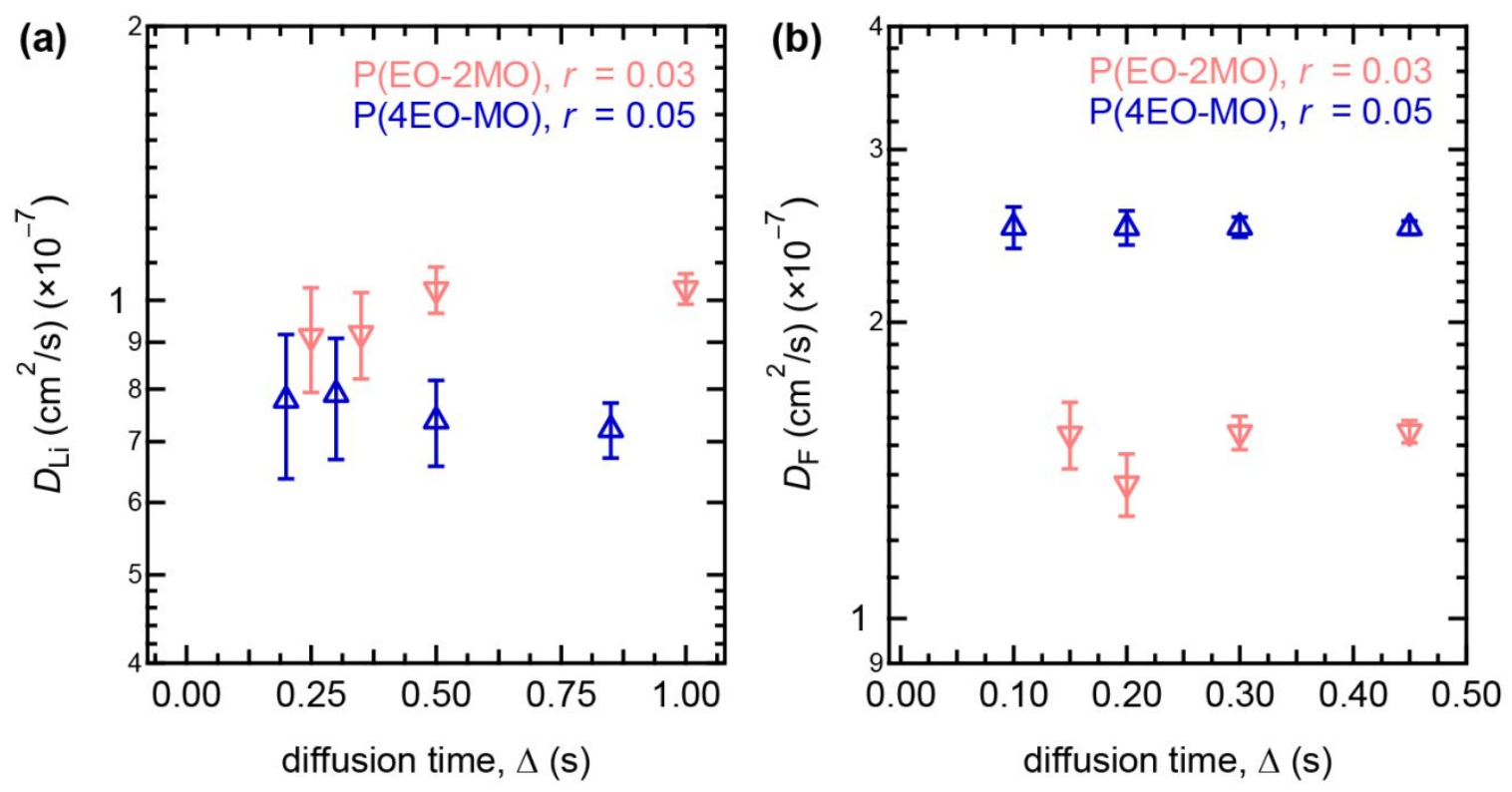

Figure S12. Measured (a) ${ }^{7} \mathrm{Li}$ and (b) ${ }^{19} \mathrm{~F}$ self-diffusion coefficients as a function of diffusion time $\Delta$ obtained from the PFG-NMR experiments performed for two representative polymer electrolyte samples: $\mathrm{P}(\mathrm{EO}-2 \mathrm{MO}), r=0.03$ and $\mathrm{P}(4 \mathrm{EO}-\mathrm{MO}), r=0.05$.

\section{Further PFG-NMR Details: Parameter Definitions and Additional Experiments}

Figure S10 shows the 13-interval pulse sequence used in the present work. The maximum gradient strength $(g)$ represents the largest strength used, i.e., the maximum height of the shaped gradient pulse. The actual gradient strength $(g)$ is equal to the value of $g^{\prime}$ scaled by a shape factor proportional to the area of the shape, e.g., the shape factor is 1 for a rectangular pulse and $2 / \pi$ for a sine-bell pulse. In the present work, the timing parameters $(\delta, \Delta$, and $\tau)$ are fixed and only the gradient strength $(g)$ is allowed to vary such that the observed signal intensity is not influenced by relaxation effects. 
Note that the definitions of $\delta, \Delta$, and $\tau$ in this work are in agreement with those used previously ${ }^{7}$ but are distinct from the so-called "conventional" definition given by others. ${ }^{8,11}$ The "conventional" parameters (here denoted with subscripts as $\delta_{\mathrm{c}}, \Delta_{\mathrm{c}}$, and $\tau_{\mathrm{c}}$ ) can be written in terms of the quantities used in this work:

$$
\begin{aligned}
& \delta_{c}=2 \delta \\
& \Delta_{c}=\Delta+2 \tau \\
& \tau_{c}=\tau-\delta
\end{aligned}
$$

For this sequence using sine-bell gradient pulses, the correction factor $\Delta^{\prime}$ appearing in the modified Stejskal-Tanner equation is given by ${ }^{8}$

$$
\Delta^{\prime}=\Delta_{c}-\frac{5 \delta_{\mathrm{c}}}{16}-\frac{\tau_{\mathrm{c}}}{2}
$$

which we can rewrite using Eq. (S2) - (S4) to give

$$
\Delta^{\prime}=\Delta-\frac{\delta}{8}+\frac{3 \tau}{2},
$$

which is the factor used in the Stejskal-Tanner equation given above (Eq. (S1)).

Representative fits of the modified Stejskal-Tanner equation to ${ }^{7} \mathrm{Li}$ and ${ }^{19} \mathrm{~F}$ PFG attenuation data using the correction factor of Eq. (S6) are shown in Figure S11. Here, ${ }^{7} \mathrm{Li}$ and ${ }^{19} \mathrm{~F}$ PFG measurements were carried out on the $\mathrm{P}(\mathrm{EO}-2 \mathrm{MO}), r=0.10$ polymer electrolyte sample. In Figure S11a and c, the integrated intensity $(I)$ data are plotted $v s$. the gradient strength $(g ; \mathrm{T} / \mathrm{m})$ and show the expected Gaussian dependence. In Figure $\mathrm{S} 11 \mathrm{~b}$ and d, the same data have been plotted as $\log I$ (i.e., the natural logarithm of $I$ ) against the quantity $(2 \delta g \gamma)^{2}\left(\Delta-\frac{\delta}{8}+\frac{3 \tau}{2}\right)$, giving a linear relationship with slope equal to $-D$ where $D$ is the ${ }^{7} \mathrm{Li}$ or ${ }^{19} \mathrm{~F}$ self-diffusion coefficient. 
For select samples, PFG measurements were repeated at multiple diffusion times (i.e., differing values of $\Delta$ ) to check for effects of restricted diffusion or other dependence on the relatively long choice of $\Delta$ employed for most measurements in this work. Representative measured ${ }^{7} \mathrm{Li}$ and ${ }^{19} \mathrm{~F}$ diffusion coefficients are shown in Figure S12. No significant dependence on the choice of $\Delta$ was observed within the error of the measurements.

To demonstrate the internal consistency and reliability of the measurements, ${ }^{7} \mathrm{Li}$ PFG experiments were again performed under similar conditions for a select sample $(\mathrm{P}(\mathrm{EO}-\mathrm{MO}), r=$ 0.08 ) after a period of $\sim 14$ months. Although a different range of gradient strengths was chosen, the sample was subject to the same equilibration and relaxation period as previously described and the other experimental conditions were equivalent to the prior experiment. Plotting the old and new data together (Figure S13), a $\sim 2 \%$ difference in the extracted $D$ values (within error of the fits) is observed.

Finally, all of the fits of the modified Stejskal-Tanner equation to the ${ }^{7} \mathrm{Li}$ and ${ }^{19} \mathrm{~F}$ PFG data for all samples studied (for a total of 40 experiments) are depicted in Figure S14. 


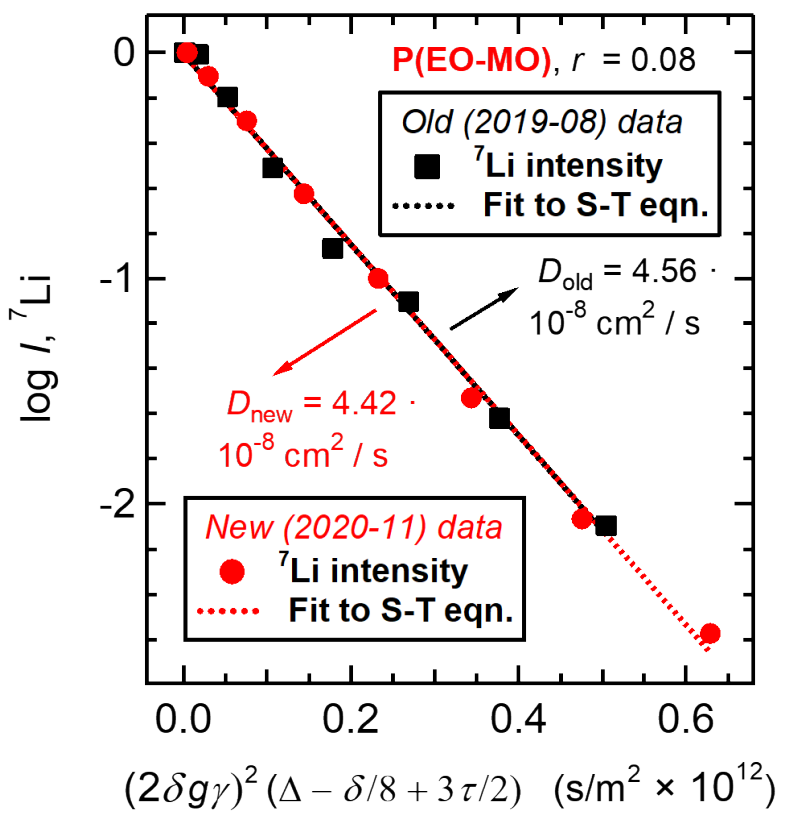

Figure S13. Comparison of previous (black) and more recent (red) ${ }^{7} \mathrm{Li}$ PFG attenuation data, including fits to the modified Stejskal-Tanner equation, for the $\mathrm{P}(\mathrm{EO}-\mathrm{MO}), r=0.08$ sample. Other than differences in the gradient strength and lengths selected, the measurements were performed under equivalent conditions; the extracted $D$ coefficients are within $\sim 2 \%$ of each other. (Here $\log$ denotes the natural logarithm.) 
(a)

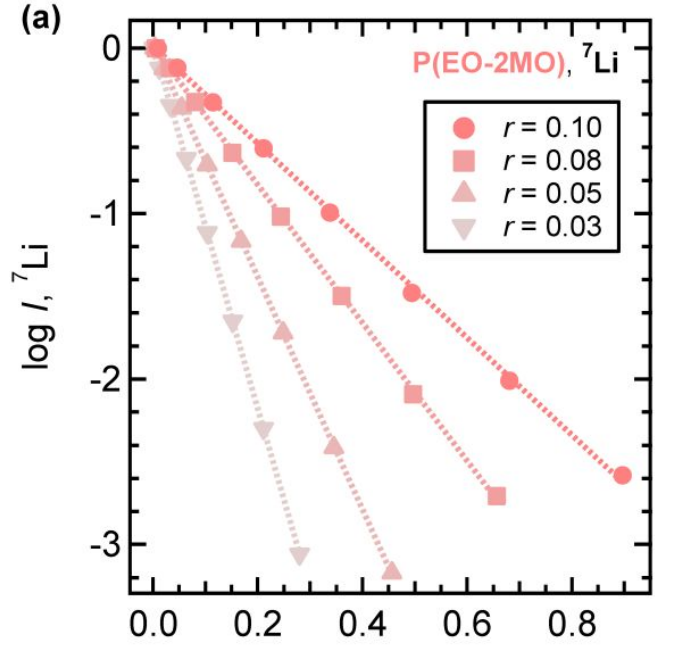

$(2 \delta g \gamma)^{2}(\Delta-\delta / 8+3 \tau / 2) \quad\left(\mathrm{s} / \mathrm{m}^{2} \times 10^{12}\right)$

(c)

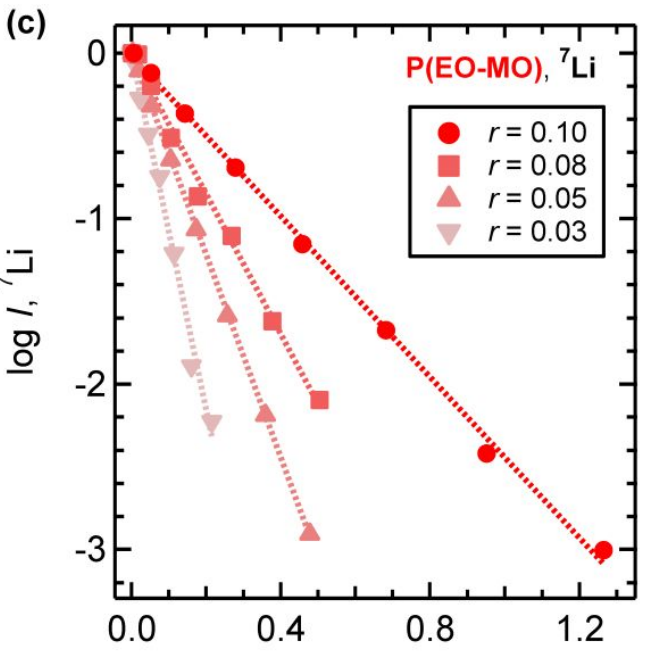

$(2 \delta g \gamma)^{2}(\Delta-\delta / 8+3 \tau / 2) \quad\left(\mathrm{s} / \mathrm{m}^{2} \times 10^{12}\right)$

(e)

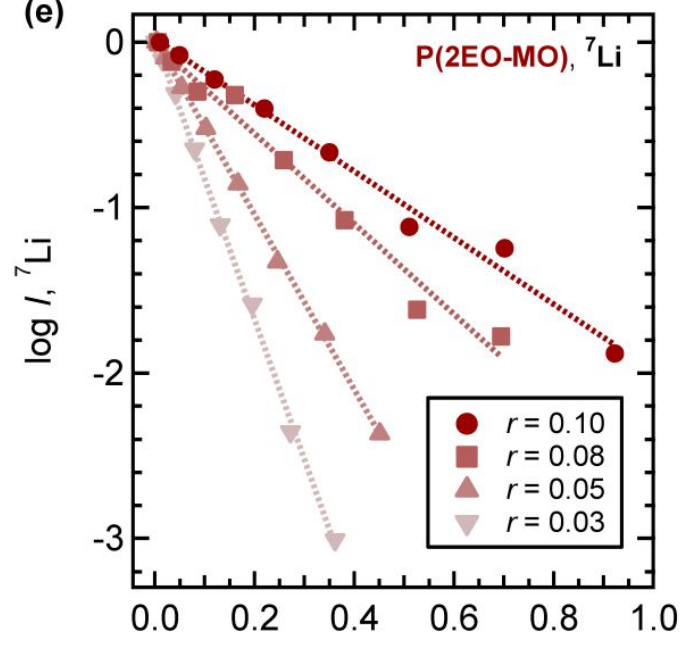

$(2 \delta g \gamma)^{2}(\Delta-\delta / 8+3 \tau / 2) \quad\left(\mathrm{s} / \mathrm{m}^{2} \times 10^{12}\right)$
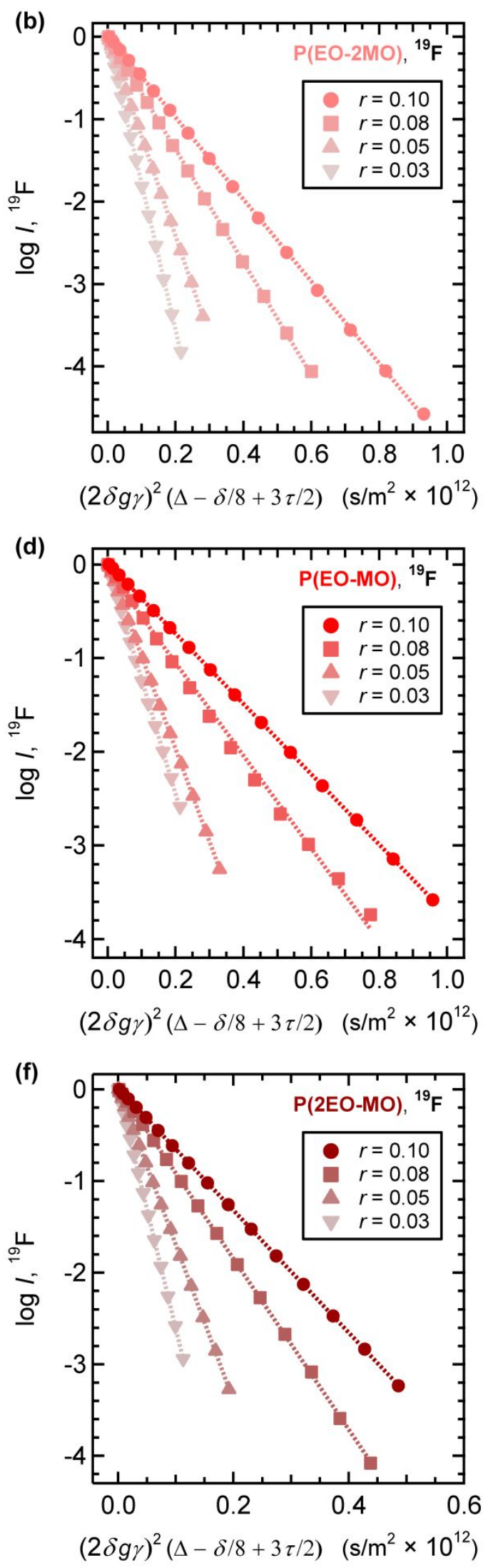

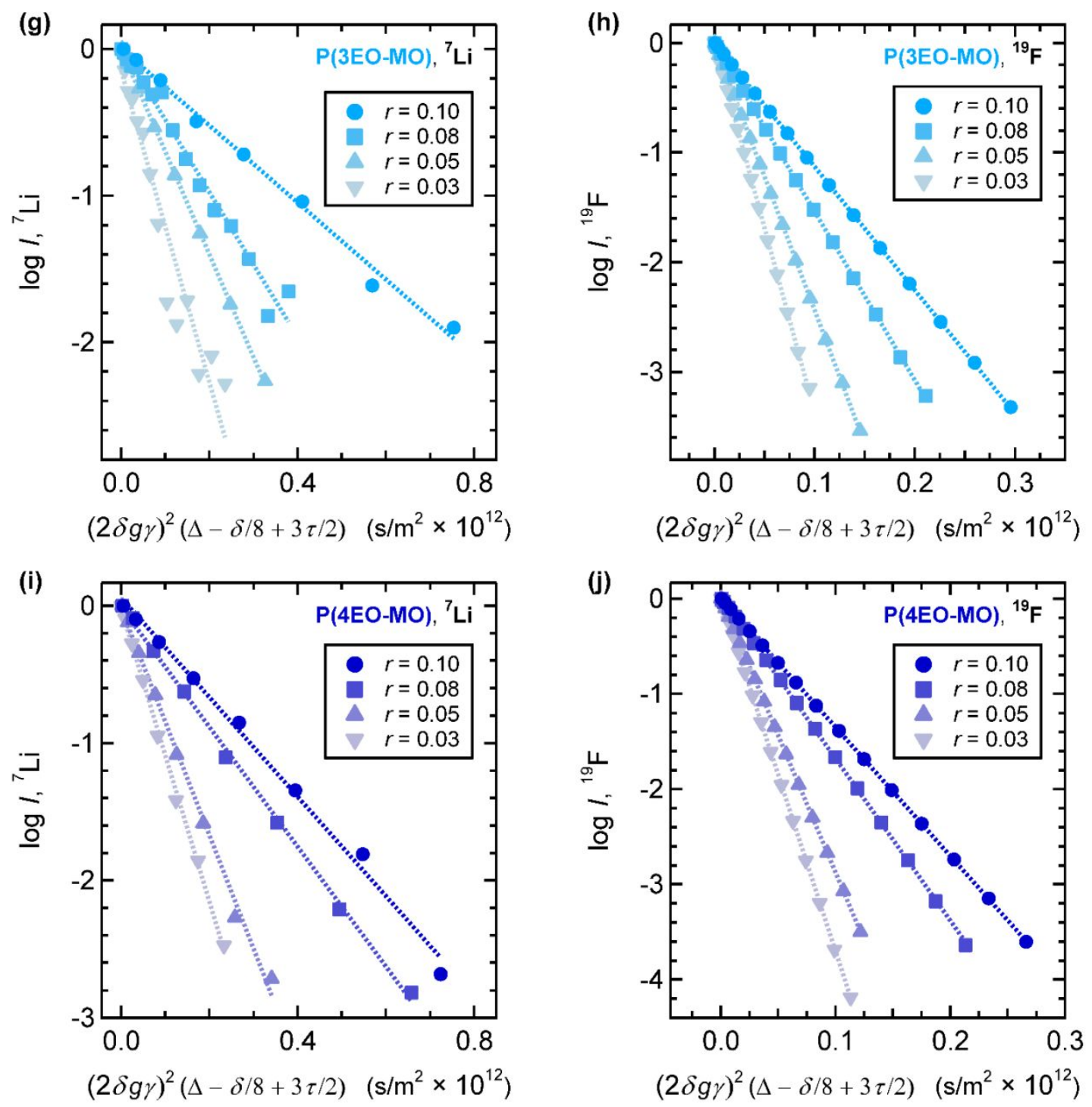

Figure S14. Depiction of all raw ${ }^{7} \mathrm{Li}$ and ${ }^{19} \mathrm{~F}$ PFG attenuation data acquired across all samples studied, with fits to the modified Stejskal-Tanner equation shown as straight lines: (a) P(EO2MO), ${ }^{7} \mathrm{Li}$; (b) $\mathrm{P}(\mathrm{EO}-2 \mathrm{MO}),{ }^{19} \mathrm{~F}$; (c) $\mathrm{P}(\mathrm{EO}-\mathrm{MO}),{ }^{7} \mathrm{Li}$; (d) $\mathrm{P}(\mathrm{EO}-\mathrm{MO}),{ }^{19} \mathrm{~F}$; (e) $\mathrm{P}(2 \mathrm{EO}-\mathrm{MO}),{ }^{7} \mathrm{Li}$; (f) $\mathrm{P}(2 \mathrm{EO}-\mathrm{MO}),{ }^{19} \mathrm{~F}$; (g) $\mathrm{P}(3 \mathrm{EO}-\mathrm{MO}),{ }^{7} \mathrm{Li}$; (h) $\mathrm{P}(3 \mathrm{EO}-\mathrm{MO}),{ }^{19} \mathrm{~F}$; (i) $\mathrm{P}(4 \mathrm{EO}-\mathrm{MO}),{ }^{7} \mathrm{Li}$; (j) $\mathrm{P}(4 \mathrm{EO}-\mathrm{MO}),{ }^{19} \mathrm{~F}$. 


\section{Additional PFG Figures and Tables}

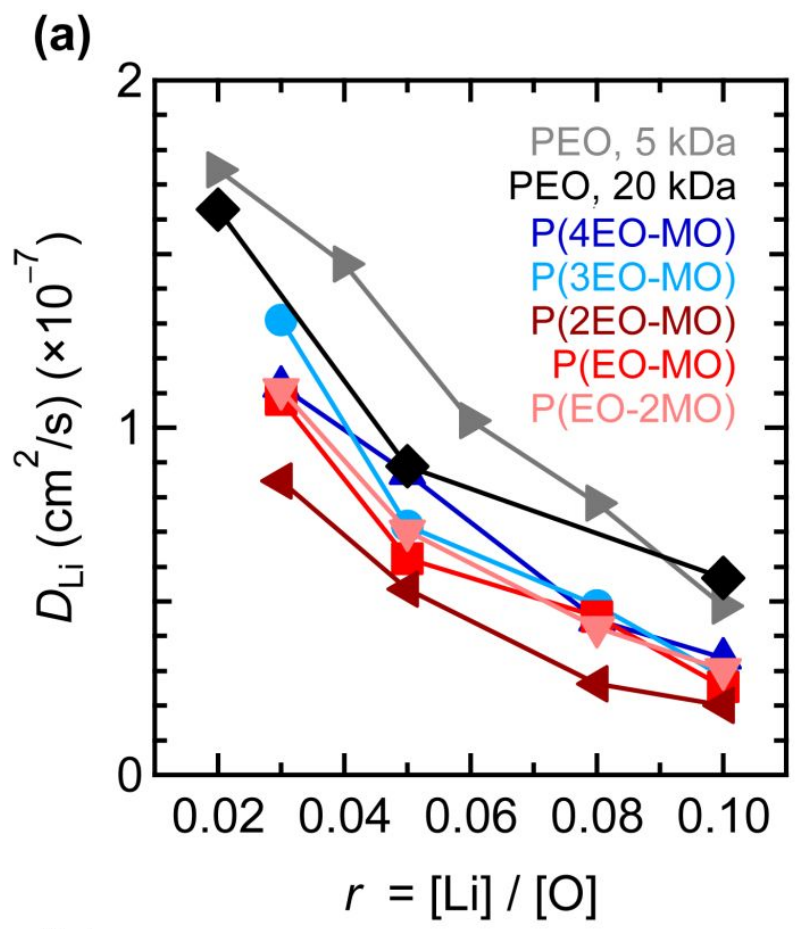

(b)

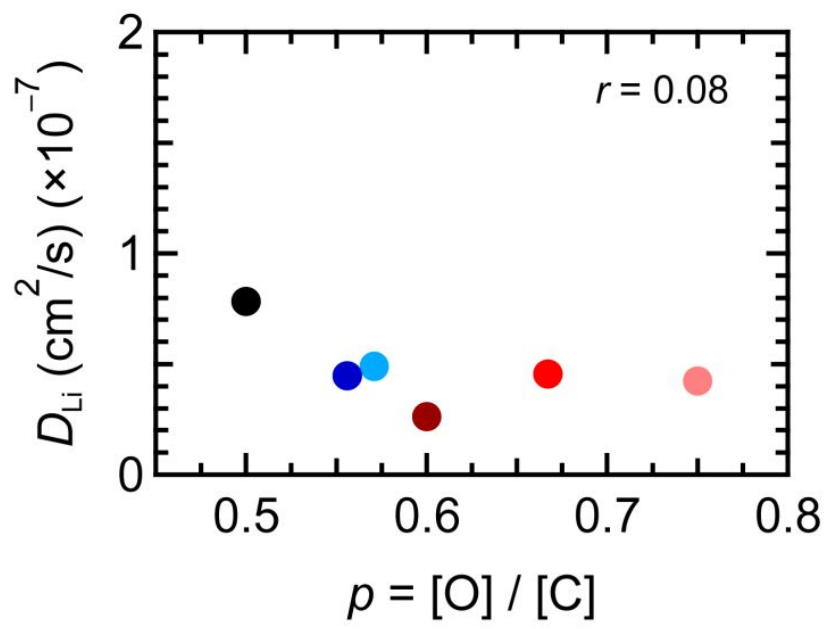

Figure S15. $\mathrm{Li}^{+}\left({ }^{7} \mathrm{Li}\right) \mathrm{PFG}-\mathrm{NMR}$ self-diffusion coefficients at $90{ }^{\circ} \mathrm{C}$ shown with a magnified scale to more clearly highlight the relative change (a) over the range of salt concentrations $(r=[\mathrm{Li}] /$ $[\mathrm{O}])$ for all compositions and (b) over the range of polyacetal compositions $(p=[\mathrm{O}] /[\mathrm{C}])$ at $r=$ 0.08 . 
(a)

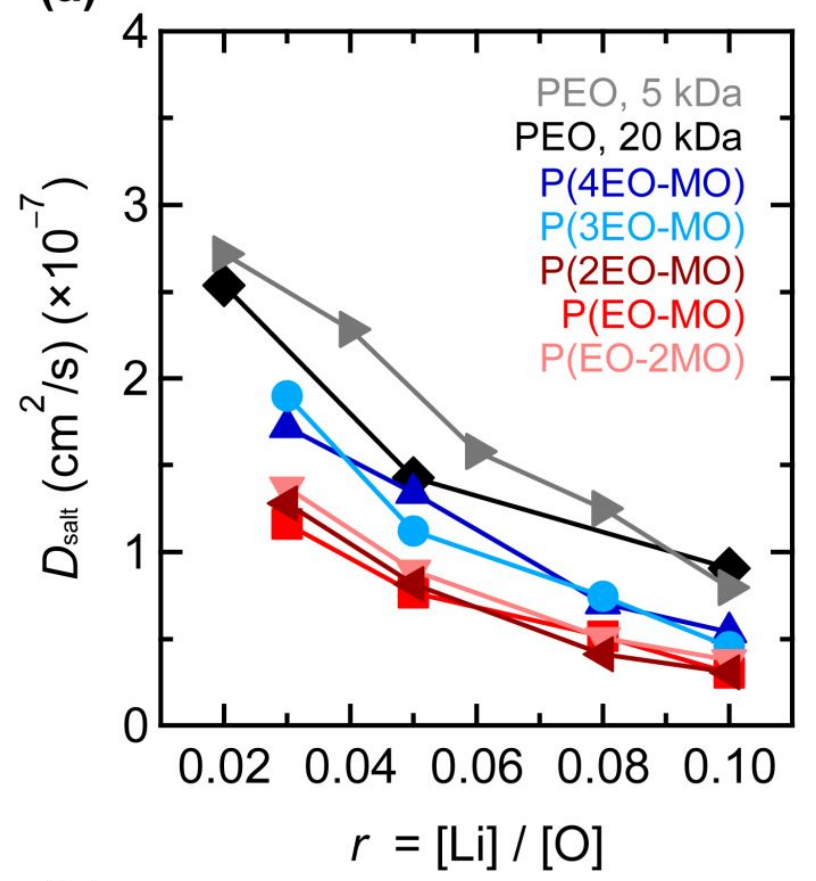

(b)

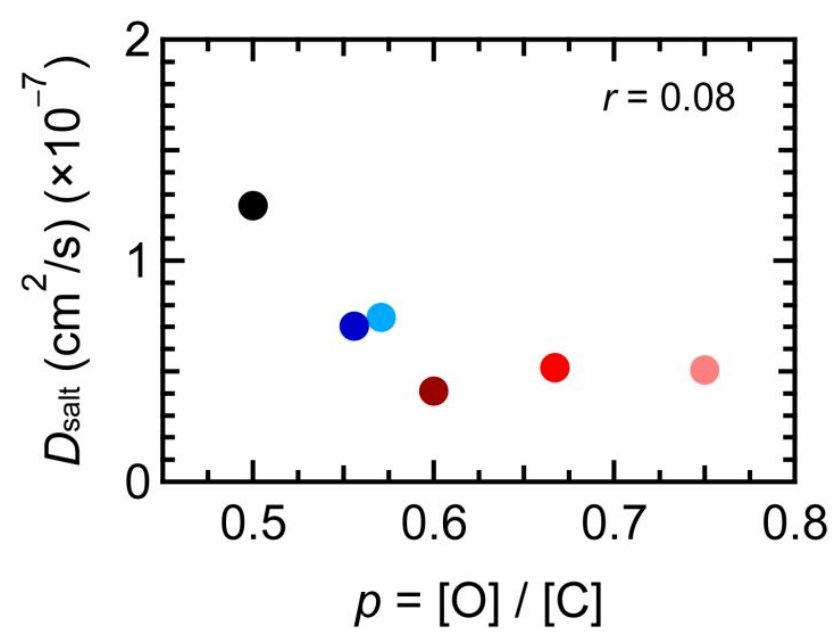

Figure S16. Effective salt diffusion coefficients $\left(D_{\text {salt }}\right)$ that have been derived from the NernstHartley equation, (a) as a function of salt concentration $(r=[\mathrm{Li}] /[\mathrm{O}])$ across the polyacetal composition range and (b) as a function of polyacetal composition $(p=[\mathrm{O}] /[\mathrm{C}])$ at a salt concentration of $r=0.08$. 


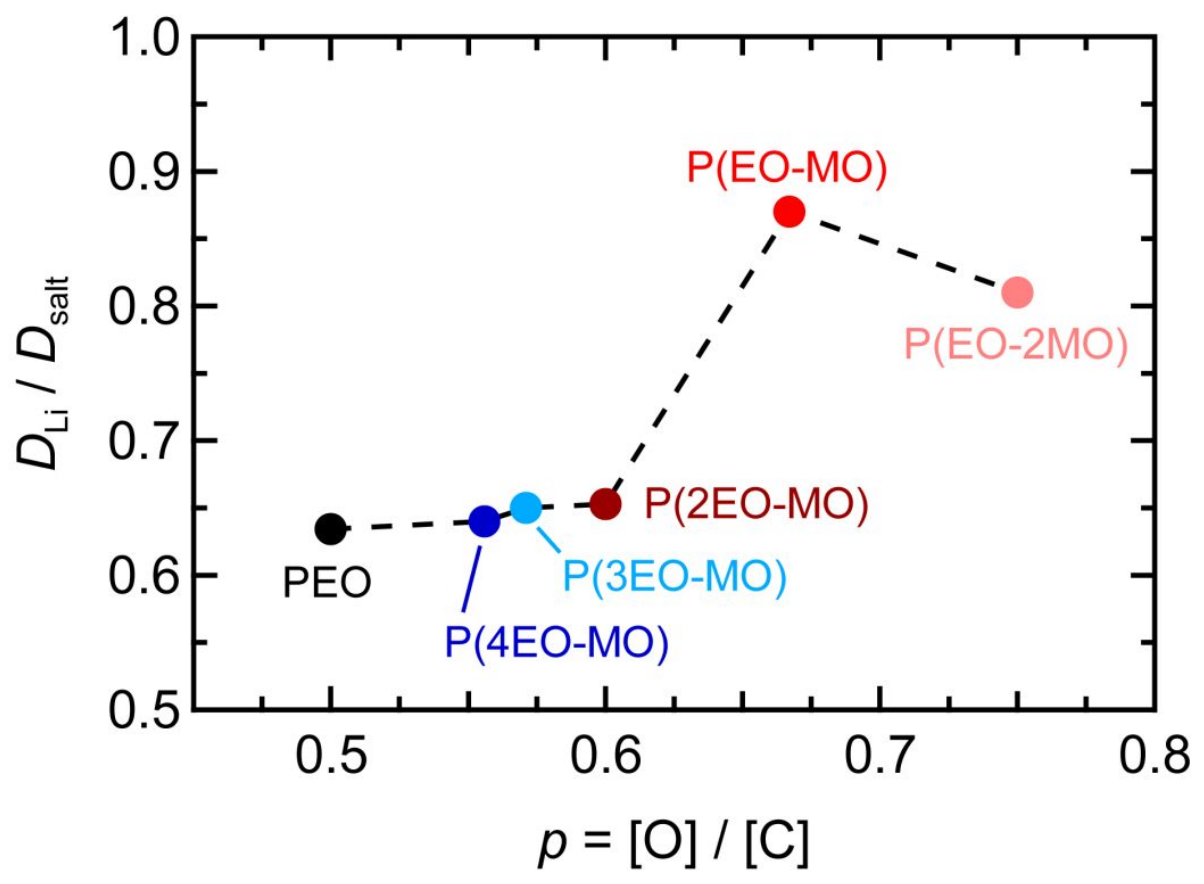

Figure S17. Ratio of diffusion coefficients, $D_{\mathrm{Li}} / D_{\text {salt, }}$, showing greater relative $\mathrm{Li}^{+}$diffusivity as $p$ increases, reaching a plateau with $\mathrm{P}(\mathrm{EO}-\mathrm{MO})$ and $\mathrm{P}(\mathrm{EO}-2 \mathrm{MO})$. Diffusion coefficients were measured at $90{ }^{\circ} \mathrm{C}$ and averaged across all studied salt concentrations. Values for PEO $\left(M_{\mathrm{n}}=5 \mathrm{kDa}\right)$ have been calculated using self-diffusion coefficients from the prior literature. The dashed line is included as a visual guide. 
Table S2. Weight percent LiTFSI loaded into a polymer at a given $r$ value for the polymers under study. Note that the values of $r$ tabulated for PEO differ from those for the polyacetals and are chosen to correspond to the prior literature data for PEO depicted in Figure 1.

\begin{tabular}{ccccccc}
\hline Polymer & $\boldsymbol{r}=\mathbf{0 . 0 1}$ & $\boldsymbol{r}=\mathbf{0 . 0 3}$ & $\boldsymbol{r}=\mathbf{0 . 0 5}$ & $\boldsymbol{r}=\mathbf{0 . 0 8}$ & $\boldsymbol{r}=\mathbf{0 . 1 0}$ \\
\hline P(EO-2MO) [wt\% LiTFSI] & 7.65 & 19.9 & 29.3 & 39.9 & 45.3 \\
P(EO-MO) [wt\% LiTFSI] & 7.20 & 18.9 & 28.0 & 38.3 & 43.7 \\
P(2EO-MO) [wt\% LiTFSI] & 6.93 & 17.9 & 27.1 & 37.1 & 42.1 \\
P(3EO-MO) [wt\% LiTFSI] & 6.62 & 17.5 & 26.2 & 36.2 & 41.5 \\
P(4EO-MO) [wt\% LiTFSI] & 6.51 & 17.3 & 25.8 & & 35.8 & 41.1 \\
\hline & $r=0.02$ & $r=0.04$ & $r=0.05$ & $r=0.06$ & $r=0.08$ & $r=0.10$ \\
\hline PEO [wt\% LiTFSI] & 11.5 & 20.7 & 24.6 & 28.1 & 34.3 & 39.5 \\
\hline
\end{tabular}


(a)

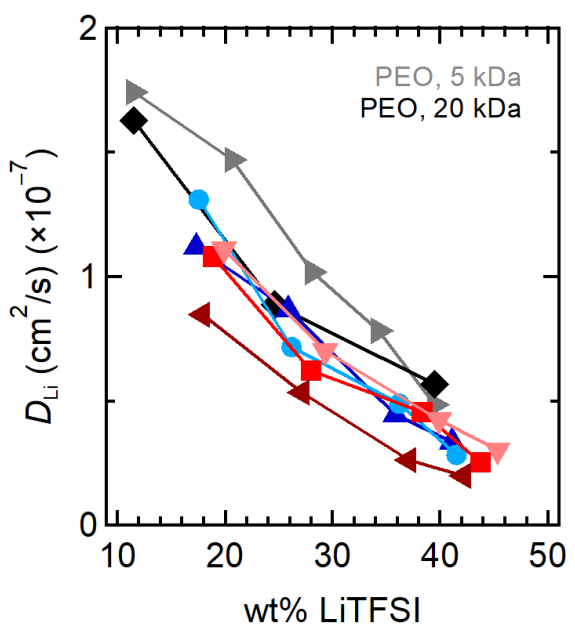

(b)

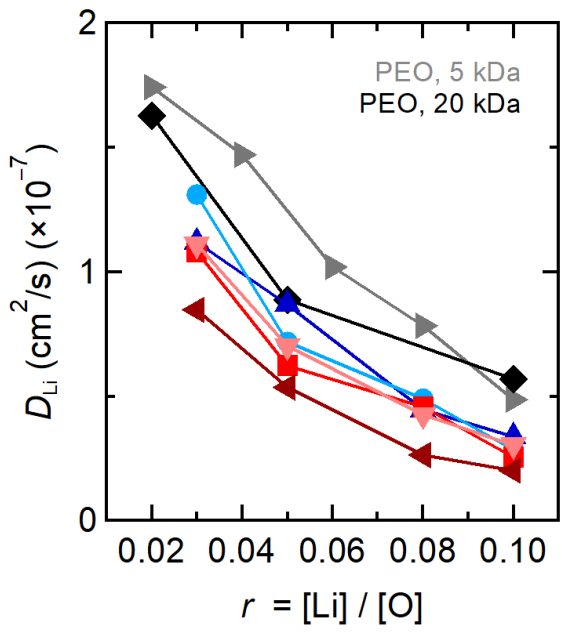

Figure S18. Comparison of $D_{\mathrm{Li}}$ versus (a) wt $\%$ LiTFSI and (b) $r=[\mathrm{Li}] /$ [O]. Although the data shift slightly when plotted against weight percent LiTFSI, identical trends in cationic diffusivity are observed in both cases. We opted to tailor our discussion around $r$ values to normalize our systems to the number of available Lewis basic oxygen binding groups.

(a)

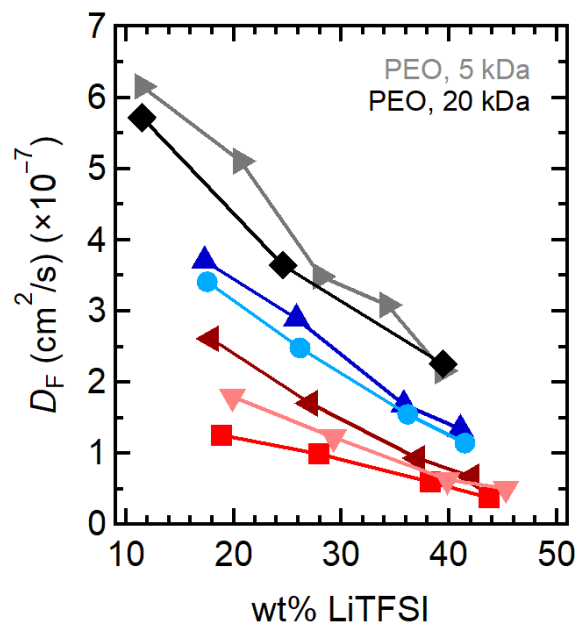

(b)

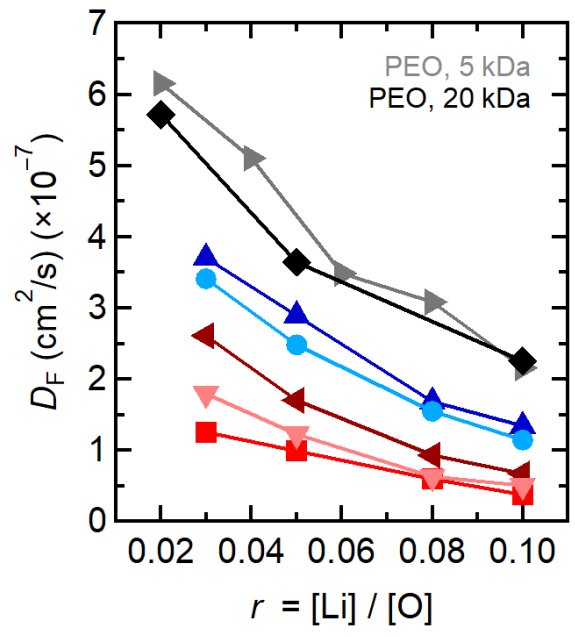

Figure S19. Comparison of $D_{\mathrm{F}}$ versus (a) wt $\%$ LiTFSI and (b) $r=[\mathrm{Li}] /[\mathrm{O}]$. Although the data shift slightly when plotted against weight percent LiTFSI, identical trends in anionic diffusivity are observed in both cases. We opted to tailor our discussion around $r$ values to normalize the systems to the number of available Lewis basic oxygen binding groups. 
Table S3. ${ }^{7} \mathrm{Li}$ (cation) self-diffusion coefficients at $90{ }^{\circ} \mathrm{C}$ as a function of $r$ value for the polymers under study, corresponding to the values depicted in Figure 1. Note that the values of $r$ tabulated for PEO differ from those for the polyacetals and are chosen to correspond to the prior literature data for PEO, as depicted in Figure 1.

\begin{tabular}{|c|c|c|c|c|}
\hline Polymer & $r=\mathbf{0 . 0 3}$ & $r=0.05$ & $r=0.08$ & $r=\mathbf{0 . 1 0}$ \\
\hline $\mathrm{P}(\mathrm{EO}-2 \mathrm{MO})\left[\times 10^{-7} \mathrm{~cm}^{2} / \mathrm{s}\right]$ & 1.11 & 0.702 & 0.424 & 0.303 \\
\hline P(EO-MO) $\left[\times 10^{-7} \mathrm{~cm}^{2} / \mathrm{s}\right]$ & 1.08 & 0.623 & 0.456 & 0.254 \\
\hline$P(2 E O-M O) ~\left[\times 10^{-7} \mathrm{~cm}^{2} / \mathrm{s}\right]$ & 0.847 & 0.535 & 0.263 & 0.200 \\
\hline P(3EO-MO) $\left[\times 10^{-7} \mathrm{~cm}^{2} / \mathrm{s}\right]$ & 1.31 & 0.718 & 0.489 & 0.285 \\
\hline P(4EO-MO) $\left[\times 10^{-7} \mathrm{~cm}^{2} / \mathrm{s}\right]$ & 1.12 & 0.868 & 0.446 & 0.337 \\
\hline
\end{tabular}

Table S4. ${ }^{19} \mathrm{~F}$ (anion) self-diffusion coefficients at $90{ }^{\circ} \mathrm{C}$ as a function of $r$ value for the polymers under study, corresponding to the values depicted in Figure 1.

\begin{tabular}{|c|c|c|c|c|}
\hline Polymer & $r=0.03$ & $r=0.05$ & $r=0.08$ & $r=0.10$ \\
\hline $\mathrm{P}(\mathrm{EO}-2 \mathrm{MO})\left[\times 10^{-7} \mathrm{~cm}^{2} / \mathrm{s}\right]$ & 1.79 & 1.22 & 0.626 & 0.501 \\
\hline $\mathrm{P}(\mathrm{EO}-\mathrm{MO})\left[\times 10^{-7} \mathrm{~cm}^{2} / \mathrm{s}\right]$ & 1.25 & 0.987 & 0.593 & 0.376 \\
\hline $\mathrm{P}(2 \mathrm{EO}-\mathrm{MO})\left[\times 10^{-7} \mathrm{~cm}^{2} / \mathrm{s}\right]$ & 2.61 & 1.70 & 0.929 & 0.666 \\
\hline $\mathrm{P}(3 \mathrm{EO}-\mathrm{MO})\left[\times 10^{-7} \mathrm{~cm}^{2} / \mathrm{s}\right]$ & 3.41 & 2.48 & 1.55 & 1.14 \\
\hline P(4EO-MO) $\left[\times 10^{-7} \mathrm{~cm}^{2} / \mathrm{s}\right]$ & 3.70 & 2.89 & 1.68 & 1.34 \\
\hline
\end{tabular}



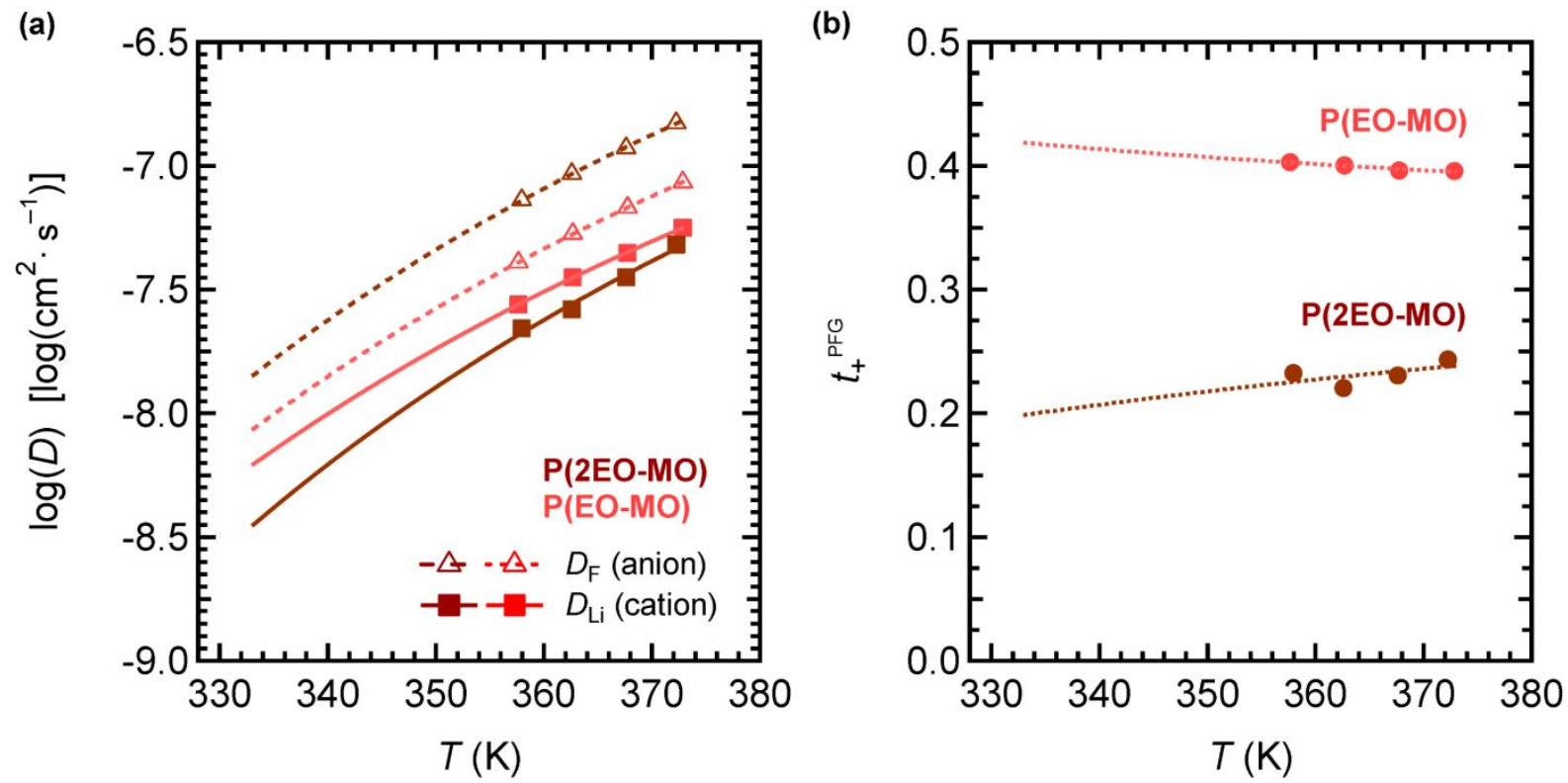

Figure S20. (a) Variable-temperature self-diffusion coefficients for anions (open triangles and dashed lines) and cations (closed squares and solid lines) for the $\mathrm{P}(2 \mathrm{EO}-\mathrm{MO})$ and $\mathrm{P}(\mathrm{EO}-\mathrm{MO})$ electrolytes at $r=0.08$, measured by ${ }^{19} \mathrm{~F}$ and ${ }^{7} \mathrm{Li} \mathrm{PFG}$ at a range of temperatures between $358 \mathrm{~K}$ and $373 \mathrm{~K}$. The fitted lines make use of the Vogel-Fulcher-Tammann (VTF) equation using the experimentally determined $T_{\mathrm{g}}$ values of the samples and have been extrapolated to $333 \mathrm{~K}$. (b) PFGbased cationic transference numbers, $t_{+}{ }^{\mathrm{PFG}}$, for $\mathrm{P}(\mathrm{EO}-\mathrm{MO})$ and $\mathrm{P}(2 \mathrm{EO}-\mathrm{MO})$, calculated from the variable-temperature diffusivity data, including the VTF fits extrapolated to $333 \mathrm{~K}$ (dotted lines). 
Table S5. Tabulated values of current fraction at $r=0.08^{1}$ and $t_{+, \mathrm{PFG}}$ values averaged across all salt concentrations.

\begin{tabular}{|c|c|c|c|}
\hline polymer & $p=[\mathrm{O}] /[\mathrm{C}]$ & $\boldsymbol{\rho}_{+}(r=0.08)$ & $t_{+},{ }^{\text {PFG }}$ (averaged [LiTFSI]) \\
\hline PEO & 0.50 & 0.08 & 0.21 \\
\hline Р(4EO-MO) & 0.56 & 0.10 & 0.22 \\
\hline Р(3EO-MO) & 0.57 & 0.13 & 0.24 \\
\hline Р(2EO-MO) & 0.60 & 0.19 & 0.23 \\
\hline P(ЕO-MO) & 0.67 & 0.43 & 0.42 \\
\hline P(EO-2MO) & 0.75 & 0.45 & 0.38 \\
\hline
\end{tabular}




\section{Molecular Dynamics (MD) Simulations}

Molecular dynamics (MD) simulations were performed with a force field that uses the GAFF functional form ${ }^{12}$ (Eq. (S7)) to describe the inter- and intramolecular interactions with parameters that were modified to correctly predict the bond lengths, bond angles, dihedral angles, and density:

$$
E_{\text {pair }}=\sum_{\text {bonds }} k_{r}\left(r-r_{e q}\right)^{2}+\sum_{\text {bonds }} k_{\theta}\left(\theta-\theta_{e q}\right)^{2}+\sum_{\text {dihedrals }} k_{n}[1+\cos (n \phi-\gamma)]+\sum_{i<j}\left[\frac{A_{i j}}{R_{i j}^{12}}-\frac{B_{i j}}{R_{i j}^{6}}+\frac{q_{i} q_{j}}{\varepsilon R_{i j}}\right]
$$

where $k_{\mathrm{r}} k_{\theta}$, and $k_{\mathrm{n}}$ are force constants, $r_{\mathrm{eq}}$ and $\theta_{\mathrm{eq}}$ are equilibrium bond length and bond angle, respectively, $n$ is the multiplicity, $\gamma$ is the phase angle for torsional angle parameters, $A$ and $B$ parameters characterize a Lennard-Jones non-bonded interaction, and $q$ is the partial charge on the atoms calculated using the prescribed restrained electrostatic potential (RESP) model. ${ }^{12,13}$ Partial charges on the ions were scaled by 0.8 based on ab-initio results and previous literature ${ }^{14,15}$ to emulate polarization effects. The Coulombic interactions were cut off at $14 \AA$ while Lennard-Jones interactions were cut off at $13 \AA$ with geometric mixing rules applied to all pairs where $i \neq j$. All MD simulations were performed using the Large-scale Atomic/Molecular Massively Parallel Simulator (LAMMPS) software package ${ }^{16}$ using a timestep of $1 \mathrm{fs}$.

Structures for MD simulations were created using a multistep annealing process as described below. First, a single strand of the polymer chain was created with a chain length of about 20 monomer units. 30 such chains along with a requisite amount of $\mathrm{Li}^{+}$and $\mathrm{TFSI}{ }^{-}$ions for the specific composition were placed randomly in a box at a very low density $\left(\sim 0.15-0.25 \mathrm{~g} / \mathrm{cm}^{3}\right)-$ much lower than the experimental density - to avoid any overlap. The system was first heated to $900 \mathrm{~K}$, relaxed for about $100 \mathrm{ps}$ at the high temperature and then brought back down to $300 \mathrm{~K}$ in the NVT ensemble (where NVT implies a constant number of particles $(\mathrm{N})$, volume $(\mathrm{V})$, and temperature (T)) at a nominal cooling rate of $3 \mathrm{~K} / \mathrm{ps}$ followed by a relaxation at room temperature allowing the density to change in the NPT ensemble (where NPT implies constant number of particles (N), 
pressure (P), and temperature (T)) for 50 ps. This entire annealing cycle was repeated about 20 times until the density at room temperature started to saturate with annealing cycles close to the experimental density. The resulting samples were then heated to $363 \mathrm{~K}$ and relaxed for $10 \mathrm{~ns}$ in the NVT ensemble for further structural analysis.
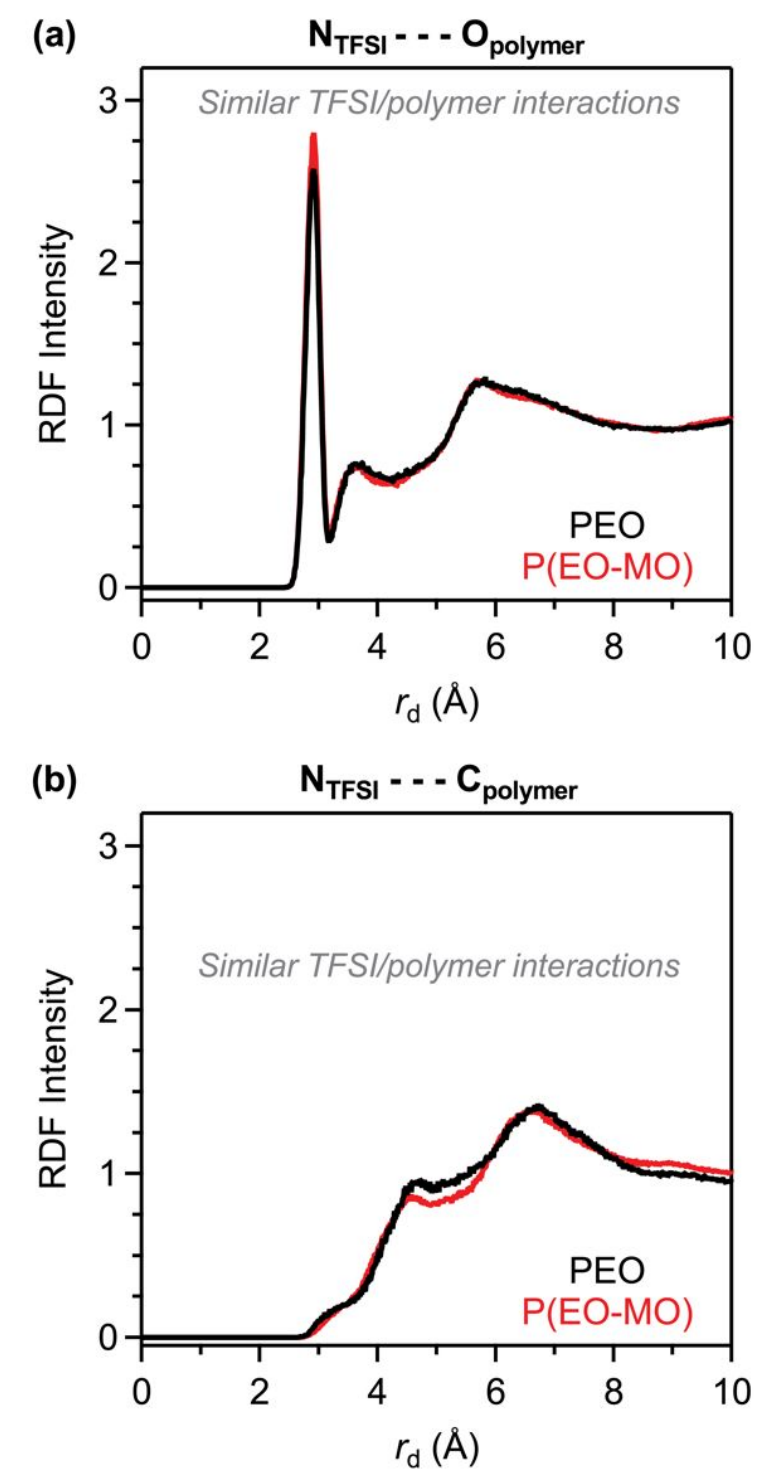

Figure S21. Radial distribution function (RDF) bond distance curves from molecular dynamics simulations representing interactions between $\mathrm{TFSI}^{-}$species (i.e., central nitrogen atoms) and (a) oxygens in the polymer or (b) carbons in the polymer in PEO (black) and P(EO-MO) (red). No significant changes in anion-polymer interactions were observed comparing the two systems. 


\section{Raman Spectroscopy of Polymer Electrolytes}

Raman spectra were obtained using a WITec alpha300 S confocal microscope coupled with a UHTS-300 CCD detector. A Nikon E Plan objective lens with 20× magnification and numerical aperture of 0.4 was used to focus a fiber-coupled $532 \mathrm{~nm}$ laser onto the sample to stimulate Raman scattering. Samples were contained in an air-free sample holder consisting of a stainless steel ConFlat flange and viewport with $2.16 \mathrm{~mm}$ thick fused silica glass window sealed with a copper gasket. The sample temperature $\left(90^{\circ} \mathrm{C}\right)$ was maintained using a custom-built copper heating block and PID controller. Light from the sample was collected through the objective lens and passed through a longpass fluorescence filter to remove non-scattered and Rayleigh-scattered light and focused onto a pinhole at the entrance of an optical fiber leading to the spectrometer. A grating of 1800 grooves $/ \mathrm{mm}$ was used with the spectral center set to $835 \mathrm{~cm}^{-1}$. The spectra reported herein

were obtained by averaging 50 spectra taken with an integration time of $0.51 \mathrm{~s}$. A background subtraction was performed on the raw spectra using the method described by Lieber and Mahadevan-Jansen in order to eliminate the fluorescence signal. ${ }^{17}$ Spectra recorded across the full frequency range are depicted in Figure S22. Additionally, in order to probe any temperaturedependent ion clustering effects, spectra of $\mathrm{P}(\mathrm{EO}-\mathrm{MO})$ and $\mathrm{P}(2 \mathrm{EO}-\mathrm{MO})$ were also recorded at 60 ${ }^{\circ} \mathrm{C}$ as shown in Figure S23; the position of the $\mathrm{TFSI}^{-}$expansion-contraction mode appeared to be independent of temperature in these samples. 


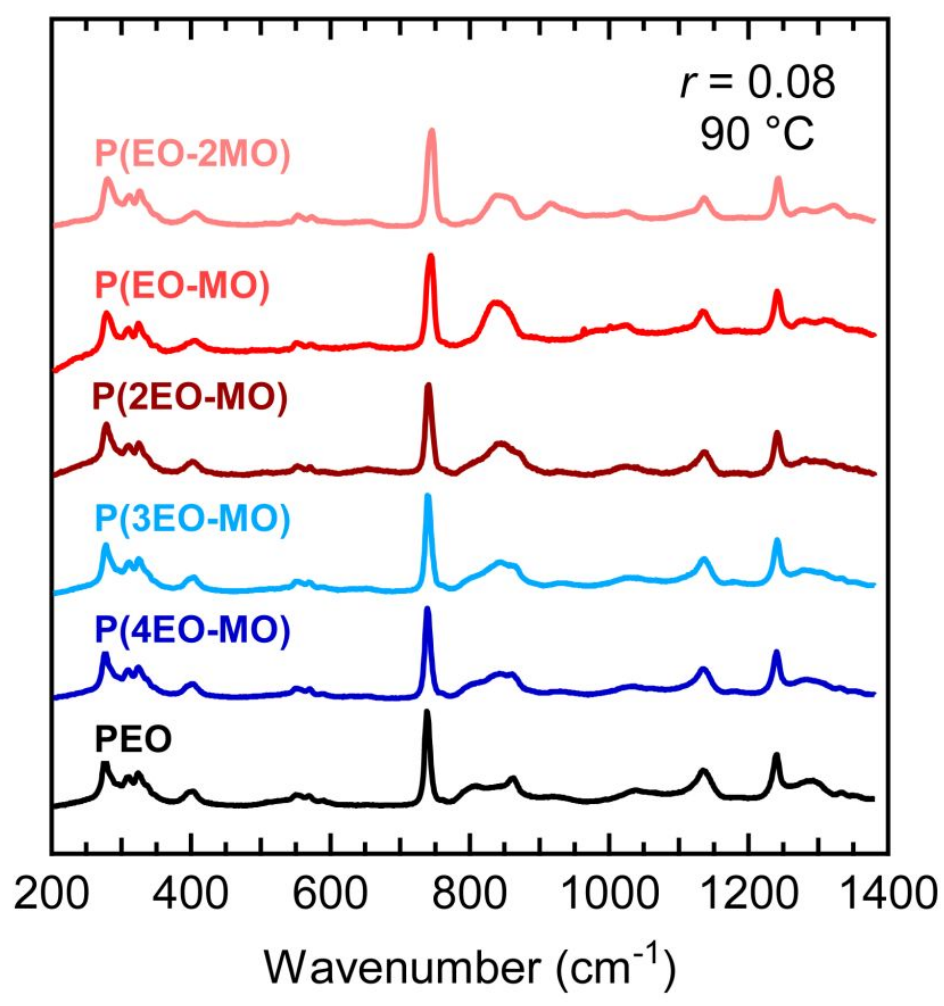

Figure S22. Raman spectra of PEO and the polyacetal electrolytes at $r=0.08$, recorded at $90{ }^{\circ} \mathrm{C}$. Note: $\mathrm{P}(2 \mathrm{EO}-\mathrm{MO})$ used for this spectrum was a sample with $M_{\mathrm{n}}=55 \mathrm{kDa}$. 
(a)

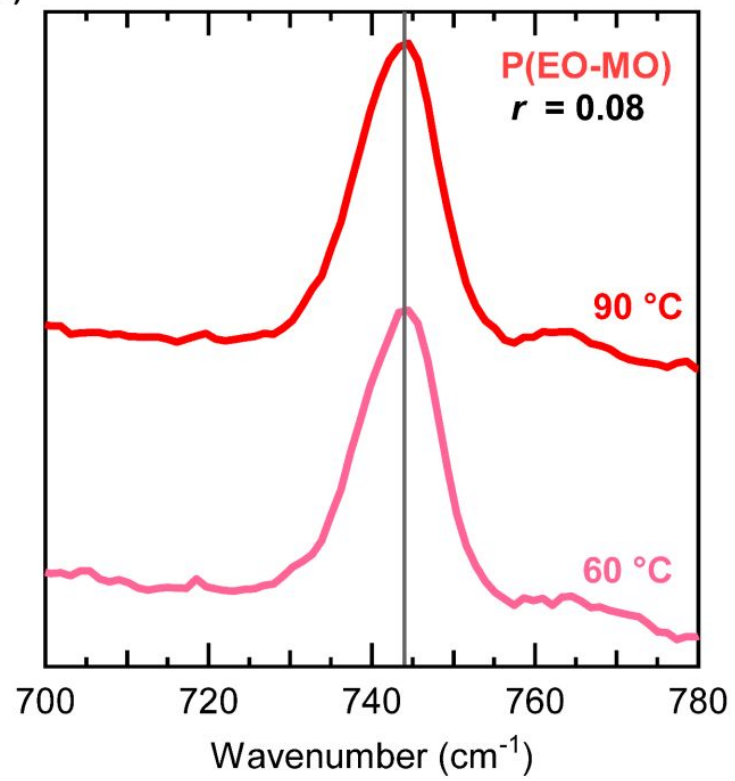

(b)

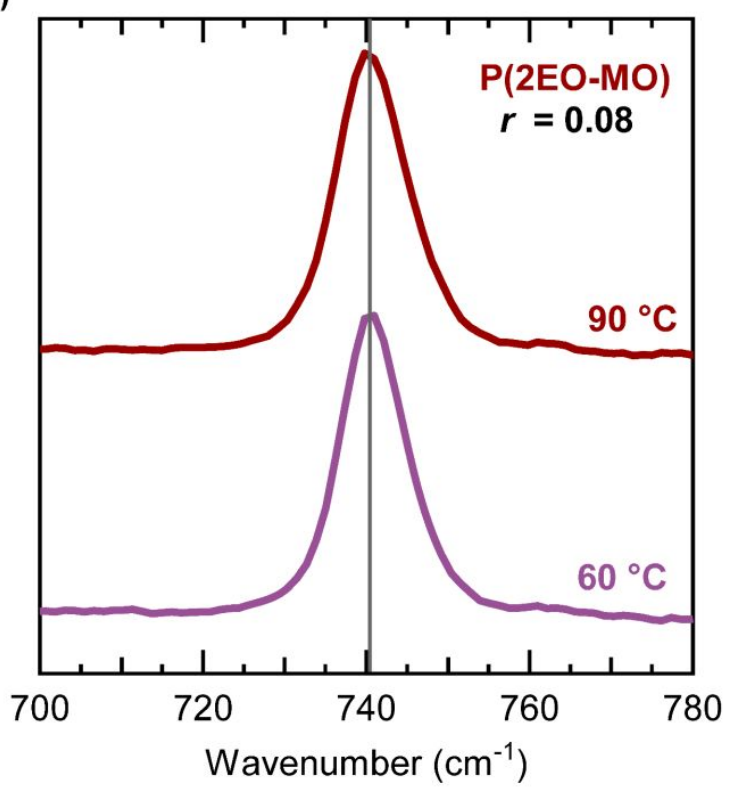

Figure S23. Raman spectra of (a) $\mathrm{P}(\mathrm{EO}-\mathrm{MO})$ and (b) $\mathrm{P}(2 \mathrm{EO}-\mathrm{MO})$ electrolytes (both $r=0.08$ ), focusing on the $\mathrm{TFSI}^{-}$expansion-contraction mode, recorded at both $60{ }^{\circ} \mathrm{C}$ and $90{ }^{\circ} \mathrm{C}$. The vertical grey line indicates the position of the maximum of this mode, which is temperature-independent for both samples. 


\section{Abbreviations}

EO

EO-MO

EO-2MO

2EO-MO

3EO-MO

4EO-MO

LiTFSI

MeOTf

MO

NaOEtTMS

PEO

$\mathrm{P}(\mathrm{EO}-\mathrm{MO})$

$\mathrm{P}(\mathrm{EO}-2 \mathrm{MO})$

$\mathrm{P}(2 \mathrm{EO}-\mathrm{MO})$

$\mathrm{P}$ (3EO-MO)

$\mathrm{P}(4 \mathrm{EO}-\mathrm{MO})$

TMSOTf

CROP

DSC

GAFF

GPC

LAMMPS

MD

NMR

PFG-NMR

RDF

RESP

rf

$D_{\mathrm{F}}$

$D_{\mathrm{Li}}$

$D_{\text {salt }}$

$Ð$

$g$

I

$I_{0}$

$M_{\mathrm{n}}$

$p$

$r$

ethylene oxide

1,3-dioxolane

1,3,5-trioxepane

1,3,6-trioxocane

1,3,6,9-tetraoxacycloundecane

1,3,6,9,12-pentaoxacyclotetradecane

lithium bis(trifluoromethanesulfonyl)imide

methyltriflate

methylene oxide

sodium 2-trimethylsilylethoxide

poly(ethylene oxide)

poly(1,3-dioxolane)

poly(1,3,5-trioxepane)

poly(1,3,6-trioxocane)

poly(1,3,6,9-tetraoxacycloundecane)

poly(1,3,6,9,12-pentaoxacyclotetradecane)

trimethylsilyltriflate

cationic ring-opening polymerization

differential scanning calorimetry

general AMBER force field

gel permeation chromatography

Large-scale Atomic/Molecular Massively Parallel Simulator

molecular dynamics

nuclear magnetic resonance spectroscopy

pulsed-field-gradient NMR

radial distribution function

restrained electrostatic potential

radio frequency

${ }^{19} \mathrm{~F}$ (anion) self-diffusion coefficient $\left(\mathrm{cm}^{2} / \mathrm{s}\right)$

${ }^{7} \mathrm{Li}$ (cation) self-diffusion coefficient $\left(\mathrm{cm}^{2} / \mathrm{s}\right)$

effective salt diffusion coefficient $\left(\mathrm{cm}^{2} / \mathrm{s}\right)$

polydispersity index

gradient pulse strength $(\mathrm{T} / \mathrm{m})$

integrated NMR signal intensity (arb. units)

integrated NMR signal intensity at zero gradient strength (arb. units)

number-averaged molecular weight $(\mathrm{kg} / \mathrm{mol})$

ratio of oxygen atoms to carbon atoms on the polymer

moles of $\mathrm{Li}^{+}$per mole of oxygen atoms on the polymer 


$\begin{array}{ll}r_{\mathrm{d}} & \text { radial distance between atoms }(\AA) \\ T & \text { temperature }\left({ }^{\circ} \mathrm{C}\right) \\ T_{\mathrm{d}, 5 \%} & \text { decomposition }(5 \% \text { weight loss }) \text { temperature }\left({ }^{\circ} \mathrm{C}\right) \\ T_{\mathrm{g}} & \text { glass transition temperature }\left({ }^{\circ} \mathrm{C}\right) \\ T_{\mathrm{m}} & \text { melting temperature }\left({ }^{\circ} \mathrm{C}\right) \\ \Delta & \text { diffusion time }(\mathrm{s}) \\ \delta & \text { gradient pulse length }(\mathrm{s}) \\ \gamma & \text { nuclear gyromagnetic ratio }(\mathrm{MHz} / \mathrm{T}) \\ \tau & \text { interpulse delay }(\mathrm{s})\end{array}$




\section{References}

(1) Snyder, R. L.; Choo, Y.; Gao, K. W.; Halat, D. M.; Abel, B. A.; Sundararaman, S.; Prendergast, D.; Reimer, J. A.; Balsara, N. P.; Coates, G. W. Improved $\mathrm{Li}^{+}$Transport in Polyacetal Electrolytes: Conductivity and Current Fraction in a Series of Polymers. ACS Energy Lett. 2021, 1886-1891.

(2) Albrecht, K.; Fleischer, D.; Kane, A.; Rentsch, C.; Thi, Q. V. T.; Yamaguchi, H.; Schulz, R. C. Polymerization of Macrocyclic Formals. Makromol. Chem. 1977, 178, 881-883.

(3) Kawakami, Y.; Suzuki, J.; Yamashita, Y. Macrocyclic Formals. V. Cationic Polymerization of 1,3,6,9,12-Pentaoxacyclotetradecane. Polym. J. 1977, 9, 519-524.

(4) Zheng, Q.; Pesko, D. M.; Savoie, B. M.; Timachova, K.; Hasan, A. L.; Smith, M. C.; Miller, T. F.; Coates, G. W.; Balsara, N. P. Optimizing Ion Transport in Polyether-Based Electrolytes for Lithium Batteries. Macromolecules 2018, 51, 2847-2858.

(5) Lascaud, S.; Perrier, M.; Vallee, A.; Besner, S.; Prud'homme, J.; Armand, M. Phase Diagrams and Conductivity Behavior of Poly(Ethylene Oxide)-Molten Salt Rubbery Electrolytes. Macromolecules 1994, 27, 7469-7477.

(6) Frenck, L.; Maslyn, J. A.; Loo, W. S.; Parkinson, D. Y.; Balsara, N. P. Impact of Salt Concentration on Nonuniform Lithium Electrodeposition through Rigid Block Copolymer Electrolytes. ACS Appl. Mater. Interfaces 2019, 11, 47878-47885.

(7) Cotts, R. M.; Hoch, M. J. R.; Sun, T.; Markert, J. T. Pulsed Field Gradient Stimulated Echo Methods for Improved NMR Diffusion Measurements in Heterogeneous Systems. J. Magn. Reson. 1989, 83, 252-266.

(8) Sinnaeve, D. The Stejskal-Tanner Equation Generalized for Any Gradient Shape-an Overview of Most Pulse Sequences Measuring Free Diffusion. Concepts Magn. Reson. Part A 2012, 40A, 39-65.

(9) Ammann, C.; Meier, P.; Merbach, A. A Simple Multinuclear NMR Thermometer. J. Magn. Reson. 1982, 46, 319-321.

(10) Spees, W. M.; Song, S.-K.; Garbow, J. R.; Neil, J. J.; Ackerman, J. J. H. Use of Ethylene Glycol to Evaluate Gradient Performance in Gradient-Intensive Diffusion MR Sequences. Magn. Reson. Med. 2012, 68, 319-324.

(11) Callaghan, P. T. Translational Dynamics and Magnetic Resonance: Principles of Pulsed Gradient Spin Echo NMR; Oxford University Press, 2011.

(12) Wang, J.; Wolf, R. M.; Caldwell, J. W.; Kollman, P. A.; Case, D. A. Development and Testing of a General Amber Force Field. J. Comput. Chem. 2004, 25, 1157-1174.

(13) Bayly, C. I.; Cieplak, P.; Cornell, W.; Kollman, P. A. A Well-Behaved Electrostatic Potential Based Method Using Charge Restraints for Deriving Atomic Charges: The RESP Model. J. Phys. Chem. 1993, 97, 10269-10280.

(14) Zhang, Y.; Maginn, E. J. A Simple AIMD Approach to Derive Atomic Charges for Condensed Phase Simulation of Ionic Liquids. J. Phys. Chem. B 2012, 116, 10036-10048.

(15) Youngs, T. G. A.; Hardacre, C. Application of Static Charge Transfer within an Ionic-Liquid Force Field and Its Effect on Structure and Dynamics. ChemPhysChem 2008, 9, 1548-1558.

(16) Plimpton, S. Fast Parallel Algorithms for Short-Range Molecular Dynamics. J. Comput. Phys. 1995, 117, 1-19.

(17) Lieber, C. A.; Mahadevan-Jansen, A. Automated Method for Subtraction of Fluorescence from Biological Raman Spectra. Appl. Spectrosc. 2003, 57, 1363-1367. 